\title{
The human language system does not support music processing
}

Xuanyi Chen ${ }^{* 1,2,3}$, Josef Affourtit*2,3, Rachel Ryskin²,3,4, Tamar I. Regev ${ }^{2,3}$, Samuel NormanHaignere $^{5}$, Olessia Jouravlev ${ }^{2,3,6}$, Saima Malik-Moraleda ${ }^{2,3,7}$, Hope Kean ${ }^{2,3}$, Rosemary Varley ${ }^{\dagger 8}$, and Evelina Fedorenko ${ }^{\dagger 2,3,7}$

${ }^{1}$ Department of Cognitive Sciences, Rice University, TX 77005, USA

${ }^{2}$ Department of Brain and Cognitive Sciences, MIT, Cambridge, MA 02139, USA

${ }^{3}$ McGovern Institute for Brain Research, MIT, Cambridge, MA 02139, USA

${ }^{4}$ Department of Cognitive \& Information Sciences, University of California, Merced, Merced, CA 95343, USA

${ }^{5}$ Zuckerman Mind, Brain, Behavior Institute, Columbia University, New York, NY 10027, USA

${ }^{6}$ Department of Cognitive Science, Carleton University, Ottawa, Ontario, Canada

${ }^{7}$ The Program in Speech and Hearing Bioscience and Technology, Harvard University, Cambridge, MA 02138, USA

${ }^{8}$ Psychology \& Language Sciences, UCL, London, WCN1 1PF, UK

* Co-first authors

+ Co-senior authors

\section{Corresponding Authors}

Xuanyi Chen and Ev Fedorenko

Xuanyi.Chen@rice.edu and evelina9@mit.edu; 43 Vassar Street, Room 46-3037, Cambridge, MA, 02139

\section{Acknowledgements}

We would like to acknowledge the Athinoula A. Martinos Imaging Center at the McGovern Institute for Brain Research at MIT, and its support team (Steve Shannon and Atsushi Takahashi). We thank former and current EvLab members for their help with fMRI data collection (especially Meilin Zhan for help with Experiment 4). We thank Josh McDermott for input on many aspects of this work, Jason Rosenberg for composing the melodies used in Experiments 2 and 3, and Zuzanna Balewski for help with creating the final materials used in Experiments 2 and 3. For Experiment 3, we thank Vitor Zimmerer for help with creating the grammaticality judgment task, Ted Gibson for help with collecting the control data, and Anya Ivanova for help with Figure 2. For Experiment 4, we thank Anne Cutler, Peter Graff, Morris Alper, Xiaoming Wang, Taibo Li, Terri Scott, Jeanne Gallée, and Lauren Clemens for help with constructing and/or recording and/or editing the language materials, and Fatemeh Khalilifar, Caitlyn Hoeflin, and Walid Bendris for help with selecting the music materials and with the experimental script. Finally, we thank the audience at the Society for Neuroscience conference (2014), the Neurobiology of Language conference (virtual edition, 2020), Ray Jackendoff, and members of the Fedorenko and Gibson labs for helpful comments and discussions. RR was supported by NIH award F32-DC-015163. SNH was supported by a graduate NSF award, as well as postdoctoral awards from the HHMI / Life Sciences research foundation and a K99/R00 award from the NIH 
(1K99DC018051-01A1). SMM was supported by a La Caixa fellowship LCF/BQ/AA17/11610043. RV was supported by Alzheimer's Society and The Stroke Association. EF was supported by the R00 award HD057522, R01 awards DC016607 and DC016950, by the Paul and Lilah Newton Brain Science Award, and funds from the Brain and Cognitive Sciences department and the McGovern Institute for Brain Research.

\section{Author contributions:}

\begin{tabular}{|c|c|c|c|c|c|c|c|c|c|c|}
\hline & $\mathrm{XC}^{*}$ & $\mathrm{JA}^{*}$ & RR & TIR & $\mathrm{SNH}$ & OJ & SMM & HK & $\mathrm{RV \dagger}$ & $\mathrm{EF} \dagger$ \\
\hline Conceptualization & & & & & $\nabla$ & & & & $\nabla$ & $\nabla$ \\
\hline $\begin{array}{l}\text { Design and } \\
\text { materials creation }\end{array}$ & $\nabla$ & & & $\nabla$ & $\nabla$ & $\square$ & & $\square$ & $\nabla$ & $\nabla$ \\
\hline $\begin{array}{l}\text { Experimental } \\
\text { script creation }\end{array}$ & $\nabla$ & $\nabla$ & & & & & & & & \\
\hline $\begin{array}{l}\text { fMRI data } \\
\text { collection }\end{array}$ & $\square$ & $\nabla$ & & & & $\square$ & & & & \\
\hline $\begin{array}{l}\text { fMRI data } \\
\text { preprocessing and } \\
\text { analysis }\end{array}$ & $\square$ & $\nabla$ & & & & $\square$ & $\nabla$ & $\nabla$ & & \\
\hline $\begin{array}{l}\text { Behavioral data } \\
\text { collection }\end{array}$ & $\nabla$ & & $\nabla$ & & & & & & $\nabla$ & \\
\hline $\begin{array}{l}\text { Behavioral data } \\
\text { analysis }\end{array}$ & & & $\nabla$ & & & & & & $\nabla$ & $\nabla$ \\
\hline $\begin{array}{l}\text { Formal statistical } \\
\text { analysis }\end{array}$ & $\nabla$ & 四 & $\nabla$ & & & & & & & $\nabla$ \\
\hline Figures & V & & $\nabla$ & $\nabla$ & & & & & & \\
\hline Writing & 四 & & $\nabla$ & & & & & & $\nabla$ & $\nabla$ \\
\hline $\begin{array}{l}\text { Editing }+ \\
\text { comments }\end{array}$ & & 四 & & $\nabla$ & $\nabla$ & $\square$ & $\nabla$ & $\square$ & & \\
\hline $\begin{array}{l}\text { Overall } \\
\text { supervision }\end{array}$ & & & & & & & & & & $\nabla$ \\
\hline
\end{tabular}

\section{Conflict of interest}

The authors declare no competing financial interests. 


\begin{abstract}
Language and music are two human-unique capacities whose relationship remains debated. Some argue for overlap in processing mechanisms, especially for structure processing, but others fail to find overlap. Using fMRI, we examined the responses of language brain regions to diverse music stimuli, and also probed the musical abilities of individuals with severe aphasia. Across four experiments, we obtained a clear answer: music does not recruit nor requires the language system. The language regions' responses to music are generally low and never exceed responses elicited by non-music auditory conditions, like animal sounds. Further, the language regions are not sensitive to music structure: they show low responses to both intact and scrambled music, and to melodies with vs. without structural violations. Finally, individuals with aphasia who cannot judge sentence grammaticality perform well on melody well-formedness judgments. Thus the mechanisms that process structure in language do not appear to support music processing.
\end{abstract}




\section{Introduction}

To interpret language or appreciate music, we must understand how different elements — words in language, notes and chords in music - relate to each other. Parallels between the structural properties of language and music have been drawn for over a century (e.g., Riemann, 1877, as cited in Swain, 1995; Lindblom \& Sundberg, 1969; Fay, 1971; Boiles, 1973; Cooper, 1973; Bernstein, 1976; Sundberg \& Lindblom, 1976; Lerdahl \& Jackendoff, 1977, 1983; Roads \& Wieneke, 1979; Krumhansl \& Keil, 1982; Baroni et al., 1983; Swain, 1995; cf. Jackendoff, 2009). However, whether music processing relies on the same mechanisms as those that support language processing continues to spark debate.

The current empirical landscape is complex. A large number of studies have argued for overlap in structural processing based on behavioral (e.g., Fedorenko et al., 2009; Slevc et al., 2009; Hoch et al., 2011; Van de Cavey \& Hartsuiker, 2016; Kunert et al., 2016), ERP (e.g., Janata, 1995; Patel et al., 1998; Koelsch et al., 2000), MEG (e.g., Maess et al., 2001), fMRI (e.g., Koelsch et al., 2002; Levitin \& Menon, 2003; Tillmann et al., 2003; Koelsch, 2006; Kunert et al., 2015; Musso et al., 2015) and ECoG (e.g., Sammler et al., 2009, 2013) evidence (see Tillman, 2012; Kunert \& Slevc, 2015; LaCroix et al., 2016, for reviews). However, we would argue that no prior study has compellingly established reliance on shared syntactic processing mechanisms in language and music.

First, evidence from behavioral, ERP, and, to a large extent, MEG studies is indirect because they do not make it possible to unambiguously determine where neural responses originate (in ERP and MEG, this is due to the 'inverse problem'; Tarantola, 2004; Baillet et al., 2014).

Second, the majority of the evidence comes from structure-violation paradigms. In such paradigms, responses to the critical condition - which contains an element that violates the rules of tonal music - are contrasted with responses to the control condition, where stimuli obey the rules of tonal music. Because structural violations (across domains) constitute unexpected events, the observed overlap may — and has been argued by some to - reflect domain-general processes, like attention or error detection (e.g., Bigand et al., 2001; Poulin-Charronat et al., 2005; Tillmann et al., 2006; Hoch et al., 2011; Perruchet \& Poulin-Charronnat, 2013). Indeed, at least in some studies, unexpected non-structural events in music, like a timbre change, have been found to lead to similar neural responses in fMRI (e.g., Koelsch et al., 2002; cf. some differences in EEG effects - e.g., Koelsch et al., 2001), putting into question the interpretation in terms of shared syntactic mechanisms. Relatedly, meta-analyses of neural responses to unexpected events (e.g., Corbetta \& Shulman, 2002; Fouragnan et al., 2018; Corlett et al., 2021) have identified regions grossly resembling those reported in studies of music structure violations (see Fedorenko \& Varley, 2016 for discussion). It is also important to note that a brain region responsible for processing structure should respond strongly to well-formed stimuli (in addition to potentially being sensitive to deviations from well-formedness) - something that is rarely established (see point five below). 
Third, most prior fMRI (and MEG) investigations have relied on comparisons of group-level activation maps. Such analyses suffer from low functional resolution (e.g., Nieto-Castañón \& Fedorenko, 2012; Fedorenko, 2021), especially in cases where the precise locations of functional regions vary across individuals, as in the association cortex (Fischl et al., 2008; Frost \& Goebel, 2012; Tahmasebi et al., 2012; Vazquez-Rodriguez et al., 2019). Thus, observing activation overlap at the group level does not unequivocally support shared mechanisms. Indeed, studies that used individual-subjects analyses have reported a low or no response to music in the language-responsive regions (Fedorenko et al., 2011; Rogalsky et al., 2011; Deen et al., 2015).

Fourth, the interpretation of some of the observed effects has relied on the so-called 'reverse inference' (Poldrack, 2006, 2011), where function is inferred from a coarse anatomical location: for example, some music-structure-related effects observed in or around 'Broca's area' have been interpreted as reflecting the engagement of linguistic-structure-processing mechanisms (e.g., Maess et al., 2001; Koelsch et al., 2002) given the long-standing association between 'Broca's area' and language, including syntactic processing specifically (e.g., Caramazza \& Zurif, 1976; Friederici et al., 2006). However, this reasoning is not valid: Broca's area is a heterogeneous region, which houses components of at least two functionally distinct brain networks (Fedorenko et al., 2012; Fedorenko \& Blank, 2020): the language-selective network, which responds during language processing, visual or auditory, but does not respond to diverse non-linguistic stimuli (Fedorenko et al., 2011; Monti et al., 2009, 2012; see Fedorenko \& Varley, 2016 for a review) and the domain-general executive control or 'multiple demand (MD)' network, which responds to any demanding cognitive task and is robustly modulated by task difficulty (Duncan, 2010, 2013; Fedorenko et al., 2013; Assem et al., 2020). As a result, here and more generally, functional interpretation based on coarse anatomical localization is not justified.

Fifth, many prior fMRI investigations have not reported the magnitudes of response to the relevant conditions and only examined statistical maps for the contrast of interest (e.g., a whole brain map showing voxels that respond reliably more strongly to melodies with vs. without a structural violation, and to sentences with vs. without a structural violation). Response magnitudes are critical for interpreting a functional profile of a brain region (see e.g., Chen et al., 2017 , for discussion). For example, a reliable violation $>$ no violation effect could be observed when both conditions elicit above-baseline responses, and the violation condition elicits a stronger response (Figure 1A left bar graph) — a reasonable profile for a brain region that supports the processing of structure in music - but also when both conditions elicit belowbaseline responses, and the violation condition elicits a less negative response (Figure 1A right bar graph). The latter kind of profile, where a brain region is more active during silence than when listening to music, would be hard to reconcile with a role in the processing of music structure. Similarly, with respect to the music-language overlap question, consider two cases of a region where both the language and the music manipulation elicit a significant effect: i) sentences and melodies with violations elicit a response of 2 units (e.g., \% BOLD signal change) and sentences and melodies without violations elicit a response of 0.5 units (Figure 1B left bar graph); and ii) sentences with violations elicit a response of 2 units, sentences without violations elicit a response of 0.5 units, melodies with violations elicit a response of 0.3 units, and melodies 
without violations elicit a response of 0.1 units (Figure 1B right bar graph). Whereas in the first case, it may be reasonable to argue that the brain region in question supports some computation that is necessary to process structure violations in any (perhaps hierarchically-structured) stimulus, or at least in both language and music, such interpretation would not be straightforward in the second case. In particular, given the large main effect of language $>$ music, any account of possible computations supported by such a brain region would need to explain this difference instead of simply focusing on the presence of a reliable effect of violation in both domains. Without examining the magnitudes of response, it is not possible to distinguish among many, potentially very different, kinds of accounts of a brain region's computations.

A. Contrast of conditions
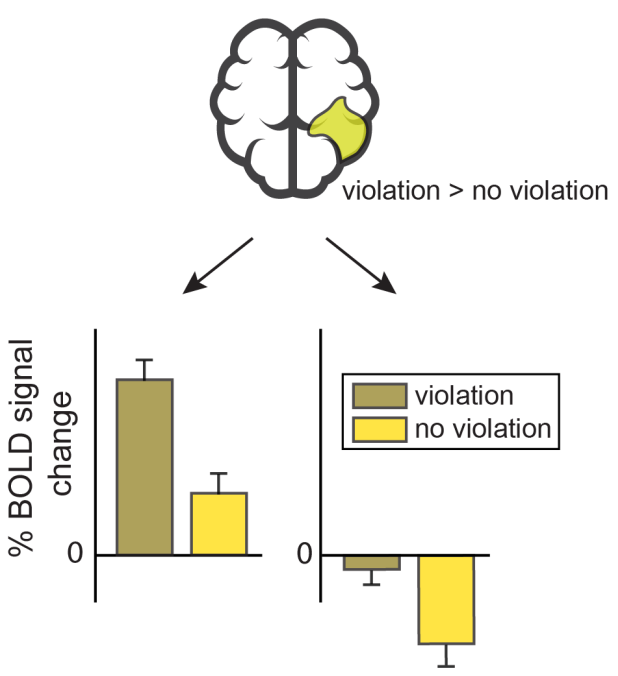

B. Conjunction of contrasts

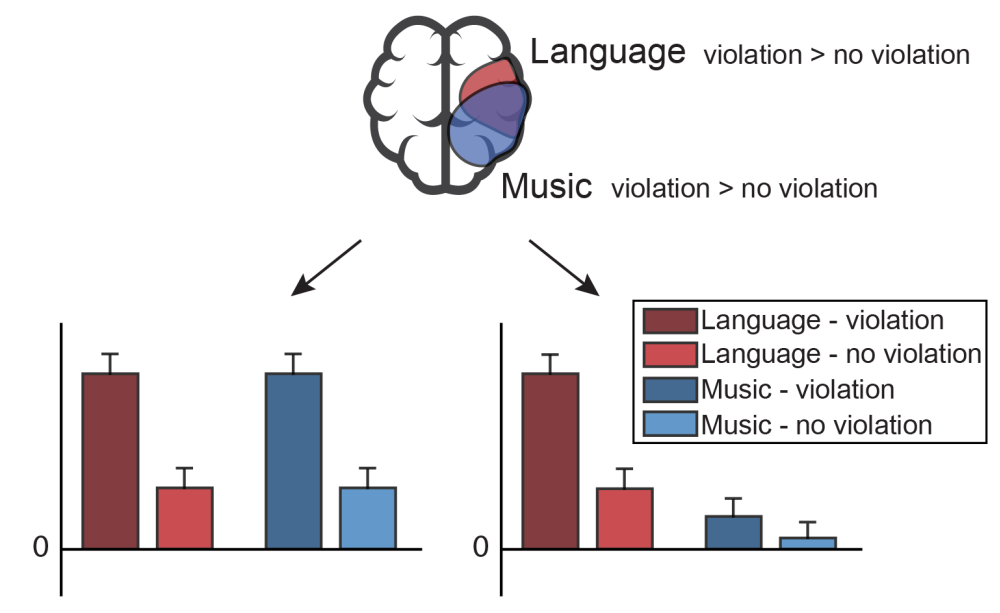

Figure 1: Illustration of the importance of examining the magnitudes of neural response to the individual conditions rather than only the statistical significance maps for the contrast(s) of interest. A significant violation $>$ no violation effect $(\mathrm{A})$, and overlap between a significant violation $>$ no violation effect in language vs. in music (B) are each compatible with two very different functional profiles, only one of which (on the left in each case) supports the typically proposed interpretation (a region that processes structure in some domain of interest in A, and a region that processes structure in both language and music in $\mathrm{B}$ ).

Aside from the limitations above, to the best of our knowledge, all prior brain imaging studies have used a single manipulation in one set of materials and one set of participants. To compellingly argue that a brain region supports (some aspects of) structural processing in both language and music, it is important to establish both the robustness of the key effect by replicating it with a new set of experimental materials and/or in a new group of participants, and its generalizability to other contrasts between conditions that engage the hypothesized computation and ones that do not. For example, to argue that a brain region houses a core syntactic mechanism needed to process hierarchical relations and/or recursion in both language and music (e.g., Patel, 2003; Fadiga et al., 2009; Roberts, 2012; Koelsch et al., 2013; Fitch \& Martins, 2014), one would need to demonstrate that this region i) responds robustly to diverse structured linguistic and musical stimuli (which all invoke the hypothesized shared computation), 
ii) is sensitive to more than a single manipulation targeting the hypothesized computations specifically (structured vs. unstructured stimuli, stimuli with vs. without structural violations, stimuli that are more vs. less structurally complex (e.g., with long-distance vs. local dependencies, adaptation to structure vs. some other aspect of the stimulus, etc.) in order to rule out paradigm-/task-specific accounts, and iii) replicates across materials and participants.

Finally, the neuropsychological patient evidence is at odds with the idea of shared mechanisms for processing language and music. If language and music relied on the same syntactic processing mechanism, individuals impaired in their processing of linguistic syntax should also exhibit impairments in musical syntax. Although some prior studies report subtle musical deficits in patients with aphasia (Patel et al., 2008; Sammler et al., 2011), the evidence is equivocal, and many aphasic patients appear to have little or no difficulties with music, including the processing of music structure (Luria et al., 1965; Brust, 1980; Marin, 1982; Basso \& Capitani, 1985; Polk \& Kertesz, 1993; Slevc et al., 2016). Similarly, children with Specific Language Impairment —a developmental disorder that affects several aspects of linguistic and cognitive processing, including syntactic processing (e.g., Bortolini et al., 1998; Bishop \& Norbury, 2002)—show no impairments in musical processing (Fancourt, 2013). In an attempt to reconcile the evidence from acquired and developmental disorders with claims about structure-processing overlap based on behavioral and neural evidence from neurotypical participants, Patel (2003, 2008, 2012; see Slevc \& Okada, 2015 for a related proposal) put forward a hypothesis whereby the representations mediating language and music are stored in distinct brain areas, but the mechanisms that perform online computations on those representations are partially overlapping. We return to this idea in the Discussion.

In an effort to bring clarity to this ongoing debate, we conducted three fMRI experiments with young neurotypical adults, and a behavioral study with individuals with severe aphasia. In each fMRI experiment, we used a well-established language 'localizer' task (Fedorenko et al., 2010) to identify language-responsive areas in each participant individually. These areas have been shown, across dozens of brain imaging studies, to be robustly sensitive to linguistic syntactic processing demands in diverse manipulations (e.g., Keller et al., 2001; Röder et al., 2002; Friederici, 2011; Pallier et al., 2011; Bautista \& Wilson, 2016, among many others) —including when defined with the same localizer as the one used here (e.g., Fedorenko et al., 2010, 2012a, 2020; Blank et al., 2016; Mollica et al., 2020; Shain, Blank et al., 2020; Shain et al., in prep.)and their damage leads to linguistic, including syntactic, deficits (e.g., Caplan et al., 1996; Dick et al., 2001; Wilson \& Saygin, 2004; Tyler et al., 2011; Wilson et al., 2012; Mesulam et al., 2014; Ding et al., 2020; Matchin \& Hickok, 2020, among many others). We then examined the responses of these language areas to music. In Experiment 1, we included diverse music stimuli including orchestral music, single-instrument music, synthetic drum music, and synthetic melodies, a minimal comparison between songs and spoken lyrics, and a set of non-music auditory control conditions. We additionally examined sensitivity to structure in music across two structure-scrambling manipulations. In Experiment 2, we further probed sensitivity to structure in music using the most common manipulation, contrasting responses to well-formed melodies vs. melodies containing a note that does not obey the constraints of Western tonal 
music. And in Experiment 3, we examined the ability to discriminate between well-formed melodies and melodies containing a structural violation in three profoundly aphasic individuals across two tasks. Finally, in Experiment 4, we examined the responses of the language regions to yet another set of music stimuli in a new set of participants. Further, the participants were all native speakers of Mandarin, a tonal language, which allowed us to evaluate the hypothesis that language regions may play a greater role in music processing in individuals with higher sensitivity to linguistic pitch (e.g., Deutsch et al., 2006, 2009; Bidelman et al., 2011; Creel et al., 2018; Ngo et al., 2016).

\section{Materials and methods}

\section{Participants}

\section{Experiments 1, 2, and 4 (fMRI):}

48 individuals (age 18-51, mean 24.3; 28 ( 58\%) females) from the Cambridge/Boston, MA community participated for payment across three fMRI experiments $(n=18$ in Experiment 1 ; $\mathrm{n}=20$ in Experiment 2; $\mathrm{n}=18$ in Experiment 4; 8 participants overlapped between Experiments 1 and 2). 33 participants were right-handed and four left-handed, as determined by the Edinburgh handedness inventory (Oldfield, 1971), or self-report (see Willems et al., 2014, for arguments for including left-handers in cognitive neuroscience experiments); the handedness data for the remaining 11 participants (one in Experiment 2 and 10 in Experiment 4) were not collected. All but one participant (with no handedness information) in Experiment 4 showed typical leftlateralized language activations in the language localizer task described below (as assessed by numbers of voxels falling within the language parcels in the left vs. right hemisphere (LH vs. $\mathrm{RH})$, using the following formula: (LH-RH)/(LH+RH); e.g., Jouravlev et al., 2020; individuals with values of 0.25 or greater were considered to have a left-lateralized language system). For the participant with right-lateralized language activations (with a lateralization value of -0.25 or lower), we used right-hemisphere language regions for the analyses (see SI-3 for an analysis where the LH language regions were used for this participant; the critical results were not affected). Participants in Experiments 1 and 2 were native English speakers; participants in Experiment 4 were native Mandarin speakers and proficient speakers of English (none had any knowledge of Russian, which was used as an unfamiliar foreign-language condition in Experiment 4). All participants gave informed consent in accordance with the requirements of MIT's Committee on the Use of Humans as Experimental Subjects (COUHES).

\section{Experiment 3 (behavioral):}

Individuals with aphasia. Three participants with severe and chronic aphasia were recruited to the study (SA, PR, and PP). All participants gave informed consent in accordance with the requirements of the Institutional Review Board at UCL (ethical approval LC/2013/05). Background information on each participant is presented in Table 1. Anatomical scans are 
shown in Figure 2A and extensive perisylvian damage in the left hemisphere, encompassing areas where language activity is observed in neurotypical individuals is illustrated in Figure 2B.

\begin{tabular}{|c|c|c|c|c|c|c|c|}
\hline Patient & Sex & $\begin{array}{l}\text { Age } \\
\text { (years) } \\
\text { at } \\
\text { testing }\end{array}$ & $\begin{array}{l}\text { Time } \\
\text { post- } \\
\text { onset } \\
\text { (years) } \\
\text { at } \\
\text { testing }\end{array}$ & Handedness & Etiology & $\begin{array}{l}\text { Premorbid } \\
\text { musical } \\
\text { experience }\end{array}$ & $\begin{array}{l}\text { Premorbid } \\
\text { employment }\end{array}$ \\
\hline $\mathrm{SA}$ & $\mathrm{M}$ & 67 & 21 & $\mathrm{R}$ & $\begin{array}{l}\text { Subdural } \\
\text { empyema }\end{array}$ & $\begin{array}{l}\text { Sang in } \\
\text { choir; basic } \\
\text { sight- } \\
\text { reading } \\
\text { ability }\end{array}$ & $\begin{array}{l}\text { Police } \\
\text { sergeant }\end{array}$ \\
\hline PR & $\mathrm{M}$ & 68 & 14 & $\mathrm{~L}$ & $\begin{array}{l}\text { Left } \\
\text { hemisphere } \\
\text { stroke }\end{array}$ & $\begin{array}{l}\text { Drummer } \\
\text { in band; } \\
\text { basic sight- } \\
\text { reading } \\
\text { ability }\end{array}$ & $\begin{array}{l}\text { Retail } \\
\text { manager }\end{array}$ \\
\hline $\mathrm{PP}$ & $\mathrm{M}$ & 77 & 10 & $\mathrm{R}$ & $\begin{array}{l}\text { Left } \\
\text { hemisphere } \\
\text { stroke }\end{array}$ & $\begin{array}{l}\text { Childhood } \\
\text { musical } \\
\text { training. } \\
\text { No adult } \\
\text { experience. }\end{array}$ & $\begin{array}{l}\text { Minerals } \\
\text { trader }\end{array}$ \\
\hline
\end{tabular}

Table 1. Background information on the aphasic participants. 


\section{A. Anatomical scans}

SA

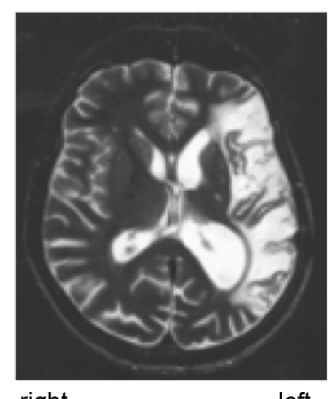

PR

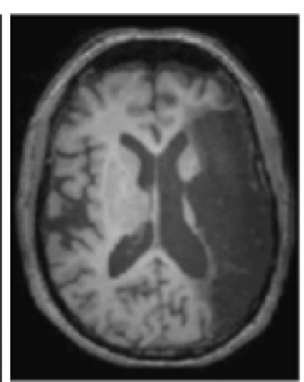

right

left

\section{B. Language network overlay}

PR

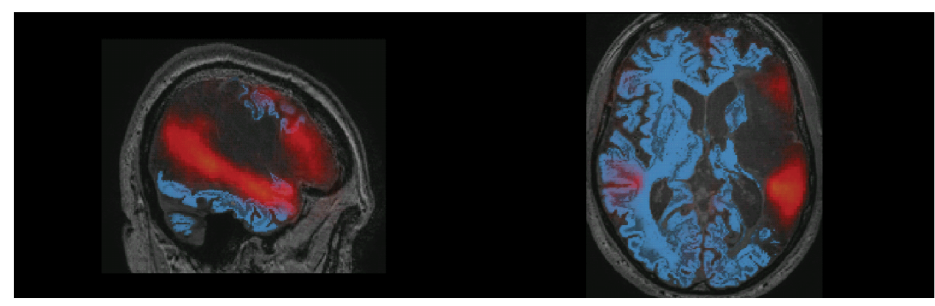

PP

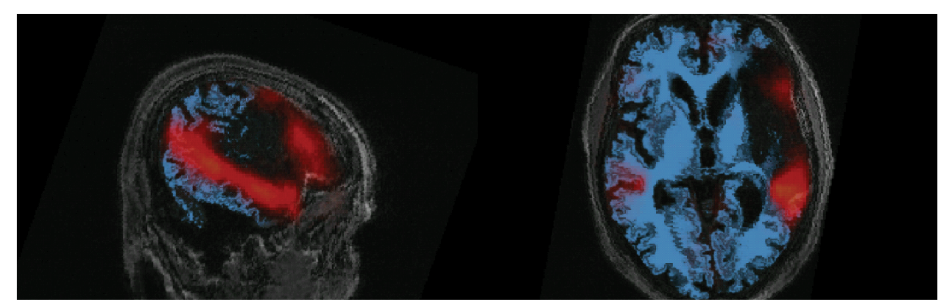

\section{Language tasks}

PP

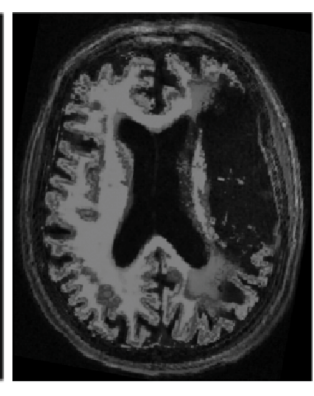

Comprehension of spoken

reversible sentences

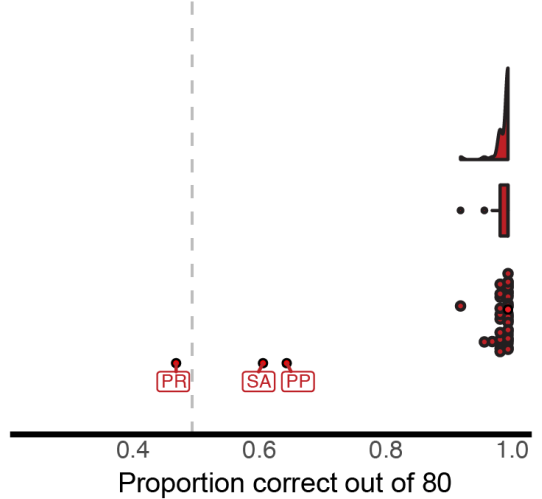

Spoken grammaticality judgement

Figure 2: A. Anatomical scans (T2-weighted for SA, T1-weighted for PR and PP) of the aphasic participants (all scans were performed during the chronic phase, as can be seen from the ventricular enlargement). Note that the right side of the image represents the left side of the brain. B. P.R.'s (top) and P.P.'s (bottom) anatomical scans (blue-tinted) shown with the probabilistic activation overlap map for the fronto-temporal language network overlaid (SA's raw anatomical data were not available). The map was created by overlaying thresholded individual activation maps (red-tinted) for the sentences $>$ nonwords contrast (Fedorenko et al., 2010) in 220 neurotypical participants (none of whom were participants in any experiments in the current study). As the images show, the language network falls largely within the lesioned tissue in the left hemisphere. C. Performance of the control and aphasic participants on two measures of linguistic syntax processing (see Design, materials, and procedure - Experiment 3): the comprehension of spoken reversible sentences (top), and the spoken grammaticality judgments (bottom). The densities show the distribution of proportion correct scores in the control participants and the boxplot shows the quartiles of the control population. The dots show individual participants (for the aphasic individuals, the initials indicate the specific participant). Dashed grey lines indicate chance performance. 
Control participants. We used Amazon's Mechanical Turk platform to recruit normative samples for the music tasks and a subset of the language tasks that are most critical to linguistic syntactic comprehension. Ample evidence now shows that online experiments yield data that closely mirror the data patterns in experiments conducted in a lab setting (e.g., Crump et al., 2013). Data from participants with IP addresses in the US who self-reported being native English speakers were included in the analyses. Fifty participants performed the critical music task, and the Scale task from the MBEA (Peretz et al., 2003), as detailed below. Data from participants who responded incorrectly to the catch trial in the MBEA Scale task $(n=5)$ were excluded from the analyses, for a final sample of 45 control participants for the music tasks. A separate sample of 50 participants performed the Comprehension of spoken reversible sentences task. Data from one participant who completed fewer than $75 \%$ of the questions and another participant who did not report being a native English speaker were excluded for a final sample of 48 control participants. Finally, a third sample of 50 participants performed the Spoken grammaticality judgment task. Data from one participant who did not report being a native English speaker were excluded for a final sample of 49 control participants.

\section{Design, materials, and procedure}

\section{Experiments 1, 2, and 4 (fMRI):}

Each participant completed a language localizer task (Fedorenko et al., 2010) and one or more of the critical music perception experiments, along with one or more tasks for unrelated studies. The scanning sessions lasted approximately two hours.

Language localizer. This task is described in detail in Fedorenko et al. (2010) and subsequent studies from the Fedorenko lab (e.g., Fedorenko et al., 2011; Blank et al., 2014; Blank et al., 2016; Pritchett et al., 2018; Paunov et al., 2019; Fedorenko et al., 2020; Shain et al., 2020, among others) and is available for download from https://evlab.mit.edu/funcloc/). Briefly, participants read sentences and lists of unconnected, pronounceable nonwords in a blocked design. Stimuli were presented one word/nonword at a time at the rate of $450 \mathrm{~ms}$ per word/nonword. Participants read the materials passively and performed a simple button-press task at the end of each trial (included in order to help participants remain alert). Each participant completed two $\sim 6$ minute runs. This localizer task has been extensively validated and shown to be robust to changes in the materials, modality of presentation (visual vs. auditory; see the results of Experiments 1 and 4 for additional replications of modality robustness), and task (Fedorenko et al., 2010; Fedorenko, 2014; Scott et al., 2017; Diachek, Blank, Siegelman et al., 2020). Further, a network that corresponds closely to the localizer contrast (sentences $>$ nonwords) emerges robustly from whole-brain task-free data_-voxel fluctuations during rest (e.g., Braga et al., 2020), providing further support for the idea that this network constitutes a 'natural kind' in the brain and a meaningful unit of analysis.

Experiment 1. Participants passively listened to diverse stimuli across 18 conditions in a longevent-related design (five conditions were not relevant to the current study and therefore not 
included in the analyses). All stimuli were $9 \mathrm{~s}$ in length. The conditions were selected to probe responses to diverse kinds of music, to examine sensitivity to structure scrambling in music, to compare responses to songs vs. spoken lyrics, and to compare responses to music stimuli vs. other auditory stimuli.

The four non-vocal music conditions (all Western tonal music) included orchestral music, singleinstrument music, synthetic drum music, and synthetic melodies. The orchestral music condition consisted of 12 stimuli (SI-Table 4a) selected from classical orchestras or jazz bands. The single-instrument music condition consisted of 12 stimuli (SI-Table $4 \mathbf{b}$ ) that were played on one of the following instruments: cello $(n=1)$, flute $(n=1)$, guitar $(n=4)$, piano $(n=4)$, sax $(n=1)$, or violin $(n=1)$. The synthetic drum music condition consisted of 12 stimuli synthesized using percussion patches from MIDI files taken from freely available online collections. The stimuli were synthesized using the MIDI toolbox for MATLAB (writemidi).

The synthetic melodies condition consisted of 12 stimuli transcribed from folk tunes obtained from freely available online collections. Each melody was defined by a sequence of notes with corresponding pitches and durations. Each note was composed of harmonics 1 through 10 of the fundamental presented in equal amplitude, with no gap in-between notes. Phase discontinuities between notes were avoided by ensuring that the starting phase of the next note was equal to the ending phase of the previous note.

The synthetic drum music and the synthetic melodies conditions had scrambled counterparts to probe sensitivity to music structure. The scrambled drum music condition was created by jittering the inter-note-interval (INI). The amount of jitter was sampled from a uniform distribution (from -0.5 to 0.5 beats). The scrambled INIs were truncated to be no smaller than $5 \%$ of the distribution of INIs from the intact drum track. The total distribution of INIs was then scaled up or down to ensure that the total duration remained unchanged. The scrambled melodies condition was created by scrambling both pitch and rhythm information. Pitch information was scrambled by randomly re-ordering the sequence of pitches and then adding jitter to disrupt the key. The amount of jitter for each note was sampled from a uniform distribution centered on the note's pitch after shuffling (from -3 to +3 semitones). The duration of each note was also jittered (from -0.2 to 0.2 beats). To ensure the total duration was unaffected by jitter, $\mathrm{N} / 2$ positive jitter values were sampled, where $\mathrm{N}$ is the number of notes, and then a negative jitter was added with the same magnitude for each of the positive samples, such that the sum of all jitters equaled 0 . To ensure the duration of each note remained positive, the smallest jitters were added to the notes with the smallest durations. Specifically, the note durations and sampled jitters were sorted by their magnitude, summed, and then the jittered durations were randomly re-ordered.

To allow for a direct comparison between music and linguistic conditions within the same experiment, we included auditory sentences and auditory nonword sequences. The sentence condition consisted of 24 lab-constructed stimuli (half recorded by a male, and half by a female). Each stimulus consisted of a short story (each three sentences long) describing common, everyday events. Any given participant heard 12 of the stimuli ( 6 male, 6 female). The nonword sequence condition consisted of 12 stimuli (recorded by a male). 
We also included two other linguistic conditions: songs and spoken lyrics. These conditions were included to test whether the addition of a melodic contour to speech (in songs) would increase the responses of the language regions. Such a pattern might be expected of a brain region that responds to both linguistic content and music structure. The songs and the lyrics conditions each consisted of 24 stimuli. We selected songs with a tune that was easy to sing without accompaniment. These materials were recorded by four male singers: each recorded between 2 and 11 song-lyrics pairs. The singers were actively performing musicians (e.g., in a capella groups) but were not professionals. Any given participant heard either the song or the lyrics version of an item for 12 stimuli in each condition.

Finally, to assess the specificity of the potential responses to music, we included three non-music conditions: animal sounds and two kinds of environmental sounds (pitched and unpitched). The animal sounds condition and the environmental sounds conditions each consisted of 12 stimuli taken from in-lab collections. If individual recordings were shorter than $9 \mathrm{~s}$, then several recordings of the same type of sound were concatenated together (100ms gap in between). We included the pitch manipulation in order to test for general responsiveness to pitch - a key component of music - in the language regions. The materials for all conditions are available at OSF: https://osf.io/68y $7 \mathrm{c} /$.

The remaining five conditions (consisting of three acoustically manipulated versions of the sentence condition, and two acoustically manipulated versions of the synthetic melodies condition) were of no relevance to the current study and are therefore not discussed.

For each participant, stimuli were randomly divided into six sets (corresponding to runs) with each set containing two stimuli from each condition. The order of the conditions for each run was selected from four predefined palindromic orders, which were constructed so that conditions targeting similar mental processes (e.g., orchestral music and single-instrument music) were separated by other conditions (e.g., speech or animal sounds). Each run contained three 10s fixation periods: at the beginning, in the middle, and at the end. Otherwise, the stimuli were separated by $3 \mathrm{~s}$ fixation periods, for a total run duration of $456 \mathrm{~s}$ ( $7 \mathrm{~min} 36 \mathrm{~s}$ ). All but two participants completed all six runs (and thus got a total of 12 experimental events per condition); the remaining two completed four runs (and thus got 8 events per condition).

Because, as noted above, we have previously established that the language localizer is robust to presentation modality, we used the visual localizer to define the language regions. However, in SI-2 we show that the critical results are similar when auditory contrasts (sentences $>$ nonwords in Experiment 1, or Mandarin sentences > foreign in Experiment 4) are instead used to define the language regions.

Experiment 2. Participants listened to well-formed melodies (adapted and expanded from Fedorenko et al., 2009) and melodies with a structural violation in a long-event-related design, and judged the well-formedness of the melodies. As discussed in the Introduction, this type of manipulation is commonly used to probe sensitivity to music structure, including in studies examining language-music overlap (e.g., Patel et al., 1998; Koelsch et al., 2000, 2002; Maess et 
al., 2001; Tillmann et al, 2003; Fedorenko et al., 2009; Slevc et al., 2009; Kunert et al., 2015; Musso et al., 2015). The melodies were between 11 and 14 notes. The well-formed condition consisted of 90 melodies, which were tonal and ended in a tonic note with an authentic cadence in the implied harmony. All melodies were isochronous, consisting of quarter notes except for the final half note. The first five notes established a strong sense of key. Each melody was then altered to create a version with a "sour" note: the pitch of one note (from among the last four notes in a melody) was altered up or down by one or two semitones, so as to result in a nondiatonic note while keeping the melodic contour (the up-down pattern) the same. The structural position of the note that underwent this change varied among the tonic, the fifth, and the major third. The full set of 180 melodies was distributed across two lists following a Latin Square design. Any given participant heard stimuli from one list. The materials are available at OSF: https://osf.io/68y $7 \mathrm{c} /$.

For each participant, stimuli were randomly divided into two sets (corresponding to runs) with each set containing 45 melodies ( 22 or 23 per condition). The order of the conditions, and the distribution of inter-trial fixation periods, was determined by the optseq 2 algorithm (Dale et al., 1999). The order was selected from among four predefined orders, with no more than four trials of the same condition in a row. In each trial, participants were presented with a melody for three seconds followed by a question, presented visually on the screen, about the well-formedness of the melody ("Is the melody well-formed?"). To respond, participants had to press one of two buttons on a button box within two seconds. When participants answered, the question was replaced by a blank screen for the remainder of the two-second window; if no response was made within the two-second window, the experiment advanced to the next trial. Responses received within one second after the end of the previous trial were still recorded to account for the possible slow responses. The screen was blank during the presentation of the melodies. Each run contained $151 \mathrm{~s}$ of fixation interleaved among the trials, for a total run duration of $376 \mathrm{~s}(6 \mathrm{~min}$ 16s). All but four participants completed both runs (due to experimenter error, two participants completed two runs from different lists which means they heard both versions of some melodies; because their neural data looked similar to the rest of the participants, we chose to include their data); the remaining four completed one run. Due to a script error, participants only heard the first 12 notes of each melody during the three seconds stimulus presentation. Therefore, we only analyzed the 80 pairs (160 of the 180 total melodies) where the contrastive note appeared within the first 12 notes.

Experiment 4. Participants passively listened to single-instrument music, environmental sounds, sentences in an unfamiliar foreign language (Russian), and Mandarin sentences in a blocked design. All stimuli were 5-5.95s in length. The conditions were selected to probe responses to music, and to compare responses to music stimuli vs. other auditory stimuli. The critical music condition consisted of 60 stimuli selected from classical pieces by J.S. Bach played on cello, flute, or violin $(n=15$ each) and jazz music played on saxophone $(n=15)$. The environmental sounds condition consisted of 60 stimuli selected from in-lab collections and included both pitched and unpitched stimuli. The foreign language condition consisted of 60 stimuli selected from Russian audiobooks (short stories by Paustovsky, and "Fathers and Sons" by Turgenev). 
The foreign language condition was included because creating a 'nonwords' condition (the baseline condition we typically use for defining the language regions; Fedorenko et al., 2010) is challenging in Mandarin given that most words are monosyllabic, thus most syllables carry some meaning. As a result, sequences of syllables are more akin to lists of words. Therefore, we included the unfamiliar foreign language condition, which we know also works well as a baseline (Ayyash, Malik-Moraleda et al., 2020). The Mandarin sentence condition consisted of 240 stimuli (120 lab-constructed sentences, each recorded by a male and a female native speaker). The Mandarin sentence stimuli were divided into four lists, each consisting of 60 unique sentences (half recorded by a male, and half by a female) and 60 unique nonword sequences (half recorded by a male, and half by a female). The materials are available at OSF: https://osf.io/68y $7 \mathrm{c} /$. The experiment also included five (speech) conditions of no relevance to the current study which are therefore not discussed.

Stimuli were grouped into blocks with each block consisting of three stimuli and lasting $18 \mathrm{~s}$ (stimuli were padded with silence to make each trial exactly six seconds long). For each participant, blocks were divided into 10 sets (corresponding to runs), with each set containing two blocks from each condition. The order of the conditions for each run was selected from eight predefined palindromic orders. Each run contained three 14s fixation periods: at the beginning, in the middle, and at the end, for a total run duration of 366s (6min 6s). Five participants completed eight of the 10 runs (and thus got 16 blocks per condition; the remaining thirteen completed six runs (and thus got 12 blocks per condition). (We had created enough materials for 10 runs, but based on observing robust effects for several key contrasts in the first few participants who completed six to eight runs, we administered 6-8 runs to the remaining participants.)

Because we have previously found that an English localizer works well in native speakers of diverse languages, including Mandarin, as long as they are proficient in English (Ayyash, MalikMoraleda et al., 2020), we used the same localizer in Experiment 4 as the one used in Experiments 1 and 2, for consistency. However, in SI-2 (SI-Figure 2c, SI-Table 2c) we show that the critical results are similar when the Mandarin sentences $>$ foreign contrast is instead used to define the language regions.

\section{Experiment 3 (behavioral):}

Language assessments. Participants with aphasia were assessed for the integrity of lexical processing using word-to-picture matching tasks in both spoken and written modalities (ADA Spoken and Written Word-Picture Matching; Franklin et al., 1992). Productive vocabulary was assessed through picture naming. In the spoken modality, the Boston Naming Test was employed (Kaplan et al., 2001), and in writing, the PALPA Written Picture Naming subtest (Kay et al., 1992). Sentence processing was evaluated in both spoken and written modalities through comprehension (sentence-to-picture matching) of reversible sentences in active and passive voice. In a reversible sentence, the heads of both noun phrases are plausible agents, and therefore, word order (in a word-order-based language like English) is the only cue to who is doing what to 
whom. Participants also completed spoken and written grammaticality judgment tasks, where they made a yes/no decision as to the grammaticality of a word string. The task employed a subset of sentences from Linebarger et al. (1983).

All three participants exhibited severe language impairments that disrupted both comprehension and production (Table 2). For lexical-semantic tasks, all three participants displayed residual comprehension ability for high imageability/picturable vocabulary, although more difficulty was evident on the synonym matching test, which included abstract words. They were all severely anomic in speech and writing. Sentence production was severely impaired with output limited to single words, social speech (expressions, like "How are you?"), and other formulaic expressions (e.g., "and so forth"). Critically, all three performed at or close to chance level on spoken and written comprehension of reversible sentences and grammaticality judgments; each patient's scores were lower than all of the healthy controls (Table 2 and Figure 2C).

\begin{tabular}{|c|c|c|c|c|}
\hline Participant & $\mathbf{S A}$ & PR & PP & Controls \\
\hline \multicolumn{5}{|l|}{ Lexical-semantic assessments } \\
\hline $\begin{array}{l}\text { ADA Spoken Word-Picture Matching } \\
(\text { chance }=16.5)\end{array}$ & $60 / 66$ & $61 / 66$ & $64 / 66$ & N/A \\
\hline $\begin{array}{l}\text { ADA Written Word-Picture Matching } \\
(\text { chance }=16.5)\end{array}$ & $62 / 66$ & $66 / 66$ & $58 / 66$ & N/A \\
\hline $\begin{array}{l}\text { ADA spoken synonym matching (chance } \\
=80)\end{array}$ & $123 / 160$ & $121 / 160$ & $135 / 160$ & $\mathrm{~N} / \mathrm{A}$ \\
\hline $\begin{array}{l}\text { ADA written synonym matching (chance } \\
=80 \text { ) }\end{array}$ & $121 / 160$ & $145 / 160$ & $143 / 160$ & $\mathrm{~N} / \mathrm{A}$ \\
\hline $\begin{array}{l}\text { Boston Naming Test } \\
\text { (NB: accepting both spoken and written } \\
\text { responses) }\end{array}$ & $4 / 60$ & $4 / 60$ & $11 / 60$ & $\mathrm{~N} / \mathrm{A}$ \\
\hline PALPA 54 Written Picture Naming & $24 / 60$ & $2 / 60$ & $1 / 60$ & N/A \\
\hline \multicolumn{5}{|l|}{ Syntactic assessments } \\
\hline $\begin{array}{l}\text { Comprehension of spoken reversible } \\
\text { sentences (chance }=40 \text { ) }\end{array}$ & $49 / 80$ & $38 / 80$ & $52 / 80$ & $\begin{array}{l}\text { Mean }= \\
79.5 / 80 \\
\mathrm{SD}=1.03 \\
\mathrm{Min}=74 / 80 \\
\mathrm{Max}=80 / 80 \\
\mathrm{~N}=48\end{array}$ \\
\hline $\begin{array}{l}\text { Comprehension of written reversible } \\
\text { sentences }(\text { chance }=40)\end{array}$ & $42 / 80$ & $49 / 80$ & $51 / 80$ & $\mathrm{~N} / \mathrm{A}$ \\
\hline $\begin{array}{l}\text { Spoken grammaticality judgments (chance } \\
=24)\end{array}$ & $33 / 48$ & $34 / 48$ & $35 / 48$ & $\begin{array}{l}\text { Mean }= \\
45.5 / 48 \\
\mathrm{SD}=2.52 \\
\mathrm{Min}=36 / 48\end{array}$ \\
\hline
\end{tabular}




\begin{tabular}{|l|l|l|l|l|}
\hline & & & & $\begin{array}{l}\text { Max }=48 / 48 \\
\text { N=49 }\end{array}$ \\
\hline $\begin{array}{l}\text { Written grammaticality judgments (chance } \\
\text { 24) }\end{array}$ & $29 / 48$ & $24 / 48$ & $29 / 48$ & N/A \\
\hline
\end{tabular}

Table 2. Results of language assessments for participants with aphasia and healthy controls. For each test, we show number of correctly answered questions out of the total number of questions.

Critical music task. Participants judged the well-formedness of the melodies from Experiment 2. Judgments were intended to reflect the detection of the key violation in the sour versions of the melodies. The full set of 180 melodies was distributed across two lists following a Latin Square design. All participants heard all 180 melodies. The control participants heard the melodies from one list, followed by the melodies from the other list, with the order of lists counter-balanced across participants. For the participants with aphasia, each list was further divided in half, and each participant was tested across four sessions, with 45 melodies per session.

Montreal Battery for the Evaluation of Amusia. To obtain another measure of music competence/sensitivity to music structure, we administered the Montreal Battery for the Evaluation of Amusia (MBEA) (Peretz et al., 2003). The battery consists of six tasks that assess musical processing components described by Peretz \& Coltheart (2003): three target melodic processing, two target rhythmic processing, and one assesses memory for melodies. Each task consists of 30 experimental trials (and uses the same set of 30 base melodies) and is preceded by practice examples. Some of the tasks additionally include a catch trial, as described below. For the purposes of the current investigation, the critical task is the "Scale" task. Participants are presented with pairs of melodies that they have to judge as identical or not. On half of the trials, one of the melodies is altered by modifying the pitch of one of the tones to be out of scale. Like our critical music task, this task aims to test participants' ability to represent and use tonal structure in Western music, except that instead of making judgments on each individual melody, participants compare two melodies on each trial. This task thus serves as a conceptual replication (Schmidt, 2009). One trial contains stimuli designed to be easy, intended as a catch trial to ensure that participants are paying attention. In this trial, the comparison melody has all its pitches set at random. This trial is excluded when computing the scores.

Control participants performed just the Scale task. Participants with aphasia performed all six tasks, distributed across three testing sessions to minimize fatigue.

\section{fMRI data acquisition, preprocessing, and first-level modeling (for Experiments 1, 2, and 4)}

Data acquisition. Whole-brain structural and functional data were collected on a whole-body 3 Tesla Siemens Trio scanner with a 32-channel head coil at the Athinoula A. Martinos Imaging Center at the McGovern Institute for Brain Research at MIT. T1-weighted structural images were collected in 176 axial slices with $1 \mathrm{~mm}$ isotropic voxels (repetition time $(\mathrm{TR})=2,530 \mathrm{~ms}$; echo time $(\mathrm{TE})=3.48 \mathrm{~ms})$. Functional, blood oxygenation level-dependent (BOLD) data were acquired using an EPI sequence with a $90^{\circ}$ flip angle and using GRAPPA with an acceleration 
factor of 2; the following parameters were used: thirty-one $4.4 \mathrm{~mm}$ thick near-axial slices acquired in an interleaved order (with $10 \%$ distance factor), with an in-plane resolution of 2.1 $\mathrm{mm} \times 2.1 \mathrm{~mm}$, FoV in the phase encoding $(\mathrm{A}>>\mathrm{P})$ direction $200 \mathrm{~mm}$ and matrix size $96 \times 96$ voxels, $\mathrm{TR}=2000 \mathrm{~ms}$ and $\mathrm{TE}=30 \mathrm{~ms}$. The first $10 \mathrm{~s}$ of each run were excluded to allow for steady state magnetization (see OSF https://osf.io/68y7c/ for the pdf of the scanning protocols).

Preprocessing. Data preprocessing was carried out with SPM12 (using default parameters, unless specified otherwise) and supporting, custom MATLAB scripts. Preprocessing of functional data included motion correction (realignment to the mean image of the first run using $2^{\text {nd }}$-degree b-spline interpolation), normalization into a common space (Montreal Neurological Institute (MNI) template) (estimated for the mean image using trilinear interpolation), resampling into $2 \mathrm{~mm}$ isotropic voxels, smoothing with a $4 \mathrm{~mm}$ FWHM Gaussian filter, and high-pass filtering at $128 \mathrm{~s}$.

First-level modeling. For both the language localizer task and the critical experiments, a standard mass univariate analysis was performed in SPM12 whereby a general linear model (GLM) estimated, for each voxel, the effect size of each condition in each experimental run. These effects were each modeled with a boxcar function (representing entire blocks/events) convolved with the canonical Hemodynamic Response Function (HRF). The model also included first-order temporal derivatives of these effects, as well as nuisance regressors representing entire experimental runs, offline-estimated motion parameters, and timepoints classified as outliers based on the motion parameters.

\section{Definition of the language functional regions of interest (for Experiments 1, 2, and 4)}

For each critical experiment, we defined a set of language functional regions of interest (fROIs) using group-constrained, subject-specific localization (Fedorenko et al., 2010). In particular, each individual map for the sentences $>$ nonwords contrast from the language localizer was intersected with a set of five binary masks. These masks (Figure 3; available at OSF: https://osf.io/68y7c/) were derived from a probabilistic activation overlap map for the same contrast in a large set of participants $(n=220)$ using watershed parcellation, as described in Fedorenko et al. (2010) for a smaller set of participants. These masks covered the frontotemporal language network in the left hemisphere. Within each mask, a participant-specific language fROI was defined as the top $10 \%$ of voxels with the highest $t$-values for the localizer contrast.

\section{Analyses}

All analyses were performed with linear mixed-effects models using the "lme4" package in R with $p$-value approximation performed by the "ImerTest" package (Bates et al., 2015; Kuznetsova et al., 2017).

\section{Validation of the language fROIs (for Experiments 1, 2, and 4)}


To ensure that the language fROIs behave as expected (i.e., show a reliably greater response to the sentences condition compared to the nonwords condition), we used an across-runs crossvalidation procedure (e.g., Nieto-Castañón \& Fedorenko, 2012). In this analysis, the first run of the localizer was used to define the fROIs, and the second run to estimate the responses (in percent BOLD signal change, PSC) to the localizer conditions, ensuring independence (e.g., Kriegeskorte et al., 2009); then the second run was used to define the fROIs, and the first run to estimate the responses; finally, the extracted magnitudes were averaged across the two runs to derive a single response magnitude for each of the localizer conditions. Statistical analyses were performed on these extracted PSC values.

\section{Sanity check and critical analyses (for Experiments 1, 2, and 4)}

To estimate the responses in the language fROIs to the conditions of the critical experiments, the data from all the runs of the language localizer were used to define the fROIs, and the responses to each condition were then estimated in these regions. Statistical analyses were then performed on these extracted PSC values. For Experiments 1 and 4, we repeated the analyses using alternative language localizer contrasts to define the language fROIs (auditory sentences $>$ nonwords in Experiment 1, and Mandarin sentences $>$ foreign in Experiment 4), which yielded quantitatively and qualitatively similar responses (see SI-2).

\section{2a. Sanity check analyses}

We conducted two sets of sanity check analyses. First, to ensure that auditory conditions that contain meaningful linguistic content elicit strong responses in the language regions relative to perceptually similar conditions with no discernible linguistic content, we compared the auditory sentences condition with the auditory nonwords condition (Experiment 1) or with the foreign language condition (Experiment 4).

And second, to ensure that the music conditions elicit strong responses in auditory cortex, we extracted the responses from a bilateral anatomically defined auditory cortical region (area Te1.2 from the Morosan et al., 2001 cytoarchitectonic probabilistic atlas) to the six critical music conditions: orchestral music, single instrument music, synthetic drum music, and synthetic melodies in Experiment 1; well-formed melodies in Experiment 2; and the music condition in Experiment 4. Statistical analyses, comparing each condition to the fixation baseline, were performed on these extracted PSC values.

\section{2b. Critical analyses}

To characterize the responses in the language network to music perception, we asked three questions. First, we asked whether music conditions elicit strong responses in the language regions. Second, we investigated whether the language network is sensitive to structure in music, as would be evidenced by stronger responses to intact than scrambled music, and stronger 
responses to structural violations compared to no-violation control. And third, we asked whether music conditions elicit strong responses in the language regions of individuals with high sensitivity to linguistic pitch—native speakers of a tonal language (Mandarin).

For each contrast (the contrasts relevant to the three research questions are detailed below), we used two types of linear mixed-effect regression models:

i) the language network model, which examined the language network as a whole; and ii) the individual language fROI models, which examined each language fROI separately.

Treating the language network as an integrated system is reasonable given that the regions of this network a) show similar functional profiles, both with respect to selectivity for language over non-linguistic processes (e.g., Fedorenko et al., 2011; Pritchett et al., 2018; Jouravlev et al., 2019; Ivanova et al., 2020, 2021) and with respect to their role in lexico-semantic and syntactic processing (e.g., Fedorenko et al., 2012b; Blank et al., 2016; Fedorenko et al., 2020); and b) exhibit strong inter-region correlations in both their activity during naturalistic cognition paradigms (e.g., Blank et al., 2014; Braga et al., 2020; Paunov et al., 2019) and key functional markers, like the strength or extent of activation in response to language stimuli (e.g., Mahowald \& Fedorenko, 2016; Mineroff, Blank et al., 2018). However, because we want to allow for the possibility that language regions differ in their response to music, we supplement the networkwise analyses with the analyses of the five language fROIs separately.

For each network-wise analysis, we fit a linear mixed-effect regression model predicting the level of BOLD response in the language fROIs in the contrasted conditions. The model included a fixed effect for condition and random intercepts for fROI and participant. Here and elsewhere, the $p$-value was estimated by applying the Satterthwaite's method-of-moment approximation to obtain the degrees of freedom (Giesbrecht \& Burns, 1985; Fai \& Cornelius, 1996; as described in Kuznetsova et al., 2017).

$$
\text { Effect size } \sim \text { condition }+(1 \mid \text { fROI })+(1 \mid \text { SubjectID })
$$

For each fROI-wise analysis, we fit a linear mixed-effect regression model predicting the level of BOLD response in each of the five language fROIs in the contrasted conditions. The model included a fixed effect for condition and a random intercept for participant. For each analysis, the result was FDR-corrected for the five fROIs.

$$
\text { Effect size } \sim \text { condition }+(1 \mid \text { SubjectID })
$$

Does music elicit responses in the language network?

To test whether language regions respond to music, we used four contrasts using data from Experiments 1 and 2. First, we compared the responses to each of the music conditions (orchestral music, single instrument music, synthetic drum music, and synthetic melodies in Experiment 1; well-formed melodies in Experiment 2) against the fixation baseline. Second, we 
compared the responses to the music conditions against the response to the nonword strings condition - an unstructured and meaningless linguistic stimulus (in Experiment 1, we used the auditory nonwords condition, and in Experiment 2, we used the visual nonwords condition from the language localizer). Third, in Experiment 1, we additionally compared the responses to the music conditions against the response to non-linguistic, non-music stimuli (animal and environmental sounds). A brain region that supports music processing should respond more strongly to music than the fixation baseline and the nonwords condition (our baseline for the language regions); further, if the response is selective, it should be stronger than the response elicited by non-music auditory stimuli. And finally, in Experiment 1, we also directly compared the responses to songs vs. lyrics. A brain region that responds to music should respond more strongly to songs given that they contain a melodic contour in addition to the linguistic content.

\section{Is the language network sensitive to structure in music?}

Experiments 1 and 2 (fMRI): Because most prior claims about the overlap between language and music concern the processing of structure, given the parallels that can be drawn between the syntactic structure of language and the tonal and rhythmic structure in music (e.g., Lerdahl \& Jackendoff, 1977, 1983; cf. Jackendoff, 2009), we used three contrasts to test whether language regions are sensitive to music structure. First and second, in Experiment 1, we compared the responses to synthetic melodies vs. their scrambled counterparts, and to synthetic drum music vs. the scrambled drum music condition. The former targets both tonal and rhythmic structure, and the latter selectively targets rhythmic structure. The reason to examine rhythmic structure is that some patient studies have argued that pitch contour processing relies on the right hemisphere, and rhythm processing draws on the left hemisphere (e.g., Zatorre, 1984; Peretz, 1990; Alcock et al., 2000), so although most prior work examining the language-music relationship has focused on tonal structure, rhythmic structure may a priori be more likely to overlap with linguistic syntactic structure given their alleged co-lateralization based on the patient literature. And third, in Experiment 2, we compared the responses to well-formed melodies vs. melodies with a sour note. A brain region that responds to structure in music should respond more strongly to intact than scrambled music (similar to how language regions respond more strongly to sentences than lists of words; e.g., Fedorenko et al., 2010; Diachek, Blank, Siegelman et al., 2020), and exhibit sensitivity to structure violations (similar to how language regions respond more strongly to sentences that contain grammatical errors: e.g., Embick et al., 2000; Newman et al., 2001; Kuperberg et al., 2003; Cooke et al., 2006; Friederici et al., 2010; Herrmann et al., 2012; Fedorenko et al., 2020).

Experiment 3 (behavioral): In Experiment 3, we further asked whether individuals with severe deficits in processing linguistic syntax also exhibit difficulties in processing music structure. To do so, we assessed participants' ability to discriminate well-formed ("good") melodies from melodies with a sour note ("bad"), while controlling for their response bias (how likely they are overall to say that something is well-formed) by computing $d$ ' for each participant (Green \& Swets, 1966), in addition to proportion correct. We then compared the $d$ 'values of each individual with aphasia to the distribution of $d$ ' values of healthy control participants using a 
Bayesian test for single case assessment (Crawford \& Garthwaite, 2007) as implemented in the psycho package in R (Makowski, 2018). (Note that for the linguistic syntax tasks, it was not necessary to conduct statistical tests comparing the performance of each individual with aphasia to the control distribution because the performance of each individual with aphasia was lower than $100 \%$ of the control participants' performances.) We similarly compared the proportion correct on the MBEA scale task of each individual with aphasia to the distribution of accuracies of healthy controls. If linguistic and music syntax draw on the same resources, then individuals with linguistic syntactic impairments should also exhibit deficits on tasks requiring the processing of music syntax.

Does music elicit responses in the language network of native speakers of a tonal language?

The above analyses focus on the language network's responses to diverse music stimuli and its sensitivity to music structure in English native speakers. However, some have argued that responses to music may differ in speakers of languages that use pitch to make lexical or grammatical distinctions (e.g., Deutsch et al., 2006, 2009; Bidelman et al., 2011; Creel et al., 2018; Ngo et al., 2016). In Experiment 4, we therefore tested whether language regions of Mandarin native speakers respond to music. Similar to Experiment 1, we compared the response to the music condition against a) the fixation baseline, b) the foreign language condition, and c) a non-linguistic, non-music condition (environmental sounds). A brain region that supports music processing should respond more strongly to music than the fixation baseline and the foreign condition; if the response is further selective, it should be stronger than the response elicited by environmental sounds.

\section{Results}

\section{Validation of the language fROIs (for Experiments 1, 2, and 4)}

Consistent with much previous work (e.g., Fedorenko et al., 2010; Mahowald \& Fedorenko 2016; Diachek, Blank, Siegelman et al., 2020), each of the language fROIs showed a robust sentences $>$ nonwords effect (all $p s<0.001$ ).

\section{2a. Sanity check analyses}

First, as expected, the auditory sentence condition elicited a stronger response than the auditory nonwords condition (Experiment 1) or the foreign language condition (Experiment 4). These effects were robust at the network level $(p s<0.001$; SI-Table 1a). Further, the sentences $>$ nonwords effect was significant in all but one language fROI in Experiment 1, and the sentences $>$ foreign effect was significant in all language fROIs in Experiment 4 ( $p$ s $<0.05$; SI-Table 1a).

And second, as expected, all music conditions elicited strong responses in a primary auditory area bilaterally (all $p \mathrm{~s} \cong 0.001 ;$ SI-Table 1b; SI-Figure 1). 


\section{2b. Critical analyses}

Does music elicit responses in the language network?

None of the music conditions elicited a strong response in the language network (Figure 3;

Table 3). The responses to music (i) fell at or below the fixation baseline (except for the wellformed melodies condition in Experiment 2, which elicited a small but above-baseline response), (ii) were lower than the response elicited by auditory nonwords (except for the LMFG language fROI, where the responses to music and nonwords were similarly low), and (iii) did not significantly differ from the responses elicited by non-linguistic, non-music conditions. Finally, the response to songs, which contain both linguistic content and a melodic contour, was not significantly higher than the response elicited by the linguistic content alone (lyrics); in fact, at the network level, the response to songs was reliably lower than to lyrics.
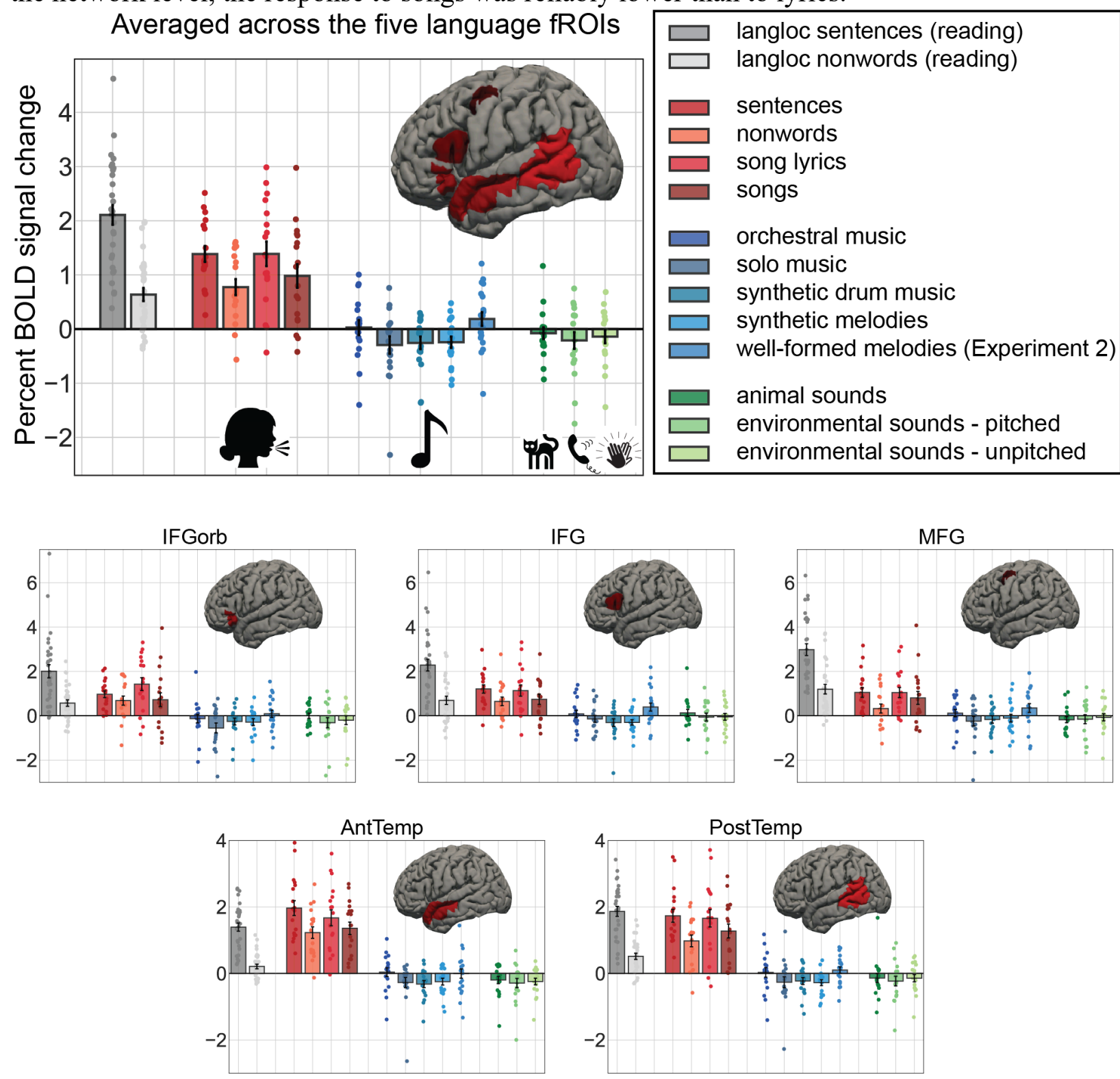
Figure 3. Responses of the language fROIs (pooling across the network - top, and for each fROI individually - bottom) to the language localizer conditions (in grey), to the four auditory conditions containing speech in Experiment 1 (red shades), to the five music conditions in Experiments 1 and 2 (blue shades), and to the three non-linguistic/non-music auditory conditions (green shades) in Experiment 1. For the language localizer results, we include here all participants in Experiments 1 and 2. The responses to the music conditions cluster around the fixation baseline, are much lower than the responses to sentences, and are not higher than the responses to non-music sounds.

\begin{tabular}{|c|c|c|c|c|c|c|}
\hline Contrast & $\begin{array}{l}\text { Language } \\
\text { network }\end{array}$ & LIFGorb & LIFG & LMFG & $\begin{array}{l}\text { LAnt } \\
\text { Temp }\end{array}$ & $\begin{array}{l}\text { LPost } \\
\text { Temp }\end{array}$ \\
\hline \multicolumn{7}{|l|}{ music $>$ fixation } \\
\hline $\begin{array}{l}\text { orchestral music } \\
>\text { fixation }\end{array}$ & $\begin{array}{l}\mathrm{b}=0.028 \\
\mathrm{se}=0.059 \\
\mathrm{t}=0.477 \\
\mathrm{p}=0.634\end{array}$ & $\begin{array}{l}\mathrm{b}=-0.129 \\
\mathrm{se}=0.188 \\
\mathrm{t}=-0.686 \\
\mathrm{p}=1.000\end{array}$ & $\begin{array}{l}\mathrm{b}=0.082 \\
\mathrm{se}=0.157 \\
\mathrm{t}=0.521 \\
\mathrm{p}=1.000\end{array}$ & $\begin{array}{l}\mathrm{b}=0.117 \\
\mathrm{se}=0.160 \\
\mathrm{t}=0.731 \\
\mathrm{p}=1.000\end{array}$ & $\begin{array}{l}\mathrm{b}=0.040 \\
\mathrm{se}=0.126 \\
\mathrm{t}=0.319 \\
\mathrm{p}=1.000\end{array}$ & $\begin{array}{l}\mathrm{b}=0.030 \\
\mathrm{se}=0.139 \\
\mathrm{t}=0.217 \\
\mathrm{p}=1.000\end{array}$ \\
\hline $\begin{array}{l}\text { single-instrument } \\
\text { music } \\
>\text { fixation }\end{array}$ & $\begin{array}{l}\mathrm{b}=-0.294 \\
\mathrm{se}=0.069 \\
\mathrm{t}=-4.280 \\
\mathrm{p}<0.001^{* * *}\end{array}$ & $\begin{array}{l}\mathrm{b}=-0.552 \\
\mathrm{se}=0.217 \\
\mathrm{t}=-2.542 \\
\mathrm{p}=0.078\end{array}$ & $\begin{array}{l}\mathrm{b}=-0.141 \\
\mathrm{se}=0.151 \\
\mathrm{t}=-0.932 \\
\mathrm{p}=1.000\end{array}$ & $\begin{array}{l}\mathrm{b}=-0.243 \\
\mathrm{se}=0.211 \\
\mathrm{t}=-1.155 \\
\mathrm{p}=1.000\end{array}$ & $\begin{array}{l}\mathrm{b}=-0.273 \\
\mathrm{se}=0.148 \\
\mathrm{t}=-1.846 \\
\mathrm{p}=0.366\end{array}$ & $\begin{array}{l}b=-0.264 \\
s e=0.159 \\
t=-1.658 \\
p=0.530\end{array}$ \\
\hline $\begin{array}{l}\text { synthetic drum } \\
\text { music } \\
>\text { fixation }\end{array}$ & $\begin{array}{l}\mathrm{b}=-0.256 \\
\mathrm{se}=0.054 \\
\mathrm{t}=-4.742 \\
\mathrm{p}<0.001^{* * *}\end{array}$ & $\begin{array}{l}b=-0.258 \\
\mathrm{se}=0.150 \\
\mathrm{t}=-1.715 \\
\mathrm{p}=0.474\end{array}$ & $\begin{array}{l}\mathrm{b}=-0.306 \\
\mathrm{se}=0.167 \\
\mathrm{t}=-1.832 \\
\mathrm{p}=0.377\end{array}$ & $\begin{array}{l}\mathrm{b}=-0.168 \\
\mathrm{se}=0.157 \\
\mathrm{t}=-1.070 \\
\mathrm{p}=1.000\end{array}$ & $\begin{array}{l}b=-0.319 \\
\mathrm{se}=0.103 \\
\mathrm{t}=-3.108 \\
\mathrm{p}=0.026^{*}\end{array}$ & $\begin{array}{l}\mathrm{b}=-0.227 \\
\mathrm{se}=0.101 \\
\mathrm{t}=-2.253 \\
\mathrm{p}=0.152\end{array}$ \\
\hline $\begin{array}{l}\text { synthetic } \\
\text { melodies } \\
>\text { fixation }\end{array}$ & $\begin{array}{l}\mathrm{b}=-0.243 \\
\mathrm{se}=0.051 \\
\mathrm{t}=-4.735 \\
\mathrm{p}<0.001 * * *\end{array}$ & $\begin{array}{l}\mathrm{b}=-0.286 \\
\mathrm{se}=0.150 \\
\mathrm{t}=-1.910 \\
\mathrm{p}=0.320\end{array}$ & $\begin{array}{l}\mathrm{b}=-0.299 \\
\mathrm{se}=0.117 \\
\mathrm{t}=-2.557 \\
\mathrm{p}=0.074\end{array}$ & $\begin{array}{l}\mathrm{b}=-0.108 \\
\mathrm{se}=0.172 \\
\mathrm{t}=-0.629 \\
\mathrm{p}=1.000\end{array}$ & $\begin{array}{l}\mathrm{b}=-0.247 \\
\mathrm{se}=0.100 \\
\mathrm{t}=-2.464 \\
\mathrm{p}=0.093\end{array}$ & $\begin{array}{l}\mathrm{b}=-0.276 \\
\mathrm{se}=0.087 \\
\mathrm{t}=-3.183 \\
\mathrm{p}=0.022^{*}\end{array}$ \\
\hline $\begin{array}{l}\text { well-formed } \\
\text { melodies (Expt 2) } \\
\text { >fixation }\end{array}$ & $\begin{array}{l}\mathrm{b}=0.186 \\
\mathrm{se}=0.062 \\
\mathrm{t}=2.998 \\
\mathrm{p}=0.003^{* *}\end{array}$ & $\begin{array}{l}\mathrm{b}=0.090 \\
\mathrm{se}=0.157 \\
\mathrm{t}=0.571 \\
\mathrm{p}=1.000\end{array}$ & $\begin{array}{l}\mathrm{b}=0.393 \\
\mathrm{se}=0.172 \\
\mathrm{t}=2.286 \\
\mathrm{p}=0.138\end{array}$ & $\begin{array}{l}\mathrm{b}=0.348 \\
\mathrm{se}=0.189 \\
\mathrm{t}=1.836 \\
\mathrm{p}=0.368\end{array}$ & $\begin{array}{l}\mathrm{b}=-0.003 \\
\mathrm{se}=0.133 \\
\mathrm{t}=-0.020 \\
\mathrm{p}=1.000\end{array}$ & $\begin{array}{l}\mathrm{b}=0.101 \\
\mathrm{se}=0.092 \\
\mathrm{t}=1.094 \\
\mathrm{p}=1.000\end{array}$ \\
\hline \multicolumn{7}{|l|}{ music $>$ nonwords } \\
\hline $\begin{array}{l}\text { orchestral music } \\
>\text { nonwords }\end{array}$ & $\begin{array}{l}\mathrm{b}=-0.746 \\
\mathrm{se}=0.092 \\
\mathrm{t}=-8.097 \\
\mathrm{p}<0.001^{* * *}\end{array}$ & $\begin{array}{l}\mathrm{b}=-0.811 \\
\mathrm{se}=0.276 \\
\mathrm{t}=-2.945 \\
\mathrm{p}=0.028^{*}\end{array}$ & $\begin{array}{l}\mathrm{b}=-0.569 \\
\mathrm{se}=0.142 \\
\mathrm{t}=-4.015 \\
\mathrm{p}=0.004 * *\end{array}$ & $\begin{array}{l}\mathrm{b}=-0.210 \\
\mathrm{se}=0.221 \\
\mathrm{t}=-0.954 \\
\mathrm{p}=1.000\end{array}$ & $\begin{array}{l}\mathrm{b}=-1.187 \\
\mathrm{se}=0.147 \\
\mathrm{t}=-8.101 \\
\mathrm{p}<0.001 * * *\end{array}$ & $\begin{array}{l}\mathrm{b}=-0.950 \\
\mathrm{se}=0.205 \\
\mathrm{t}=-4.646 \\
\mathrm{p}=0.001 * *\end{array}$ \\
\hline $\begin{array}{l}\text { single-instrument } \\
\text { music } \\
>\text { nonwords }\end{array}$ & $\begin{array}{l}\mathrm{b}=-1.068 \\
\mathrm{se}=0.100 \\
\mathrm{t}=-10.714 \\
\mathrm{p}<0.001^{* * *}\end{array}$ & $\begin{array}{l}\mathrm{b}=-1.234 \\
\mathrm{se}=0.296 \\
\mathrm{t}=-4.167 \\
\mathrm{p}=0.001 * *\end{array}$ & $\begin{array}{l}\mathrm{b}=-0.791 \\
\mathrm{se}=0.222 \\
\mathrm{t}=-3.567 \\
\mathrm{p}=0.011^{*}\end{array}$ & $\begin{array}{l}\mathrm{b}=-0.571 \\
\mathrm{se}=0.235 \\
\mathrm{t}=-2.431 \\
\mathrm{p}=0.128\end{array}$ & $\begin{array}{l}\mathrm{b}=-1.500 \\
\mathrm{se}=0.196 \\
\mathrm{t}=-7.648 \\
\mathrm{p}<0.001 * * *\end{array}$ & $\begin{array}{l}\mathrm{b}=-1.244 \\
\mathrm{se}=0.234 \\
\mathrm{t}=-5.315 \\
\mathrm{p}<0.001 * * *\end{array}$ \\
\hline $\begin{array}{l}\text { synthetic drum } \\
\text { music } \\
\text { >nonwords }\end{array}$ & $\begin{array}{l}b=-1.029 \\
\mathrm{se}=0.087 \\
\mathrm{t}=-11.839 \\
\mathrm{p}<0.001 * * *\end{array}$ & $\begin{array}{l}\mathrm{b}=-0.940 \\
\mathrm{se}=0.212 \\
\mathrm{t}=-4.430 \\
\mathrm{p}=0.001 * *\end{array}$ & $\begin{array}{l}\mathrm{b}=-0.956 \\
\mathrm{se}=0.182 \\
\mathrm{t}=-5.252 \\
\mathrm{p}<0.001 * * *\end{array}$ & $\begin{array}{l}\mathrm{b}=-0.496 \\
\mathrm{se}=0.245 \\
\mathrm{t}=-2.026 \\
\mathrm{p}=0.290\end{array}$ & $\begin{array}{l}\mathrm{b}=-1.546 \\
\mathrm{se}=0.187 \\
\mathrm{t}=-8.262 \\
\mathrm{p}<0.001 * * *\end{array}$ & $\begin{array}{l}\mathrm{b}=-1.207 \\
\mathrm{se}=0.177 \\
\mathrm{t}=-6.817 \\
\mathrm{p}<0.001 * * *\end{array}$ \\
\hline $\begin{array}{l}\text { synthetic } \\
\text { melodies } \\
\text {-nonwords }\end{array}$ & $\begin{array}{l}\mathrm{b}=-1.017 \\
\mathrm{se}=0.088 \\
\mathrm{t}=-11.623 \\
\mathrm{p}<0.001^{* * *}\end{array}$ & $\begin{array}{l}\mathrm{b}=-0.969 \\
\mathrm{se}=0.209 \\
\mathrm{t}=-4.642 \\
\mathrm{p}=0.001 * *\end{array}$ & $\begin{array}{l}\mathrm{b}=-0.949 \\
\mathrm{se}=0.153 \\
\mathrm{t}=-6.224 \\
\mathrm{p}<0.001 * * *\end{array}$ & $\begin{array}{l}\mathrm{b}=-0.435 \\
\mathrm{se}=0.252 \\
\mathrm{t}=-1.727 \\
\mathrm{p}=0.506\end{array}$ & $\begin{array}{l}\mathrm{b}=-1.474 \\
\mathrm{se}=0.195 \\
\mathrm{t}=-7.541 \\
\mathrm{p}<0.001 * * *\end{array}$ & $\begin{array}{l}\mathrm{b}=-1.256 \\
\mathrm{se}=0.176 \\
\mathrm{t}=-7.136 \\
\mathrm{p}<0.001 * * *\end{array}$ \\
\hline $\begin{array}{l}\text { well-formed } \\
\text { melodies (Expt 2) }\end{array}$ & $\begin{array}{l}\mathrm{b}=-0.462 \\
\mathrm{se}=0.089 \\
\mathrm{t}=-5.169\end{array}$ & $\begin{array}{l}\mathrm{b}=-0.540 \\
\mathrm{se}=0.213 \\
\mathrm{t}=-2.537\end{array}$ & $\begin{array}{l}\mathrm{b}=-0.411 \\
\mathrm{se}=0.203 \\
\mathrm{t}=-2.029\end{array}$ & $\begin{array}{l}\mathrm{b}=-0.703 \\
\mathrm{se}=0.250 \\
\mathrm{t}=-2.817\end{array}$ & $\begin{array}{l}b=-0.237 \\
\mathrm{se}=0.138 \\
\mathrm{t}=-1.714\end{array}$ & $\begin{array}{l}\mathrm{b}=-0.380 \\
\mathrm{se}=0.122 \\
\mathrm{t}=-3.113\end{array}$ \\
\hline
\end{tabular}




\begin{tabular}{|c|c|c|c|c|c|c|}
\hline $\begin{array}{l}\text { >nonwords } \\
\text { (visual) }\end{array}$ & $\mathrm{p}<0.001^{* * *}$ & $\mathrm{p}=0.096$ & $\mathrm{p}=0.279$ & $\mathrm{p}=0.053$ & $\mathrm{p}=0.507$ & $\mathrm{p}=0.027^{*}$ \\
\hline \multicolumn{7}{|c|}{ music $>$ non-linguistic, non-music auditory conditions } \\
\hline $\begin{array}{l}\text { music (combined) } \\
>\text { animal sounds }\end{array}$ & $\begin{array}{l}\mathrm{b}=-0.114 \\
\mathrm{se}=0.060 \\
\mathrm{t}=-1.915 \\
\mathrm{p}=0.056\end{array}$ & $\begin{array}{l}\mathrm{b}=-0.306 \\
\mathrm{se}=0.148 \\
\mathrm{t}=-2.069 \\
\mathrm{p}=0.210\end{array}$ & $\begin{array}{l}\mathrm{b}=-0.295 \\
\mathrm{se}=0.146 \\
\mathrm{t}=-2.021 \\
\mathrm{p}=0.235\end{array}$ & $\begin{array}{l}\mathrm{b}=0.080 \\
\mathrm{se}=0.151 \\
\mathrm{t}=0.528 \\
\mathrm{p}=1.000\end{array}$ & $\begin{array}{l}\mathrm{b}=-0.002 \\
\mathrm{se}=0.090 \\
\mathrm{t}=-0.023 \\
\mathrm{p}=1.000\end{array}$ & $\begin{array}{l}\mathrm{b}=-0.048 \\
\mathrm{se}=0.094 \\
\mathrm{t}=-0.513 \\
\mathrm{p}=1.000\end{array}$ \\
\hline $\begin{array}{l}\text { music (combined) } \\
\text { >environmental } \\
\text { (pitched) }\end{array}$ & $\begin{array}{l}\mathrm{b}=0.019 \\
\mathrm{se}=0.060 \\
\mathrm{t}=0.307 \\
\mathrm{p}=0.759\end{array}$ & $\begin{array}{l}\mathrm{b}=0.005 \\
\mathrm{se}=0.144 \\
\mathrm{t}=0.033 \\
\mathrm{p}=1.000\end{array}$ & $\begin{array}{l}\mathrm{b}=-0.104 \\
\mathrm{se}=0.133 \\
\mathrm{t}=-0.781 \\
\mathrm{p}=1.000\end{array}$ & $\begin{array}{l}\mathrm{b}=0.055 \\
\mathrm{se}=0.159 \\
\mathrm{t}=0.347 \\
\mathrm{p}=1.000\end{array}$ & $\begin{array}{l}\mathrm{b}=0.092 \\
\mathrm{se}=0.094 \\
\mathrm{t}=0.975 \\
\mathrm{p}=1.000\end{array}$ & $\begin{array}{l}\mathrm{b}=0.045 \\
\mathrm{se}=0.094 \\
\mathrm{t}=0.475 \\
\mathrm{p}=1.000\end{array}$ \\
\hline $\begin{array}{l}\text { music (combined) } \\
\text { >environmental } \\
\text { (unpitched) }\end{array}$ & $\begin{array}{l}\mathrm{b}=-0.052 \\
\mathrm{se}=0.063 \\
\mathrm{t}=-0.823 \\
\mathrm{p}=0.411\end{array}$ & $\begin{array}{l}\mathrm{b}=-0.109 \\
\mathrm{se}=0.163 \\
\mathrm{t}=-0.666 \\
\mathrm{p}=1.000\end{array}$ & $\begin{array}{l}\mathrm{b}=-0.118 \\
\mathrm{se}=0.152 \\
\mathrm{t}=-0.778 \\
\mathrm{p}=1.000\end{array}$ & $\begin{array}{l}\mathrm{b}=-0.030 \\
\mathrm{se}=0.151 \\
\mathrm{t}=-0.198 \\
\mathrm{p}=1.000\end{array}$ & $\begin{array}{l}\mathrm{b}=0.042 \\
\mathrm{se}=0.097 \\
\mathrm{t}=0.429 \\
\mathrm{p}=1.000\end{array}$ & $\begin{array}{l}\mathrm{b}=-0.043 \\
\mathrm{se}=0.100 \\
\mathrm{t}=-0.426 \\
\mathrm{p}=1.000\end{array}$ \\
\hline \multicolumn{7}{|c|}{ (melodic contour + linguistic content) > linguistic content } \\
\hline $\begin{array}{l}\text { songs } \\
>\text { lyrics }\end{array}$ & $\begin{array}{l}\mathrm{b}=-0.408 \\
\mathrm{se}=0.102 \\
\mathrm{t}=-4.014 \\
\mathrm{p}<0.001^{* * *}\end{array}$ & $\begin{array}{l}\mathrm{b}=-0.705 \\
\mathrm{se}=0.287 \\
\mathrm{t}=-2.454 \\
\mathrm{p}=0.122\end{array}$ & $\begin{array}{l}\mathrm{b}=-0.394 \\
\mathrm{se}=0.195 \\
\mathrm{t}=-2.025 \\
\mathrm{p}=0.290\end{array}$ & $\begin{array}{l}\mathrm{b}=-0.243 \\
\mathrm{se}=0.220 \\
\mathrm{t}=-1.107 \\
\mathrm{p}=1.000\end{array}$ & $\begin{array}{l}\mathrm{b}=-0.313 \\
\mathrm{se}=0.163 \\
\mathrm{t}=-1.925 \\
\mathrm{p}=0.351\end{array}$ & $\begin{array}{l}\mathrm{b}=-0.384 \\
\mathrm{se}=0.171 \\
\mathrm{t}=-2.246 \\
\mathrm{p}=0.188\end{array}$ \\
\hline
\end{tabular}

Table 3. Statistical results for the contrasts between the music conditions and fixation, nonwords, animal sounds, and environmental sounds in Experiments 1 and 2, and for the contrast between songs and lyrics in Experiment 1. The significance values for the individual ROIs have been FDR-corrected for the number of fROIs $(n=5)$.

Is the language network sensitive to structure in music?

Experiments 1 and 2 (fMRI): The language regions did not show strong sensitivity to structural manipulations in music (Figure 4; Table 4). In Experiment 1, the responses to synthetic melodies did not significantly differ from (or were weaker than) the responses to the scrambled counterparts, and the responses to synthetic drum music did not significantly differ from the responses to scrambled drum music. In Experiment 2, at the network level, we observed a small but reliable $(\mathrm{p}<0.05)$ effect of sour-note $>$ well-formed melodies. This effect was not significant in any of the five individual fROIs (even prior to the FDR correction). Moreover, as discussed above, the responses elicited by the well-formed melodies were very low: around the level of the fixation baseline. The responses to both the well-formed melodies and sour-note melodies are below the response elicited by the unstructured (and meaningless) language localizer control condition (nonword sequences). 

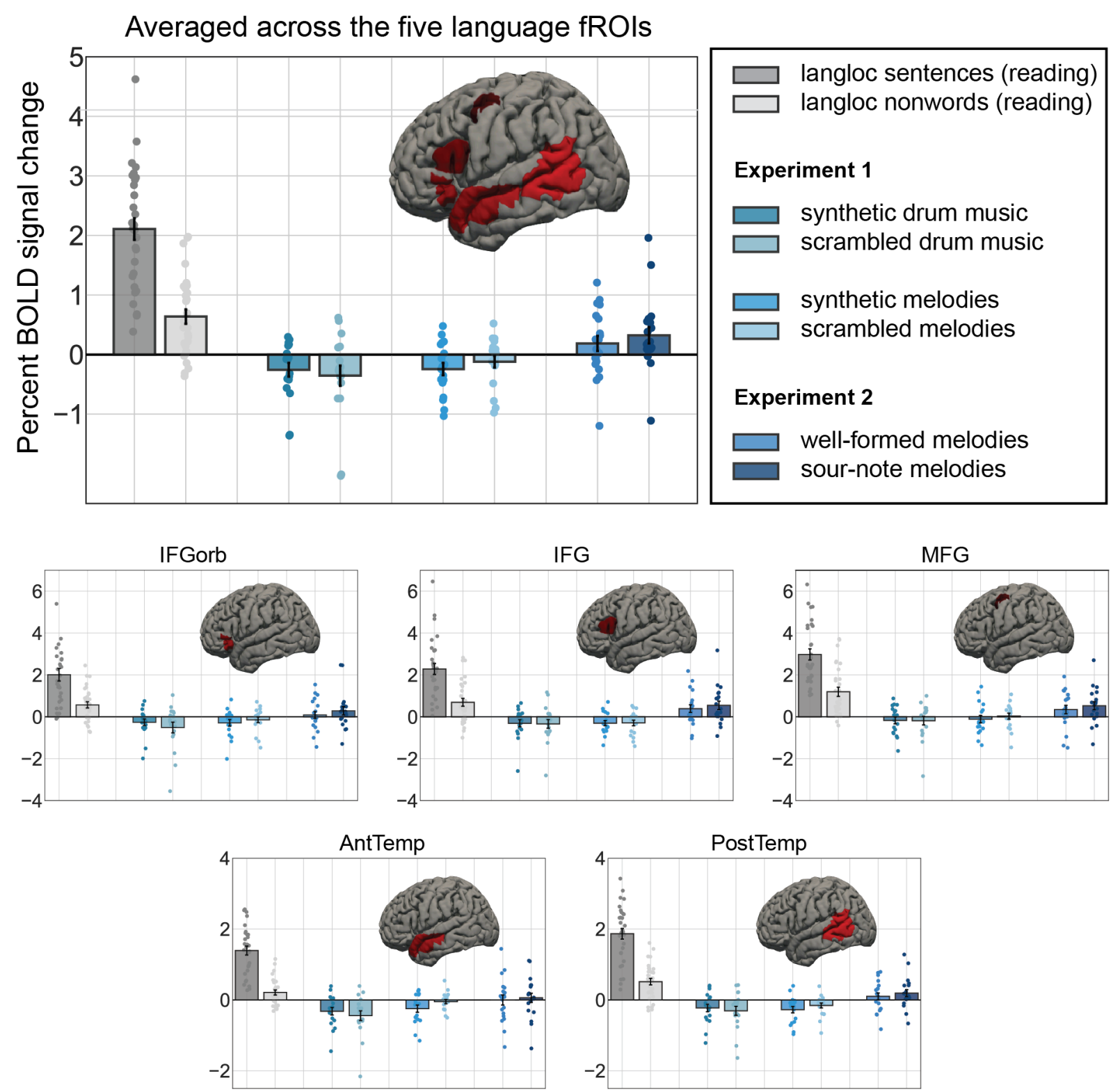

Figure 4. Responses of the language fROIs (pooling across the network - top, and for each fROI individually - bottom) to the language localizer conditions (in grey), and to the three sets of conditions targeting structure in music (in blue). For the language localizer results, we include here participants in Experiments 1 and 2. The responses to the music conditions cluster around the fixation baseline, and are much lower than the response to sentences. One of the three critical contrasts (sour-note $>$ well-formed melodies) elicits a small but reliable effect at the network level, but it is not individually significant in any of the five fROIs.

\begin{tabular}{|l|l|l|l|l|l|l|}
\hline Contrast & $\begin{array}{l}\text { Language } \\
\text { network }\end{array}$ & LIFGorb & LIFG & LMFG & $\begin{array}{l}\text { LAnt } \\
\text { Temp }\end{array}$ & $\begin{array}{l}\text { LPost } \\
\text { Temp }\end{array}$ \\
\hline synthetic drum & $\mathrm{b}=0.099$ & $\mathrm{~b}=0.252$ & $\mathrm{~b}=0.028$ & $\mathrm{~b}=0.014$ & $\mathrm{~b}=0.124$ & $\mathrm{~b}=0.079$ \\
music & $\mathrm{se}=0.073$ & $\mathrm{se}=0.191$ & $\mathrm{se}=0.176$ & $\mathrm{se}=0.186$ & $\mathrm{se}=0.103$ & $\mathrm{se}=0.110$ \\
scrambled drum & $\mathrm{t}=1.358$ & $\mathrm{t}=1.322$ & $\mathrm{t}=0.157$ & $\mathrm{t}=0.073$ & $\mathrm{t}=1.210$ & $\mathrm{t}=0.719$ \\
& $\mathrm{p}=0.176$ & $\mathrm{p}=1.000$ & $\mathrm{p}=1.000$ & $\mathrm{p}=1.000$ & $\mathrm{p}=1.000$ & $\mathrm{p}=1.000$ \\
\hline
\end{tabular}




\begin{tabular}{|l|l|l|l|l|l|l|}
\hline music & & & & & & \\
\hline synthetic melodies & $\mathrm{b}=-0.124$ & $\mathrm{~b}=-0.147$ & $\mathrm{~b}=-0.009$ & $\mathrm{~b}=-0.143$ & $\mathrm{~b}=-0.199$ & $\mathrm{~b}=-0.121$ \\
>scrambled & $\mathrm{se}=0.061$ & $\mathrm{se}=0.130$ & $\mathrm{se}=0.153$ & $\mathrm{se}=0.202$ & $\mathrm{se}=0.101$ & $\mathrm{se}=0.106$ \\
synthetic melodies & $\mathrm{t}=-2.015$ & $\mathrm{t}=-1.133$ & $\mathrm{t}=-0.057$ & $\mathrm{t}=-0.708$ & $\mathrm{t}=-1.971$ & $\mathrm{t}=-1.142$ \\
& $\mathrm{p}=0.046^{*}$ & $\mathrm{p}=1.000$ & $\mathrm{p}=1.000$ & $\mathrm{p}=1.000$ & $\mathrm{p}=0.322$ & $\mathrm{p}=1.000$ \\
\hline sour-note & $\mathrm{b}=0.138$ & $\mathrm{~b}=0.199$ & $\mathrm{~b}=0.156$ & $\mathrm{~b}=0.182$ & $\mathrm{~b}=0.062$ & $\mathrm{~b}=0.091$ \\
melodies & $\mathrm{se}=0.069$ & $\mathrm{se}=0.098$ & $\mathrm{se}=0.104$ & $\mathrm{se}=0.084$ & $\mathrm{se}=0.051$ & $\mathrm{se}=0.054$ \\
>well-formed & $\mathrm{t}=2.008$ & $\mathrm{t}=2.042$ & $\mathrm{t}=1.495$ & $\mathrm{t}=2.174$ & $\mathrm{t}=1.218$ & $\mathrm{t}=1.687$ \\
melodies & $\mathrm{p}=0.046^{*}$ & $\mathrm{p}=0.273$ & $\mathrm{p}=0.752$ & $\mathrm{p}=0.210$ & $\mathrm{p}=1.000$ & $\mathrm{p}=0.536$ \\
\hline
\end{tabular}

Table 4. Statistical results for the contrasts between the synthetic drum music and scrambled drum music, synthetic melodies and scrambled melodies, and sour-note and well-formed melodies contrasts in Experiments 1 and 2. The significance values for the individual ROIs have been FDR-corrected for the number of fROIs $(n=5)$.

Experiment 3 (behavioral): In the critical music task, where participants were asked to judge the well-formedness of musical structure, neurotypical control participants responded correctly, on average, on $87.1 \%$ of trials, suggesting that the task was sufficiently difficult to preclude ceiling effects. Patients with severe aphasia showed intact sensitivity to music structure. The three patients had accuracies of $89.4 \%$ (PR), 94.4\% (SA), and 97.8\% (PP), falling on the higher end of the controls' performance range (Figure 5). Crucially, none of the three aphasic participants' $d$ ' scores were lower than the average control participants' $d$ ' scores $(\mathrm{M}=2.75, \mathrm{SD}=0.75)$. In fact, the patients' $d$ ' scores were high: SA's $d$ ' was 3.51, higher than $83.91 \%$ (95\% Credible Interval (CI) $[75.20,92.03])$ of the control population, PR's $d$ ' was 3.09 , higher than $67.26 \%$ (95\% CI $[56.60,78.03])$ of the control population, and PP's $d$ ' was 3.99 , higher than $94.55 \%$ (95\% CI $[89.40,98.57])$ of the control population. In the Scale task from the Montreal Battery for the Evaluation of Aphasia, the control participants' performance showed a similar distribution to that reported in Peretz et al. (2003). All participants with aphasia performed within the normal range, with two participants making no errors. PR and PP's score was higher than $85.24 \%$ (95\% CI $[76.94,93.06])$ of the control population, providing a conceptual replication of the results from the well-formed/sour-note melody discrimination task. SA's score was higher than $30.57 \%(95 \%$ CI $[20.00,41.50])$ of the control population.

\begin{tabular}{|l|l|l|l|l|}
\hline Participant & SA & PR & PP & Controls \\
\hline Critical Music Task & $170 / 180$ & $161 / 180$ & $176 / 180$ & $\begin{array}{l}\text { M }=156.5 / 180 \\
\text { SD }=15.8 \\
\text { Min }=109 / 180 \\
\text { Max }=177 / 180 \\
\text { N=45 }\end{array}$ \\
& & & & \\
\hline Montreal Battery for the Evaluation of Amusia & & & & \\
\hline (Critical for this study) Task 1 (Scale) & $27 / 30$ & $30 / 30$ & $30 / 30$ & $\begin{array}{l}\text { M }=28 / 30 \\
\text { M }=1.89 \\
\text { Min }=23 / 30 \\
\text { Max }=30 / 30 \\
\text { N = 45 }\end{array}$ \\
\hline Task 2 (Interval; "Same Contour" on MBEA CD) & $26 / 30$ & $22 / 30$ & $18 / 30$ & \\
\hline Task 3 (Contour; "Different Contour" on MBEA CD) & $22 / 30$ & $23 / 30$ & $18 / 30$ & \\
\hline
\end{tabular}




\begin{tabular}{|l|l|l|l|l|}
\hline $\begin{array}{l}\text { Task 4 (Rhythm; "Rhythmic Contour" on MBEA } \\
\text { CD) }\end{array}$ & $25 / 30$ & $25 / 30$ & $22 / 30$ & \\
\hline Task 5 (Meter; "Metric" on MBEA CD) & $28 / 30$ & $22 / 30$ & $24 / 30$ & \\
\hline Task 6 (Incidental Memory) & $28 / 30$ & $28 / 30$ & $22 / 30$ & \\
\hline
\end{tabular}

Table 5. Results for participants with aphasia and control participants on the critical music task and the Scale task of the MBEA (Peretz et al., 2003). For participants with aphasia, we report the results from all six MBEA tasks, for completeness.

Critical music task

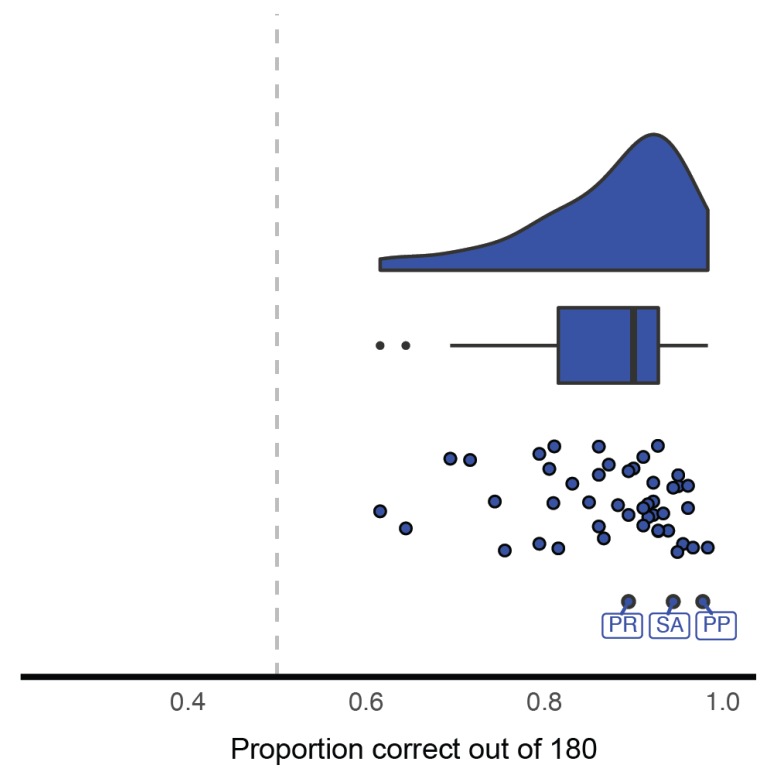

Scale subset of MBEA

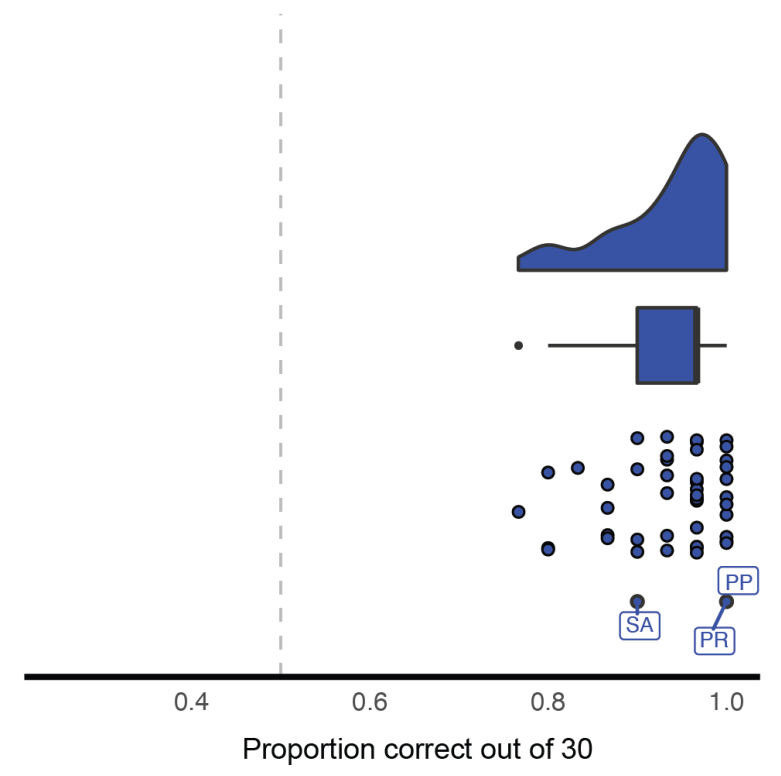

Figure 5. Performance of the control and aphasic participants on two measures of music syntax processing: the critical music task (left), the Scale task of the MBEA (right). The densities show the distribution of proportion correct scores in the control participants and the boxplot shows the quartiles of the control population. The dots show individual participants (for the aphasic individuals, the initials indicate the specific participant). Dashed grey lines indicate chance performance.

Does music elicit responses in the language network of native speakers of a tonal language?

Results from Mandarin native speakers replicated the results from Experiment 1: the music condition did not elicit a strong response in the language network (Figure 6; Table 6). Although the response to music was above the fixation baseline at the network level and in some fROIs, the response did not differ from (or was lower than) the responses elicited by an unfamiliar foreign language (Russian) and environmental sounds. 

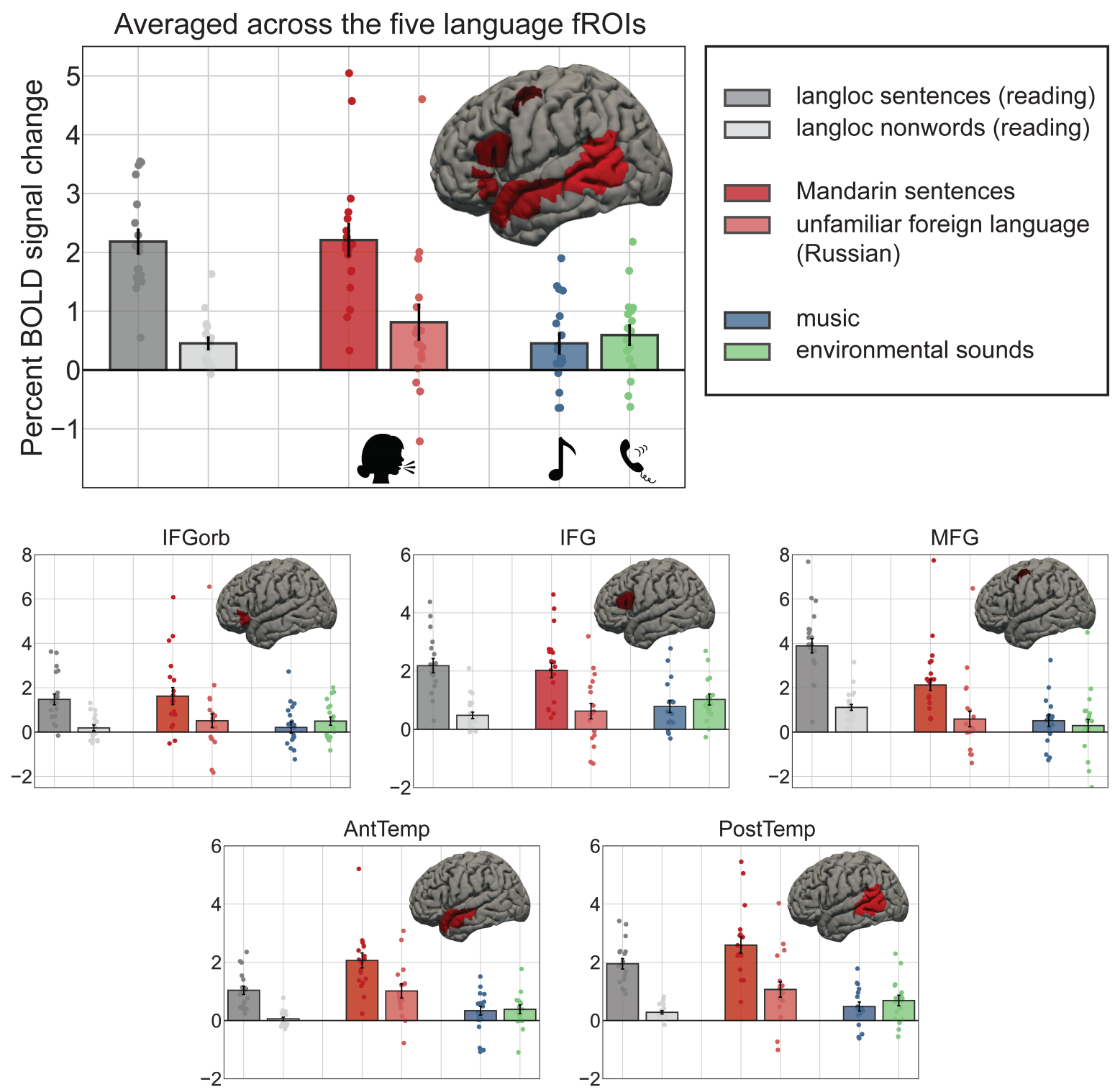

Figure 6. Responses of the language fROIs (pooling across the network - top, and for each fROI individually - bottom) to the language localizer conditions (in grey), to the two auditory conditions containing speech (red shades), to the music condition (blue), and to the nonlinguistic/non-music auditory condition (green) in Experiment 4. The response to the music condition is much lower than the responses to sentences, and is not higher than the response to foreign language and environmental sounds.

\begin{tabular}{|l|l|l|l|l|l|l|}
\hline Contrast & $\begin{array}{l}\text { Language } \\
\text { network }\end{array}$ & LIFGorb & LIFG & LMFG & $\begin{array}{l}\text { LAnt } \\
\text { Temp }\end{array}$ & $\begin{array}{l}\text { LPost } \\
\text { Temp }\end{array}$ \\
\hline music & $\mathrm{b}=0.454$ & $\mathrm{~b}=0.299$ & $\mathrm{~b}=0.761$ & $\mathrm{~b}=0.480$ & $\mathrm{~b}=0.268$ & $\mathrm{~b}=0.462$ \\
$>$ fixation & $\mathrm{se}=0.080$ & $\mathrm{se}=0.222$ & $\mathrm{se}=0.201$ & $\mathrm{se}=0.253$ & $\mathrm{se}=0.166$ & $\mathrm{se}=0.151$ \\
& $\mathrm{t}=5.687$ & $\mathrm{t}=1.346$ & $\mathrm{t}=3.790$ & $\mathrm{t}=1.901$ & $\mathrm{t}=1.614$ & $\mathrm{t}=3.049$ \\
& $\mathrm{p}<0.001 * * *$ & $\mathrm{p}=0.934$ & $\mathrm{p}=0.005^{* *}$ & $\mathrm{p}=0.326$ & $\mathrm{p}=0.577$ & $\mathrm{p}=0.030^{*}$ \\
\hline music & $\mathrm{b}=-0.359$ & $\mathrm{~b}=-0.360$ & $\mathrm{~b}=0.123$ & $\mathrm{~b}=-0.219$ & $\mathrm{~b}=-0.703$ & $\mathrm{~b}=-0.638$ \\
& $\mathrm{se}=0.141$ & $\mathrm{se}=0.416$ & $\mathrm{se}=0.309$ & $\mathrm{se}=0.473$ & $\mathrm{se}=0.240$ & $\mathrm{se}=0.254$ \\
\hline
\end{tabular}




\begin{tabular}{|l|l|l|l|l|l|l|}
\hline >foreign & $\mathrm{t}=-2.547$ & $\mathrm{t}=-0.865$ & $\mathrm{t}=0.398$ & $\mathrm{t}=-0.463$ & $\mathrm{t}=-2.926$ & $\mathrm{t}=-2.511$ \\
& $\mathrm{p}=0.012^{*}$ & $\mathrm{p}=1.000$ & $\mathrm{p}=1.000$ & $\mathrm{p}=1.000$ & $\mathrm{p}=0.045^{*}$ & $\mathrm{p}=0.109$ \\
\hline music & $\mathrm{b}=-0.141$ & $\mathrm{~b}=-0.249$ & $\mathrm{~b}=-0.240$ & $\mathrm{~b}=0.038$ & $\mathrm{~b}=-0.042$ & $\mathrm{~b}=-0.210$ \\
>environmental & $\mathrm{se}=0.108$ & $\mathrm{se}=0.187$ & $\mathrm{se}=0.193$ & $\mathrm{se}=0.304$ & $\mathrm{se}=0.147$ & $\mathrm{se}=0.179$ \\
sounds & $\mathrm{t}=-1.299$ & $\mathrm{t}=-1.328$ & $\mathrm{t}=-1.248$ & $\mathrm{t}=0.125$ & $\mathrm{t}=-0.285$ & $\mathrm{t}=-1.171$ \\
& $\mathrm{p}=0.196$ & $\mathrm{p}=1.000$ & $\mathrm{p}=1.000$ & $\mathrm{p}=1.000$ & $\mathrm{p}=1.000$ & $\mathrm{p}=1.000$ \\
\hline
\end{tabular}

Table 6. Statistical results for the contrasts between the music condition and fixation, foreign language, and environmental sounds in Experiment 4. The significance values for the individual ROIs have been FDR-corrected for the number of fROIs $(n=5)$.

\section{Discussion}

We here tackled a much investigated but still debated question: do the brain regions of the language network support the processing of music, especially music structure? Across three fMRI experiments and an investigation of patients with severe aphasia, we obtained a clear answer: the brain regions of the language network, which support the processing of linguistic syntax (e.g., Fedorenko et al., 2010, 2020; Pallier et al., 2011; Bautista \& Wilson, 2016; Blank et al., 2016), do not support - and are not needed for-music processing. We found overall low responses to diverse kinds of music in the language brain regions (Figure 3), including in speakers of a tonal language (Figure 6), and little or no sensitivity to the manipulations of music structure (Figure 4). We further found that the ability to make well-formedness judgments about the tonal structure of music was preserved in severely aphasic patients who cannot make grammaticality judgments for sentences (Figure 5). These results align with prior neuropsychological patient evidence of language/music dissociations (e.g., Luria et al., 1965; Brust, 1980; Marin, 1982; Basso \& Capitani, 1985; Polk \& Kertesz, 1993; Peretz \& Coltheart, 2003; Slevc et al., 2016), but stand in sharp contrast to numerous reports arguing for shared structure processing mechanisms in the two domains (e.g., Patel et al., 1998; Koelsch et al., 2000; Maess et al., 2001; Koelsch et al., 2002; Levitin \& Menon, 2003; see Kunert \& Slevc, 2015; LaCroix et al., 2016, for reviews).

Below, we discuss several issues that are relevant for interpreting the current results and/or that these results inform, and outline some limitations of scope of our study.

\section{Theoretical considerations about the language-music relationship.}

Why might we a priori think that the language network, or some of its components, may be important for processing music in general, or for processing music structure specifically? Similarities between language and music have long been noted and discussed. For example, as summarized in Jackendoff (2009; see also Patel, 2008), both capacities are human-specific, involve the production of sound (though this is not always the cases for language: cf. sign languages, or written language in literate societies), and have multiple culture-specific variants. However, Jackendoff (2009) notes that i) most cognitive capacities / mechanisms that have been argued to be common to language and music are not uniquely shared by language and music, and ii) language and music differ in several critical ways, and these differences are important to 
consider alongside potential similarities when theorizing about possible shared representations and computations.

To elaborate on the first point: the cognitive capacity that has perhaps received the most attention in discussions of cognitive and neural mechanisms that may be shared by language and music is the combinatorial capacity of the two domains (e.g., Riemann, 1877, as cited in Swain, 1995; Lindblom \& Sundberg, 19769; Fay, 1971; Sundberg \& Lindblom, 1976; Lerdahl \& Jackendoff, 1977, 1983; Roads, 1979; Krumhansl \& Keil, 1982). In particular, in language, words can be combined into complex hierarchical structures to form novel phrases and sentences, and in music, notes and chords can similarly be combined to form novel melodies. Further, in both domains, the combinatorial process is constrained by a set of rules. However, this capacity can be observed, in some form, in many other domains, from visual processing, to math, to social cognition, to motor planning, to general reasoning. Similarly, other cognitive capacities necessary to process language and music — including a large long-term memory store for previously encountered elements and patterns, a working memory capacity needed to integrate information as it comes in, an ability to form expectations about upcoming elements, and an ability to engage in joint action - are important for information processing in other domains. An observation that some mental capacity is necessary for multiple domains is compatible with at least two architectures: one where the relevant capacity is implemented (perhaps in a similar way) in each relevant set of domain-specific circuits, and another where the relevant capacity is implemented in a centralized mechanism that all domains draw on (e.g., Fedorenko \& Shain, submitted). Those arguing for overlap between language and music processing advocate a version of the latter. Critically, any shared mechanism that language and music would draw on should also support information processing in other domains that require the relevant computation. A possible exception, according to Jackendoff (2009), may be the fine-scale vocal motor control that is needed for speech and vocal music production (cf. sign language or instrumental music), but not any other behaviors.

More importantly, aside from the similarities that have been noted between language and music, numerous differences characterize the two domains. Most notable are their different functions. Language enables humans to express propositional meanings, and thus to share thoughts with one another. The function of music has long been debated (e.g., Darwin, 1871; Pinker, 1994; see e.g., McDermott, 2008 and Mehr et al., 2020, for a summary of key ideas), but most proposed functions have to do with emotional or affective processing, often with a social component ${ }^{1}$ (Jackendoff, 2009; Savage et al., 2020). If function drives the organization of the brain (and biological systems more generally; e.g., Rueffler et al., 2012) by imposing particular computational demands on each domain (e.g., Mehr et al., 2020), these fundamentally different functions of language and music provide a theoretical reason to expect cognitive and neural separation between them. Besides, even the components of language and music that appear

\footnotetext{
${ }^{1}$ Although some have discussed the notions of 'meaning' in music (e.g., Meyer, 1961; Raffman, 1993; Cross \& Tolbert, 2009; Koelsch, 2001), it is uncontroversial that music cannot be used to express propositional thought (for discussion, see Patel, 2008; Jackendoff, 2009; Slevc, 2009).
} 
similar on the surface (e.g., combinatorial processing) differ in deep and important ways (e.g., Patel, 2008; Jackendoff, 2009; Slevc, 2009).

\section{Functional selectivity of the language network.}

The current results add to the growing body of evidence that the left-lateralized fronto-temporal brain network that supports language processing is highly selective for linguistic input (e.g., Fedorenko et al., 2011; Monti et al., 2009, 2012; Pritchett et al., 2018; Jouravlev et al., 2019; Ivanova et al., 2020, 2021; see Fedorenko \& Blank, 2020 for a review) and not critically needed for many forms of complex cognition (e.g., Varley \& Siegal, 2000; Varley et al., 2005; Apperly et al., 2006; Woolgar et al., 2018; Ivanova et al., 2021; see Fedorenko \& Varley, 2016 for a review). Importantly, this selectivity holds across all components of the language network, including the parts that fall within 'Broca's area' in the left inferior frontal gyrus. As discussed in the introduction, many claims about shared structure processing in language and music have focused specifically on Broca's area (e.g., Patel, 2003; Fadiga et al., 2009; Fitch \& Martins, 2014). The evidence presented here shows that the language-responsive parts of Broca's area, which are robustly sensitive to linguistic syntactic manipulations (e.g., Just et al., 1996; Stromswold et al., 1996; Ben-Shachar et al., 2003; Caplan et al., 2008; Peelle et al., 2010; Blank et al., 2016; see Friederici, 2011, for a meta-analysis), do not respond when we listen to music and are not sensitive to structure in music. These results rule out the hypothesis that language and music processing rely on the same mechanism housed in Broca's area.

It is also worth noting that the underlying premise of the latter hypothesis - of a special relationship between Broca's area and the processing of linguistic syntax (e.g., Caramazza \& Zurif, 1976; Friederici, 2018)—-has been questioned and overturned. First, syntactic processing appears to not be carried out focally, but instead to be distributed across the entire language network, with all of its regions showing sensitivity to syntactic manipulations (e.g., Fedorenko et al., 2010, 2020; Pallier et al., 2011; Blank et al., 2016; Shain, Blank et al., 2020), and with damage to different components leading to similar syntactic comprehension deficits (e.g., Caplan et al., 1996; Dick et al., 2001; Wilson \& Saygin, 2004; Mesulam et al., 2014; Mesulam et al., 2015). And second, the language-responsive part of Broca's area, like other parts of the language network, is sensitive to both syntactic processing and word meanings, and even sub-lexical structure (Fedorenko et al., 2010, 2012b, 2020; Regev et al., 2021). The lack of segregation between syntactic and lexico-semantic processing is in line with the idea of 'lexicalized syntax' where the rules for how words can combine with one another are highly dependent on the particular lexical items (e.g., Goldberg, 2002; Jackendoff, 2002, 2007; Sag et al., 2003; Levin \& Rappaport-Hovav, 2005; Bybee, 2010; Jackendoff and Audring, 2020), and is contra the idea of 'abstract syntax' where the combinatorial rules are blind to the content/meaning of the to-becombined elements (e.g., Chomsky, 1965, 1995; Fodor, 1983; Pinker \& Prince, 1988; Pinker, 1991, 1999; Pallier et al., 2011).

\section{Overlap in structure processing in language and music outside of the core language network?}


We have here focused on the core fronto-temporal language network. Could structure processing in language and music draw on shared resources elsewhere in the brain? The prime candidate is the domain-general executive control network (e.g., Duncan \& Owen, 2000; Duncan, 2001, 2010; Assem et al., 2020), which supports functions like working memory and inhibitory control. Indeed, according to Patel's Shared Structural Integration Resource Hypothesis (SSIRH; 2003, 2008, 2012), language and music draw on separate representations, stored in distinct cortical areas, but rely on the same working memory store to integrate incoming elements into evolving structures. Relatedly, Slevc et al. (2013) have recently argued that another executive resourceinhibitory control - may be required for structure processing in both language and music. Although it is certainly possible that some aspects of linguistic and/or musical processing would require domain-general executive resources, we would argue that any such engagement does not reflect the engagement of computations like syntactic structure building. In particular, Blank \& Fedorenko (2017) found that activity in the brain regions of the domain-general executive network does not closely 'track' linguistic stimuli, as evidenced by low inter-subject correlations during the processing of linguistic input. Further, Diachek, Blank, Siegelman et al. (2020) recently showed in a large-scale fMRI investigation that the domain-general executive network is not engaged during language processing in the absence of secondary task demands (cf. the core language network, which is not sensitive to task demands). And Shain et al. (2020, in prep.) have shown that the language network, but not the domain-general executive network, is sensitive to linguistic surprisal and working-memory integration costs (see also Wehbe et al., 2021). In tandem, this evidence argues against the role of executive resources in core linguistic computations like those related to lexical access and combinatorial processing, including syntactic parsing and semantic composition (see also Hasson et al., 2015 and Dasgupta \& Gershman, 2021 for general arguments against the separation between memory and computation in the brain). Thus, although the contribution of executive resources to music processing deserves further investigation, any overlap within the executive system between linguistic and music processing cannot reflect core linguistic computations, as those seem to be carried out by the language network (see Fedorenko \& Shain, submitted, for a review).

Because we had included a localizer for the domain-general executive network in our fMRI experiments (based on a spatial working memory task; Fedorenko et al., 2013; Blank et al., 2014; Shashidara et al., 2019), we examined the responses of these executive brain regions to the music conditions and other conditions in the current study. We found that music conditions elicit a response at or below the fixation baseline, with the exception of the conditions in Experiment 2, which included an explicit task (well-formedness judgments) (the results are available at: https://osf.io/68y $7 \mathrm{c} /$ ). The above-baseline responses to the music conditions accompanied by a task align with the general sensitivity of the executive network to task demands and its role in goal-directed behaviors (e.g., Duncan, 2010; Assem et al., 2020; Diachek, Blank, Siegelman et al., 2020). The fact that the condition with music violations elicits a stronger response than the well-formed condition fits the sensitivity of this system to unexpected events across domains, at least in task-based paradigms (e.g., Corbetta \& Shulman, 2002; Fouragnan et al., 2018; Corlett et al., 2021; cf. Shain, Blank et al., 2020). The fact that passively listening to rich structured musical stimuli does not elicit an above-baseline response argues against the possible role of this network in core computations related to music structure processing. In interpreting past studies, 
and in any future studies, it is / will be important to rule out extraneous task demands as the source of overlap between music and language processing.

\section{What brain system processes music, including its structure?}

We have shown here that the language system shows little or no response when we listen to music. It is worth briefly talking about the brain areas that are sensitive to structure in music. Norman-Haignere et al. (2015; see also Boebinger et al., 2020) reported robust selectivity of parts of the auditory cortex for music over diverse kinds of other sounds, including speech (see Peretz et al., 2015, for review and discussion). They further showed that these music-selective components are sensitive to the scrambling of music structure in stimuli similar to those used here in Experiment 1 (see also Fedorenko et al., 2012c; responses of music-sensitive areas to the conditions of Experiment 1 are available at: https://osf.io/68y $7 \mathrm{c} /$ ).

\section{Overlap between music processing and other aspects of speech / language}

The current study investigated the role of the language network - which supports 'high-level' comprehension and production - in music processing. As a result, the claims we make are restricted to those aspects of language that are supported by this network. These include the processing of word meanings and combinatorial (syntactic and semantic) processing, but exclude speech perception, prosodic processing, higher-level discourse structure building, and at least some aspects of pragmatic reasoning. Some of these components of language (e.g., pragmatic reasoning) seem a priori unlikely to share resources with music. Others (e.g., speech perception) have been shown to robustly dissociate from music (Norman-Haignere et al., 2015; Kell et al., 2018). However, some components of speech and language may, and some do, draw on the same resources as aspects of music. For example, aspects of pitch perception have been argued to overlap between speech and music based on behavioral and neuropsychological evidence (e.g., Wong \& Perrachione, 2007; Perrachione et al., 2013; Patel et al., 2008). Indeed, brain regions selectively responsive to different kinds of tonal sounds have been previously reported (Patterson et al., 2002; Penagos et al., 2004; Norman-Haignere et al., 2013, 2015). Other aspects of highlevel auditory perception, including aspects of rhythm, may turn out to overlap as well, and deserve further investigation (see Patel, 2008, for an extensive review).

In conclusion, we have here provided extensive evidence against the role of the language network in music processing, including the processing of music structure. Although the relationship between music and aspects of speech and language will likely continue to generate interest in the research community, and aspects of speech and language other than those implemented in the core fronto-temporal network (Fedorenko \& Thompson-Schill, 2014; Fedorenko, 2020) may indeed share some processing resources with (aspects of) music, we hope that the current study helps bring clarity to the debate about structure processing in language and music. 


\section{References:}

Alcock, K. J., Wade, D., Anslow, P., \& Passingham, R. E. (2000). Pitch and timing abilities in adult left-hemisphere-dysphasic and right-hemisphere-damaged subjects. Brain and Language, 75(1), 47-65.

Amalric, M., \& Dehaene, S. (2018). Cortical circuits for mathematical knowledge: evidence for a major subdivision within the brain's semantic networks. Philosophical Transactions of the Royal Society B: Biological Sciences, 373(1740), 20160515.

Apperly, I. A., Samson, D., Carroll, N., Hussain, S., \& Humphreys, G. (2006). Intact first-and second-order false belief reasoning in a patient with severely impaired grammar. Social Neuroscience, 1(3-4), 334-348.

Assem, M., Glasser, M. F., Van Essen, D. C., \& Duncan, J. (2020). A domain-general cognitive core defined in multimodally parcellated human cortex. Cerebral Cortex, 30(8), 4361-4380.

Ayyash, D.*, Malik-Moraleda, S.*, Gallée, J., Mineroff, Z., Jouravlev, O., Fedorenko, E., (2020, May 2-5). The Universal Language Network: A Cross-Linguistic Investigation Spanning 41 Languages and 10 Language Families [Poster Presentation]. $27^{\text {th }}$ Cognitive Neuroscience Society (CNS) Annual Meeting, Virtual.

Baillet, S. (2014) Forward and Inverse Problems of MEG/EEG. In: Jaeger, D., Jung, R. (Eds.) Encyclopedia of Computational Neuroscience. New York, NY: Springer.

Baroni, M., Maguire, S., \& Drabkin, W. (1983). The concept of musical grammar. Music Analysis, 2(2), 175-208.

Basso, A., \& Capitani, E. (1985). Spared musical abilities in a conductor with global aphasia and ideomotor apraxia. Journal of Neurology, Neurosurgery \& Psychiatry, 48(5), 407-412.

Bates, D., Mächler, M., Bolker, B., \& Walker, S. (2015). Fitting linear mixed-effects models using lme4. Journal of Statistical Software, 67(1), 1-48.

Bautista, A., \& Wilson, S. M. (2016). Neural responses to grammatically and lexically degraded speech. Language, Cognition and Neuroscience, 31(4), 567-574.

Ben-Shachar, M., Hendler, T., Kahn, I., Ben-Bashat, D., \& Grodzinsky, Y. (2003). The neural reality of syntactic transformations: Evidence from functional magnetic resonance imaging. Psychological science, 14(5), 433-440.

Bernstein, L. (1976). The unanswered question: Six talks at Harvard. Cambridge, MA: Harvard University Press. 
Bidelman, G. M., Gandour, J. T., \& Krishnan, A. (2011). Musicians and tone-language speakers share enhanced brainstem encoding but not perceptual benefits for musical pitch. Brain and Cognition, 77(1), 1-10.

Bigand, E., Tillmann, B., Poulin, B., D'Adamo, D. A., \& Madurell, F. (2001). The effect of harmonic context on phoneme monitoring in vocal music. Cognition, 81(1), B11-B20.

Bishop, D.V.M., \& Norbury, C.F. (2002). Exploring the borderlands of autistic disorder and specific language impairment: a study using standardised diagnostic instruments. Journal of Child Psychology and Psychiatry, 43(7), 917-29.

Blank, I., Kanwisher, N. \& Fedorenko, E. (2014). A functional dissociation between language and multiple-demand systems revealed in patterns of BOLD signal fluctuations. Journal of Neurophysiology, 112(5), 1105-1118.

Blank, I., Balewski, Z., Mahowald, K. \& Fedorenko, E. (2016). Syntactic processing is distributed across the language system. Neuroimage, 127, 307-323.

Blank, I. \& Fedorenko, E. (2017). Domain-general brain regions do not track linguistic input as closely as language-selective regions. Journal of Neuroscience, 37(41), 9999-10011.

Boebinger, D., Norman-Haignere, S., McDermott, J., \& Kanwisher, N. (2020). Cortical music selectivity does not require musical training. https://www.biorxiv.org/content/10.1101/2020.01.10.902189v1

Boilès, C. L. (1973). Reconstruction of proto-melody. Anuario Interamericano de Investigacion Musical, 9, 45-63.

Bortolini, U., Leonard, L.B., \& Caselli, M.C. (1998). Specific Language Impairment in Italian and English: evaluating alternative accounts of grammatical deficits. Language and Cognitive Processes, 13(1), 1-20.

Braga, R. M., DiNicola, L. M., Becker, H. C., \& Buckner, R. L. (2020). Situating the leftlateralized language network in the broader organization of multiple specialized large-scale distributed networks. Journal of neurophysiology, 124(5), 1415-1448.

Brust, J. C. (1980). Music and language: musical alexia and agraphia. Brain: a journal of neurology, 103(2), 367-392.

Bybee, J. (2010). Language, usage and cognition. Cambridge: Cambridge University Press.

Caplan, D., Hildebrandt, N., \& Makris, N. (1996). Location of lesions in stroke patients with deficits in syntactic processing in sentence comprehension. Brain, 119(3), 933-949. 
Caplan, D., Stanczak, L., \& Waters, G. (2008). Syntactic and thematic constraint effects on blood oxygenation level dependent signal correlates of comprehension of relative clauses. Journal of Cognitive Neuroscience, 20(4), 643-656.

Caramazza, A., \& Zurif, E. B. (1976). Dissociation of algorithmic and heuristic processes in language comprehension: Evidence from aphasia. Brain and Language, 3(4), 572-582.

Chen, G., Taylor, P. A., \& Cox, R. W. (2017). Is the statistic value all we should care about in neuroimaging?. NeuroImage, 147, 952-959.

Chomsky, N. (1965). Aspects of the Theory of Syntax. Cambridge, MA: MIT press.

Chomsky, N. (1995). The minimalist program. Cambridge, MA: MIT Press.

Cooke, A., Grossman, M., DeVita, C., Gonzalez-Atavales, J., Moore, P., Chen, W., Gee, J., \& Detre, J. (2006). Large-scale neural network for sentence processing. Brain and Language, 96(1), 14-36.

Corbetta, M., \& Shulman, G. L. (2002). Control of goal-directed and stimulus-driven attention in the brain. Nature Reviews Neuroscience, 3(3), 201-215.

Corlett, P. R., Mollick, J. A., \& Kober, H. (2021). Substrates of Human Prediction Error for Incentives, Perception, Cognition, and Action. https://doi.org/10.31234/osf.io/pf89k

Crawford, J. R., \& Garthwaite, P. H. (2007). Comparison of a single case to a control or normative sample in neuropsychology: Development of a Bayesian approach. Cognitive Neuropsychology, 24(4), 343-372.

Creel, S. C., Weng, M., Fu, G., Heyman, G. D., \& Lee, K. (2018). Speaking a tone language enhances musical pitch perception in 3-5-year-olds. Developmental Science, 21(1), e12503.

Crump, M. J., McDonnell, J. V., \& Gureckis, T. M. (2013). Evaluating Amazon's Mechanical Turk as a tool for experimental behavioral research. PloS one, 8(3), e57410.

Darwin C. The Descent of Man, and Selection in Relation to Sex. London: John Murray; 1871.

Dasgupta, I., \& Gershman, S. J. (2021). Memory as a Computational Resource. Trends in Cognitive Sciences.

Deen, B., Koldewyn, K., Kanwisher, N., \& Saxe, R. (2015). Functional organization of social perception and cognition in the superior temporal sulcus. Cerebral Cortex, 25(11), 45964609.

Deutsch, D., Henthorn, T., Marvin, E., \& Xu, H. (2006). Absolute pitch among American and Chinese conservatory students: Prevalence differences, and evidence for a speech-related critical period. The Journal of the Acoustical Society of America, 119(2), 719-722. 
Deutsch, D., Dooley, K., Henthorn, T., \& Head, B. (2009). Absolute pitch among students in an American music conservatory: Association with tone language fluency. The Journal of the Acoustical Society of America, 125(4), 2398-2403.

Diachek, E.*, Blank, I.*, Siegelman, M.*, Affourtit, J. \& Fedorenko, E. (2020). The domaingeneral multiple demand (MD) network does not support core aspects of language comprehension: a large-scale fMRI investigation. Journal of Neuroscience, 40(23), 45364550 .

Dick, F., Bates, E., Wulfeck, B., Utman, J. A., Dronkers, N., \& Gernsbacher, M. A. (2001). Language deficits, localization, and grammar: evidence for a distributive model of language breakdown in aphasic patients and neurologically intact individuals. Psychological review, 108(4), 759.

Ding, J., Martin, R. C., Hamilton, A. C., \& Schnur, T. T. (2020). Dissociation between frontal and temporal-parietal contributions to connected speech in acute stroke. Brain, 143(3), 862876.

Duncan, J., \& Owen, A. M. (2000). Common regions of the human frontal lobe recruited by diverse cognitive demands. Trends in Neurosciences, 23(10), 475-483.

Duncan, J. (2001). An adaptive coding model of neural function in prefrontal cortex. Nature Reviews Neuroscience, 2(11), 820-829.

Duncan, J. (2010). The multiple-demand (MD) system of the primate brain: mental programs for intelligent behaviour. Trends in Cognitive Sciences, 14(4), 172-179.

Duncan, J. (2013). The structure of cognition: attentional episodes in mind and brain. Neuron, $80(1), 35-50$.

Embick, D., Marantz, A., Miyashita, Y., O'Neil, W., \& Sakai, K. L. (2000). A syntactic specialization for Broca's area. Proceedings of the National Academy of Sciences, 97(11), 6150-6154.

Fadiga, L., Craighero, L., \& D'Ausilio, A. (2009). Broca's area in language, action, and music. Annals of the New York Academy of Sciences, 1169(1), 448-58.

Fancourt, A. (2013). Exploring musical cognition in children with Specific Language Impairment. Doctoral thesis, Goldsmiths, University of London.

Fay, T. (1971). Perceived hierarchic structure in language and music. Journal of Music theory, $15(1 / 2), 112-137$.

Fedorenko, E., Patel, A., Casasanto, D., Winawer, J., \& Gibson, E. (2009). Structural integration in language and music: Evidence for a shared system. Memory \& Cognition, 37(1), 1-9. 
Fedorenko, E., Hsieh, P.-J., Nieto-Castañon, A., Whitfield-Gabrieli, S. \& Kanwisher, N. (2010). A new method for fMRI investigations of language: Defining ROIs functionally in individual subjects. Journal of Neurophysiology, 104(2), 1177-94.

Fedorenko, E., Behr, M. \& Kanwisher, N. (2011). Functional specificity for high-level linguistic processing in the human brain. Proceedings of the National Academy of Sciences, 108(39), 16428-16433.

Fedorenko, E., Duncan, J. \& Kanwisher, N. (2012a). Language-selective and domain-general regions lie side by side within Broca's area. Current Biology, 22(21), 2059-2062.

Fedorenko, E., Nieto-Castañon, A. \& Kanwisher, N. (2012b). Lexical and syntactic representations in the brain: An fMRI investigation with multi-voxel pattern analyses. Neuropsychologia, 50(4), 499-513.

Fedorenko, E., McDermott, J., Norman-Haignere, S. \& Kanwisher, N. (2012c). Sensitivity to musical structure in the human brain. Journal of Neurophysiology, 108(12), 3289-3300.

Fedorenko, E., Duncan, J. \& Kanwisher, N. (2013). Broad domain-generality in focal regions of frontal and parietal cortex. Proceedings of the National Academy of Sciences, 110(41), 16616-16621.

Fedorenko, E. (2014). The role of domain-general cognitive control in language comprehension. Frontiers in Psychology, 5, 335.

Fedorenko, E. \& Varley, R. (2016). Language and thought are not the same thing: Evidence from neuroimaging and neurological patients. Annals of the NY Academy of Sciences, 1369(1), 132-153.

Fedorenko, E. \& Blank, I. (2020). Broca's Area Is Not a Natural Kind. Trends in Cognitive Sciences, 24(4), 270-284.

Fedorenko, E., Blank, I., Siegelman, M. \& Mineroff, Z. (2020). Lack of selectivity for syntax relative to word meanings throughout the language network. Cognition, 203, 104348.

Fedorenko, E. (2020). The brain network that supports high-level language processing. In Gazzaniga, Ivry, Mangun (Ed.), Cognitive Neuroscience: The Biology of the Mind (5th edition). Cambridge, MA: MIT Press.

Fedorenko, E. (2021). The early origins and the growing popularity of the individual-subject analytic approach in human neuroscience. Current Opinion in Behavioral Sciences.

Fedorenko, E. and Shain, C. (submitted). Local implementation of general computations: The case of human language comprehension. 
Fischl, B., Rajendran, N., Busa, E., Augustinack, J., Hinds, O., Yeo, B. T., Mohlberg, H., Amunts, K., \& Zilles, K. (2008). Cortical folding patterns and predicting cytoarchitecture. Cerebral Cortex, 18(8), 1973-1980.

Fitch, W. T., \& Martins, M. D. (2014). Hierarchical processing in music, language, and action: Lashley revisited. Annals of the New York Academy of Sciences, 1316(1), 87-104.

Fodor, J. D. (1983). Phrase structure parsing and the island constraints. Linguistics and Philosophy, 6(2), 163-223.

Fouragnan, E., Retzler, C., \& Philiastides, M. G. (2018). Separate neural representations of prediction error valence and surprise: Evidence from an fMRI meta-analysis. Human Brain Mapping, 39(7), 2887-2906.

Franklin, S., Turner, J.E., Ellis, A.W. (1992). ADA Comprehension Battery. Action for Dysphasic Adults, Canterbury House, Royal Street, London SE1 7LL.

Friederici, A. D., Fiebach, C. J., Schlesewsky, M., Bornkessel, I. D., \& Von Cramon, D. Y. (2006). Processing linguistic complexity and grammaticality in the left frontal cortex. Cerebral Cortex, 16(12), 1709-1717.

Friederici, A. D., Kotz, S. A., Scott, S. K., \& Obleser, J. (2010). Disentangling syntax and intelligibility in auditory language comprehension. Human Brain Mapping, 31(3), 448-457.

Friederici, A. D. (2011). The brain basis of language processing: from structure to function. Physiological Reviews, 91(4), 1357-1392.

Friederici, A. D. (2018). The neural basis for human syntax: Broca's area and beyond. Current opinion in behavioral sciences, 21, 88-92.

Frost, M. A., \& Goebel, R. (2012). Measuring structural-functional correspondence: spatial variability of specialised brain regions after macro-anatomical alignment. NeuroImage, 59(2), 1369-1381.

Giesbrecht, F., \& Burns, J. (1985). Two-Stage Analysis Based on a Mixed Model: Large-Sample Asymptotic Theory and Small-Sample Simulation Results. Biometrics, 41(2), 477-486.

Goldberg, A. E. (2002). “Construction Grammar.” Encyclopedia of Cognitive Science. Macmillan Reference Limited Nature Publishing Group.

Green, D. M., \& Swets, J. A. (1966). Signal detection theory and psychophysics. New York: Wiley.

Hasson, U., Chen, J., \& Honey, C. J. (2015). Hierarchical process memory: memory as an integral component of information processing. Trends in cognitive sciences, 19(6), 304-313. 
Herholz, S. C., \& Zatorre, R. J. (2012). Musical training as a framework for brain plasticity: behavior, function, and structure. Neuron, 76(3), 486-502.

Herrmann, B., Obleser, J., Kalberlah, C., Haynes, J. D., \& Friederici, A. D. (2012). Dissociable neural imprints of perception and grammar in auditory functional imaging. Human Brain Mapping, 33(3), 584-595.

Hoch, L., Poulin-Charronnat, B., \& Tillmann, B. (2011). The influence of task-irrelevant music on language processing: syntactic and semantic structures. Frontiers in Psychology, 2, 112.

Hrong-Tai Fai, A., \& Cornelius, P. L. (1996). Approximate F-tests of multiple degree of freedom hypotheses in generalized least squares analyses of unbalanced split-plot experiments. Journal of statistical computation and simulation, 54(4), 363-378.

Ivanova, A., Srikant, S., Sueoka, Y., Kean, H., Dhamala, R., O’Reilly, U-M., Bers, M. U., \& Fedorenko, E. (2020). Comprehension of computer code relies primarily on domain-general executive resources. eLife, 9:e58906.

Ivanova, A., Mineroff, Z., Zimmerer, V., Kanwisher, N., Varley, R. \& Fedorenko, E. (2021) The language network is recruited but not required for non-verbal semantic processing. https://www.biorxiv.org/content/10.1101/696484v1.

Ivanova, A., Siegelman, M., Cheung, C., Pongos, A., Kean H., \& Fedorenko, E. (2020c), October 21-24). The effect of task on sentence processing in the language and multiple demand brain networks [Poster presentation]. SNL 2020, virtual.

Jackendoff, R. (2002). English particle constructions, the lexicon, and the autonomy of syntax. In Dehé, N., Jackendoff, R., McIntyre, A., \& Urban, S. (Eds.) Verb-particle explorations, (pp. 67-94). Berlin: De Gruyter.

Jackendoff, R. (2007). A parallel architecture perspective on language processing. Brain Research, 1146, 2-22.

Jackendoff, R. (2009). Parallels and nonparallels between language and music. Music Perception, 26(3), 195-204.

Jackendoff, R., \& Audring, J. (2020). The texture of the lexicon: relational morphology and the parallel architecture. Oxford: Oxford University Press.

Janata, P. (1995). ERP measures assay the degree of expectancy violation of harmonic contexts in music. Journal of Cognitive Neuroscience, 7(2), 153-164.

Jouravlev, O., Zheng, D., Balewski, Z., Pongos, A., Levan, Z., Goldin-Meadow, S., \& Fedorenko, E. (2019). Speech-accompanying gestures are not processed by the language-processing mechanisms. Neuropsychologia, 132, 107132. 
Jouravlev, O., Kell, A., Mineroff, Z., Haskins, A.J., Ayyash, D., Kanwisher, N. \& Fedorenko, E. (2020). Reduced language lateralization in autism and the broader autism phenotype as assessed with robust individual-subjects snalyses. Autism Research, 0, 1-16.

Just, M. A., Carpenter, P. A., Keller, T. A., Eddy, W. F., \& Thulborn, K. R. (1996). Brain activation modulated by sentence comprehension. Science, 274(5284), 114-116.

Kaplan, E., Goodglass, H., \& Weintraub, S. (2001). Boston Naming Test. 2nd Ed. Philadelphia, PA: Lippincott Williams \& Wilkins.

Kay, J., Lesser, R., \& Coltheart, M. (1992). Psycholinguistic Assessments of Language Processing in Aphasia (PALPA). Hove: Erlbaum.

Kell, A. J., Yamins, D. L., Shook, E. N., Norman-Haignere, S. V., \& McDermott, J. H. (2018). A task-optimized neural network replicates human auditory behavior, predicts brain responses, and reveals a cortical processing hierarchy. Neuron, 98(3), 630-644.

Keller, T. A., Carpenter, P. A., \& Just, M. A. (2001). The neural bases of sentence comprehension: a fMRI examination of syntactic and lexical processing. Cerebral Cortex, 11(3), 223-237.

Koelsch, S., Gunter, T., Friederici, A. D., \& Schröger, E. (2000). Brain indices of music processing: "nonmusicians" are musical. Journal of Cognitive Neuroscience, 12(3), 520-541.

Koelsch, S., Gunter, T. C., von Cramon, D. Y., Zysset, S., Lohmann, G., \& Friederici, A. D. (2002). Bach speaks: A cortical" language-network" serves the processing of music. Neuroimage, 17(2), 956-966.

Koelsch, S. (2006). Significance of Broca's area and ventral premotor cortex for music-syntactic processing. Cortex, 42(4), 518-520.

Koelsch, S., Rohrmeier, M., Torrecuso, R., \& Jentschke, S. (2013). Processing of hierarchical syntactic structure in music. Proceedings of the National Academy of Sciences, 110(38), 15443-15448.

Kriegeskorte, N., Simmons, W. K., Bellgowan, P. S., \& Baker, C. I. (2009). Circular analysis in systems neuroscience: the dangers of double dipping. Nature Neuroscience, 12(5), 535.

Krumhansl, C. L., \& Keil, F. C. (1982). Acquisition of the hierarchy of tonal functions in music. Memory \& Cognition, 10(3), 243-251.

Kunert, R., \& Slevc, L. R. (2015). A Commentary on:"Neural overlap in processing music and speech". Frontiers in Human Neuroscience, 9, 330.

Kunert, R., Willems, R. M., Casasanto, D., Patel, A. D., \& Hagoort, P. (2015). Music and language syntax interact in Broca's area: An fMRI study. PloS one, 10(11), e0141069. 
Kunert, R., Willems, R. M., \& Hagoort, P. (2016). Language influences music harmony perception: effects of shared syntactic integration resources beyond attention. Royal Society open science, 3(2), 150685.

Kuperberg, G. R., Holcomb, P. J., Sitnikova, T., Greve, D., Dale, A. M., \& Caplan, D. (2003). Distinct patterns of neural modulation during the processing of conceptual and syntactic anomalies. Journal of Cognitive Neuroscience, 15(2), 272-293.

Kuznetsova, A., Brockhoff, P. B., \& Christensen, R. H. (2017). lmerTest package: tests in linear mixed effects models. Journal of Statistical Software, 82(13), 1-26.

LaCroix, A., Diaz, A. F., \& Rogalsky, C. (2015). The relationship between the neural computations for speech and music perception is context-dependent: an activation likelihood estimate study. Frontiers in Psychology, 6, 1138.

Lerdahl, F., \& Jackendoff, R. (1977). Toward a formal theory of tonal music. Journal of Music Theory, 21(1), 111-171.

Lerdahl, F., \& Jackendoff, R. (1983). An overview of hierarchical structure in music. Music Perception, 1(2), 229-252.

Levin, B., \& Rappaport-Hovav, M. (2005). Argument realization. Cambridge: Cambridge University Press.

Levitin, D. J., \& Menon, V. (2003). Musical structure is processed in "language" areas of the brain: a possible role for Brodmann Area 47 in temporal coherence. Neuroimage, 20(4), 2142-2152.

Linebarger, M. C., Schwartz, M. F., \& Saffran, E. M. (1983). Sensitivity to grammatical structure in so-called agrammatic aphasics. Cognition, 13(3), 361-392.

Lindblom, B., \& Sundberg, J. (1969). Towards a generative theory of melody. Speech Transmission Laboratory. Quarterly Progress and Status Reports, 10, 53-86.

Luria, A. R., Tsvetkova, L. S., \& Futer, D. S. (1965). Aphasia in a composer. Journal of the Neurological Sciences, 2(3), 288-292.

Maess, B., Koelsch, S., Gunter, T. C., \& Friederici, A. D. (2001). Musical syntax is processed in Broca's area: an MEG study. Nature Neuroscience, 4(5), 540-545.

Mahowald, K. \& Fedorenko, E. (2016). Reliable individual-level neural markers of high-level language processing: A necessary precursor for relating neural variability to behavioral and genetic variability. NeuroImage, 139, 74-93. 
Makowski, (2018). The psycho Package: an Efficient and Publishing-Oriented Workflow for Psychological Science. Journal of Open Source Software, 3(22), 470, https://doi.org/10.21105/joss.00470

Marin, O.S.M. 1982. Neurological Aspects of Music Perception and Performance. New York: Academic Press.

Matchin, W., \& Hickok, G. (2020). The cortical organization of syntax. Cerebral Cortex, 30(3), 1481-1498.

Mehr, S., Krasnow, M., Bryant, G., \& Hagen, E. (2020). Origins of music in credible signaling. Behavioral and Brain Sciences, 1-41.

Mesulam, M. M., Rogalski, E. J., Wieneke, C., Hurley, R. S., Geula, C., Bigio, E. H., Thompson, C. K., \& Weintraub, S. (2014). Primary progressive aphasia and the evolving neurology of the language network. Nature Reviews Neurology, 10(10), 554.

Mesulam, M. M., Thompson, C. K., Weintraub, S., \& Rogalski, E. J. (2015). The Wernicke conundrum and the anatomy of language comprehension in primary progressive aphasia. Brain, 138(8), 2423-2437.

McDermott, J. (2008). The evolution of music. Nature, 453(7193), 287-288.

Mineroff, Z.*, Blank, I.*, Mahowald, K. \& Fedorenko, E. (2018). A robust dissociation among the language, multiple demand, and default mode networks: evidence from inter-region correlations in effect size. Neuropsychologia, 119, 501-511.

Mollica, F., Shain, C., Affourtit, J., Kean, H., Siegelman, M., \& Fedorenko, E. (2020), October 21-24). Another look at the constituent structure of sentences in the human brain [Poster presentation]. SNL 2020, virtual.

Monti, M. M., Parsons, L. M., \& Osherson, D. N. (2009). The boundaries of language and thought in deductive inference. Proceedings of the National Academy of Sciences, 106(30), 12554-12559.

Monti, M. M., Parsons, L. M., \& Osherson, D. N. (2012). Thought beyond language: Neural dissociation of algebra and natural language. Psychological Science, 23(8), 914-922.

Morosan, P., Rademacher, J., Schleicher, A., Amunts, K., Schormann, T., \& Zilles, K. (2001). Human primary auditory cortex: cytoarchitectonic subdivisions and mapping into a spatial reference system. NeuroImage, 13(4), 684-701.

Musso, M., Weiller, C., Horn, A., Glauche, V., Umarova, R., Hennig, J., Schneider, A., \& Rijntjes, M. (2015). A single dual-stream framework for syntactic computations in music and language. NeuroImage, 117, 267-283. 
Newman, A. J., Pancheva, R., Ozawa, K., Neville, H. J., \& Ullman, M. T. (2001). An eventrelated fMRI study of syntactic and semantic violations. Journal of Psycholinguistic Research, 30(3), 339-364.

Ngo, M. K., Vu, K. P. L., \& Strybel, T. Z. (2016). Effects of music and tonal language experience on relative pitch performance. The American Journal of Psychology, 129(2), 125-134.

Nieto-Castañon, A. \& Fedorenko, E. (2012). Subject-specific functional localizers increase sensitivity and functional resolution of multi-subject analyses. NeuroImage, 63(3), 16461669.

Norman-Haignere, S., Kanwisher, N., \& McDermott, J. H. (2013). Cortical pitch regions in humans respond primarily to resolved harmonics and are located in specific tonotopic regions of anterior auditory cortex. Journal of Neuroscience, 33(50), 19451-19469.

Norman-Haignere, S., Kanwisher, N. G., \& McDermott, J. H. (2015). Distinct cortical pathways for music and speech revealed by hypothesis-free voxel decomposition. Neuron, 88(6), 1281-1296.

Pallier, C., Devauchelle, A. D., \& Dehaene, S. (2011). Cortical representation of the constituent structure of sentences. Proceedings of the National Academy of Sciences, 108(6), 2522-2527.

Patel, A. D., Gibson, E., Ratner, J., Besson, M., \& Holcomb, P. J. (1998). Processing syntactic relations in language and music: An event-related potential study. Journal of Cognitive Neuroscience, 10(6), 717-733.

Patel, A. D. (2003). Language, music, syntax and the brain. Nature Neuroscience, 6(7), 674-681.

Patel, A. D. (2008). Music, Language, and the Brain. Oxford: Oxford University Press.

Patel, A. D., Iversen, J. R., Wassenaar, M., \& Hagoort, P. (2008). Musical syntactic processing in agrammatic Broca's aphasia. Aphasiology, 22(7-8), 776-789.

Patel, A.D. (2012). Language, music, and the brain: a resource-sharing framework. In: P. Rebuschat, M. Rohrmeier, J. Hawkins, \& I. Cross (Eds.), Language and Music as Cognitive Systems (pp. 204-223). Oxford: Oxford University Press.

Patterson, R. D., Uppenkamp, S., Johnsrude, I. S., \& Griffiths, T. D. (2002). The processing of temporal pitch and melody information in auditory cortex. Neuron, 36(4), 767-776.

Paunov, A., Blank, I. A., \& Fedorenko, E. (2019). Functionally distinct language and Theory of Mind networks are synchronized at rest and during language comprehension. Journal of Neurophysiology, 121, 1244-1265. 
Peelle, J. E., Troiani, V., Wingfield, A., \& Grossman, M. (2010). Neural processing during older adults' comprehension of spoken sentences: age differences in resource allocation and connectivity. Cerebral Cortex, 20(4), 773-782.

Penagos, H., Melcher, J. R., \& Oxenham, A. J. (2004). A neural representation of pitch salience in nonprimary human auditory cortex revealed with functional magnetic resonance imaging. Journal of Neuroscience, 24(30), 6810-6815.

Peretz, I. (1990). Processing of local and global musical information by unilateral brain-damaged patients. Brain, 113(4), 1185-1205.

Peretz, I., Champod, A. S., \& Hyde, K. (2003). Varieties of musical disorders: the Montreal Battery of Evaluation of Amusia. Annals of the New York Academy of Sciences, 999(1), 5875.

Peretz, I., \& Coltheart, M. (2003). Modularity of music processing. Nature Neuroscience, 6(7), 688-691.

Peretz, I., Vuvan, D., Lagrois, M. É., \& Armony, J. L. (2015). Neural overlap in processing music and speech. Philosophical Transactions of the Royal Society B: Biological Sciences, 370(1664), 20140090.

Perrachione, T. K., Fedorenko, E. G., Vinke, L., Gibson, E., \& Dilley, L. C. (2013). Evidence for shared cognitive processing of pitch in music and language. PLoS One, 8(8), e73372.

Perruchet, P., \& Poulin-Charronnat, B. (2013). Challenging prior evidence for a shared syntactic processor for language and music. Psychonomic Bulletin \& Review, 20(2), 310-317.

Pinker, S., \& Prince, A. (1988). On language and connectionism: Analysis of a parallel distributed processing model of language acquisition. Cognition, 28(1-2), 73-193.

Pinker, S. (1991). Rules of language. Science, 253(5019), 530-535.

Pinker, S. (1994), The Language Instinct: How the Mind Creates Language, New York: Harper Collins Publishers, Inc

Pinker, S. (1999). Out of the minds of babes. Science, 283(5398), 40-41.

Poldrack, R. A. (2006). Can cognitive processes be inferred from neuroimaging data?. Trends in Cognitive Sciences, 10(2), 59-63.

Poldrack, R. A. (2011). Inferring mental states from neuroimaging data: from reverse inference to large-scale decoding. Neuron, 72(5), 692-697.

Polk, M., \& Kertesz, A. (1993). Music and language in degenerative disease of the brain. Brain and Cognition, 22(1), 98-117. 
Poulin-Charronnat, B., Bigand, E., Madurell, F., \& Peereman, R. (2005). Musical structure modulates semantic priming in vocal music. Cognition, 94, B67-B78.

Pritchett, B., Hoeflin, C., Koldewyn, K., Dechter, E. \& Fedorenko, E. (2018). High-level language processing regions are not engaged in action observation or imitation. Journal of Neurophysiology, 120(5), 2555-2570.

Riemann, H. (1877). Musikalische Syntaxis: Grundriss einer harmonischen Satzbildungslehre. Leipzig: Breitkopf und Härtel.

Roads, C., \& Wieneke, P. (1979). Grammars as representations for music. Computer Music Journal, 48-55.

Roberts, I. (2012). Comments and a conjecture inspired by Fabb and Halle. In Rebuschat, P., Rohrmeier, M., Hawkins, J. A., \& Cross, I. (Eds.) Language and Music as Cognitive Systems (pp. 51-66.). Oxford: Oxford University Press.

Röder, B., Stock, O., Neville, H., Bien, S., \& Rösler, F. (2002). Brain activation modulated by the comprehension of normal and pseudo-word sentences of different processing demands: a functional magnetic resonance imaging study. NeuroImage, 15(4), 1003-1014.

Rogalsky, C., \& Hickok, G. (2011). The role of Broca's area in sentence comprehension. Journal of Cognitive Neuroscience, 23(7), 1664-1680.

Rueffler, C., Hermisson, J., \& Wagner, G. P. (2012). Evolution of functional specialization and division of labor. Proceedings of the National Academy of Sciences, 109(6), E326-E335.

Sag, I., Wasow, T., \& Bender, E. (2003). Formal syntax, an introduction. CSLI publication.

Sammler, D., Koelsch, S., Ball, T., Brandt, A., Elger, C. E., Friederici, A. D., Grigutsch, M., Huppertz, H.-J., Knosche, T. R., Wellmer, J., Widman, G., \& Schulze-Bonhaged, A. (2009). Overlap of musical and linguistic syntax processing: intracranial ERP evidence. Annals of the New York Academy of Sciences, 1169(1), 494-498.

Sammler, D., Koelsch, S., \& Friederici, A. D. (2011). Are left fronto-temporal brain areas a prerequisite for normal music-syntactic processing?. Cortex, 47(6), 659-673.

Sammler, D., Koelsch, S., Ball, T., Brandt, A., Grigutsch, M., Huppertz, H. J., Wellmer, J., Widman, G., Elger, C. E., Friederici, A. D., \& Schulze-Bonhaged, A. (2013). Co-localizing linguistic and musical syntax with intracranial EEG. NeuroImage, 64, 134-146.

Savage, P. E., Loui, P., Tarr, B., Schachner, A., Glowacki, L., Mithen, S., \& Fitch, W. T. (2020). Music as a coevolved system for social bonding. Behavioral and Brain Sciences, 1-36. 
Schmidt, S. (2009). Shall We Really Do It Again? The Powerful Concept of Replication Is Neglected in the Social Sciences. Review of General Psychology, 13(2), 90-100.

Scott, T.L., Gallée, J., \& Fedorenko, E. (2017). A new fun and robust version of an fMRI localizer for the frontotemporal language system. Cognitive Neuroscience, 8(3), 167-176.

Shain, C.*, Blank, I.*, Van Shijndel, M., Schuler, W. \& Fedorenko, E. (2020). fMRI reveals language-specific predictive coding during naturalistic sentence comprehension. Neuropsychologia, 138, 107307.

Shain, C., Blank, I., Fedorenko, E., Gibson, E., Schuler, W. (in prep.) fMRI evidence of working memory retrieval during naturalistic listening.

Slevc, L. R., Rosenberg, J. C., \& Patel, A. D. (2009). Making psycholinguistics musical: Selfpaced reading time evidence for shared processing of linguistic and musical syntax. Psychonomic Bulletin \& Review, 16(2), 374-381.

Slevc, L. R., Reitman, J., \& Okada, B. (2013). Syntax in music and language: the role of cognitive control. In Proceedings of the Annual Meeting of the Cognitive Science Society (Vol. 35, No. 35).

Slevc, L. R., \& Okada, B. M. (2015). Processing structure in language and music: a case for shared reliance on cognitive control. Psychonomic Bulletin \& Review, 22(3), 637-652.

Slevc, L. R., Faroqi-Shah, Y., Saxena, S., \& Okada, B. M. (2016). Preserved processing of musical structure in a person with agrammatic aphasia. Neurocase, 22(6), 505-511.

Stromswold, K., Caplan, D., Alpert, N., \& Rauch, S. (1996). Localization of syntactic comprehension by positron emission tomography. Brain and Language, 52(3), 452-473.

Sundberg, J., \& Lindblom, B. (1976). Generative theories in language and music descriptions. Cognition, 4(1), 99-122.

Swain, J. P. (1995). The concept of musical syntax. The Musical Quarterly, 79(2), 281-308.

Tahmasebi, A. M., Davis, M. H., Wild, C. J., Rodd, J. M., Hakyemez, H., Abolmaesumi, P., \& Johnsrude, I. S. (2012). Is the link between anatomical structure and function equally strong at all cognitive levels of processing?. Cerebral cortex, 22(7), 1593-1603.

Tarantola, A. (2004). Inverse problem theory and methods for model parameter estimation. Society for Industrial and Applied Mathematics.

Tillmann, B., Janata, P., \& Bharucha, J. J. (2003). Activation of the inferior frontal cortex in musical priming. Cognitive Brain Research, 16(2), 145-161. 
Tillmann, B., Koelsch, S., Escoffier, N., Bigand, E., Lalitte, P., Friederici, A. D., \& von Cramon, D. Y. (2006). Cognitive priming in sung and instrumental music: activation of inferior frontal cortex. NeuroImage, 31(4), 1771-1782.

Tillmann, B. (2012). Music and Language Perception: Expectations, Structural Integration, and Cognitive Sequencing. Topics in Cognitive Science, 4(4), 568-584.

Tyler, L. K., Marslen-Wilson, W. D., Randall, B., Wright, P., Devereux, B. J., Zhuang, J., Papoutsi, M., \& Stamatakis, E. A. (2011). Left inferior frontal cortex and syntax: function, structure and behaviour in patients with left hemisphere damage. Brain, 134(2), 415-431.

Van de Cavey, J., \& Hartsuiker, R. J. (2016). Is there a domain-general cognitive structuring system? Evidence from structural priming across music, math, action descriptions, and language. Cognition, 146, 172-184.

Varley, R., \& Siegal, M. (2000). Evidence for cognition without grammar from causal reasoning and 'theory of mind' in an agrammatic aphasic patient. Current Biology, 10(12), 723-726.

Varley, R. A., Klessinger, N. J., Romanowski, C. A., \& Siegal, M. (2005). Agrammatic but numerate. Proceedings of the National Academy of Sciences, 102(9), 3519-3524.

Vázquez-Rodríguez, B., Suárez, L. E., Markello, R. D., Shafiei, G., Paquola, C., Hagmann, P., van den Heuvel, M. P., Bernhardt, B. C., Spreng, R. N. \& Misic, B. (2019). Gradients of structure-function tethering across neocortex. Proceedings of the National Academy of Sciences, 116(42), 21219-21227.

Wehbe, L., Blank, I., Shain, C., Futrell, R., Levy, R., Malsburg, T. Smith, N., Gibson, E., Fedorenko, E. (2021). Incremental language comprehension difficulty predicts activity in the language network but not the multiple demand network https://doi.org/10.1101/2020.04.15.043844.

Wilson, S. M., \& Saygın, A. P. (2004). Grammaticality judgment in aphasia: Deficits are not specific to syntactic structures, aphasic syndromes, or lesion sites. Journal of Cognitive Neuroscience, 16(2), 238-252.

Wilson, S. M., Galantucci, S., Tartaglia, M. C., \& Gorno-Tempini, M. L. (2012). The neural basis of syntactic deficits in primary progressive aphasia. Brain and Language, 122(3), 190198.

Woolgar, A., Duncan, J., Manes, F., \& Fedorenko, E. (2018). Fluid intelligence is supported by the multiple-demand system not the language system. Nature Human Behaviour, 2(3), 200204.

Zatorre, R. J. (1984). Musical perception and cerebral function: A critical review. Music Perception, 2(2), 196-221. 


\section{Supplementary Information}

\section{SI-1. Sanity Check Analyses}

Auditory sentences $>$ nonwords and sentences $>$ foreign contrasts

\begin{tabular}{|l|l|l|l|l|l|l|}
\hline Contrast & $\begin{array}{l}\text { Language } \\
\text { network }\end{array}$ & LIFGorb & LIFG & LMFG & $\begin{array}{l}\text { LAnt } \\
\text { Temp }\end{array}$ & $\begin{array}{l}\text { LPost } \\
\text { Temp }\end{array}$ \\
\hline sentences & $\mathrm{b}=0.612$ & $\mathrm{~b}=0.288$ & $\mathrm{~b}=0.557$ & $\mathrm{~b}=0.722$ & $\mathrm{~b}=0.740$ & $\mathrm{~b}=0.754$ \\
>nonwords & $\mathrm{se}=0.096$ & $\mathrm{se}=0.236$ & $\mathrm{se}=0.184$ & $\mathrm{se}=0.198$ & $\mathrm{se}=0.106$ & $\mathrm{se}=0.123$ \\
(Expt 1) & $\mathrm{t}=6.397$ & $\mathrm{t}=1.218$ & $\mathrm{t}=3.035$ & $\mathrm{t}=3.639$ & $\mathrm{t}=6.953$ & $\mathrm{t}=6.154$ \\
& $\mathrm{p}<0.001 * * *$ & $\mathrm{p}=1.000$ & $\mathrm{p}=0.036^{*}$ & $\mathrm{p}=0.010^{*}$ & $\mathrm{p}<0.001 * * *$ & $\mathrm{p}<0.001 * * *$ \\
\hline sentences & $\mathrm{b}=1.397$ & $\mathrm{~b}=1.134$ & $\mathrm{~b}=1.518$ & $\mathrm{~b}=1.723$ & $\mathrm{~b}=1.044$ & $\mathrm{~b}=1.565$ \\
$>$ foreign & $\mathrm{se}=0.133$ & $\mathrm{se}=0.337$ & $\mathrm{se}=0.247$ & $\mathrm{se}=0.213$ & $\mathrm{se}=0.164$ & $\mathrm{se}=0.207$ \\
(Expt 4) & $\mathrm{t}=10.529$ & $\mathrm{t}=3.367$ & $\mathrm{t}=6.151$ & $\mathrm{t}=8.097$ & $\mathrm{t}=6.384$ & $\mathrm{t}=7.554$ \\
\hline
\end{tabular}

Table SI-1a. Responses to the auditory sentences $>$ nonwords and sentences $>$ foreign contrasts in Experiments 1 and 4. The significance values for the individual ROIs have been FDRcorrected for the number of fROIs $(n=5)$.

Response to the six music conditions in bilateral primary auditory cortex

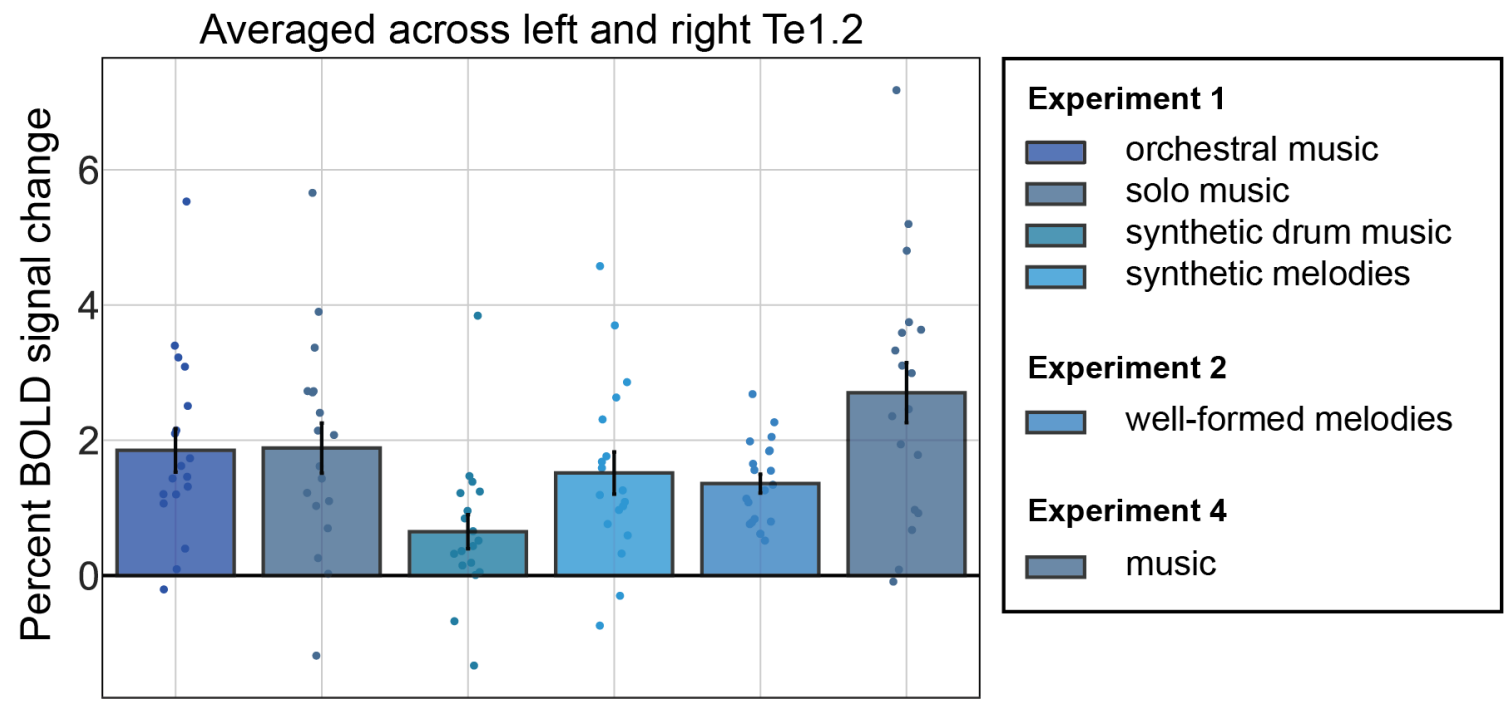

Figure SI-1. Responses of the bilateral Te1.2 to the six music conditions in Experiments 1, 2, and 4. All music conditions show reliable above-baseline responses.

\begin{tabular}{|l|l|}
\hline Contrast & Bilateral Te1.2 \\
\hline orchestral music (Expt 1) $>$ fixation & $\mathrm{b}=1.848 \mathrm{se}=0.140 \mathrm{t}=13.210 \mathrm{p}<0.001^{* * *}$ \\
\hline single-instrument music (Expt 1) $>$ fixation & $\mathrm{b}=1.879 \mathrm{se}=0.156 \mathrm{t}=12.058 \mathrm{p}<0.001^{* * *}$ \\
\hline synthetic drum music (Expt 1) $>$ fixation & $\mathrm{b}=0.640 \mathrm{se}=0.112 \mathrm{t}=5.702 \mathrm{p}<0.001^{* * *}$ \\
\hline synthetic melodies (Expt 1) $>$ fixation & $\mathrm{b}=1.508 \mathrm{se}=0.133 \mathrm{t}=11.363 \mathrm{p}<0.001^{* * *}$ \\
\hline well-formed melodies (Expt 2) $>$ fixation & $\mathrm{b}=1.364 \mathrm{se}=0.063 \mathrm{t}=21.715 \mathrm{p}<0.001^{* * *}$ \\
\hline music (Expt 3) $>$ fixation & $\mathrm{b}=2.704 \mathrm{se}=0.186 \mathrm{t}=14.569 \mathrm{p}<0.001^{* * *}$ \\
\hline
\end{tabular}


Table SI-1b. Responses to the music conditions relative to the fixation baseline in bilateral Te1.2. The significance values for the individual ROIs have been FDR-corrected for the number of fROIs $(n=5)$.

\section{SI-2. Critical Analyses in language fROIs defined by an auditory contrast (Experiments 1 and 4)}

We performed the same set of critical analyses in language fROIs defined using auditory sentences $>$ nonwords in English (Experiment 1) and Mandarin sentences $>$ foreign (Experiment 4). Similar to the approach described in the main text for the definition of language fROIs based on the visual sentences $>$ nonwords contrast, an across-runs cross-validation procedure was used to ensure independence between the data used to define the fROIs and to estimate their response magnitudes. The results are consistent with the results from the visual sentences $>$ nonwords language fROIs: 1) responses to music fall at or below baseline, are not higher than responses elicited by nonwords, and do not differ from other non-linguistic, non-music conditions, and songs do not elicit a stronger response than lyrics; 2) responses to synthetic melodies and synthetic drum music do not significantly differ from their scrambled counterparts; and 3) for Mandarin native speakers, although the response to music is above baseline at the network level, the responses do not significantly differ from nonwords and environmental sounds.

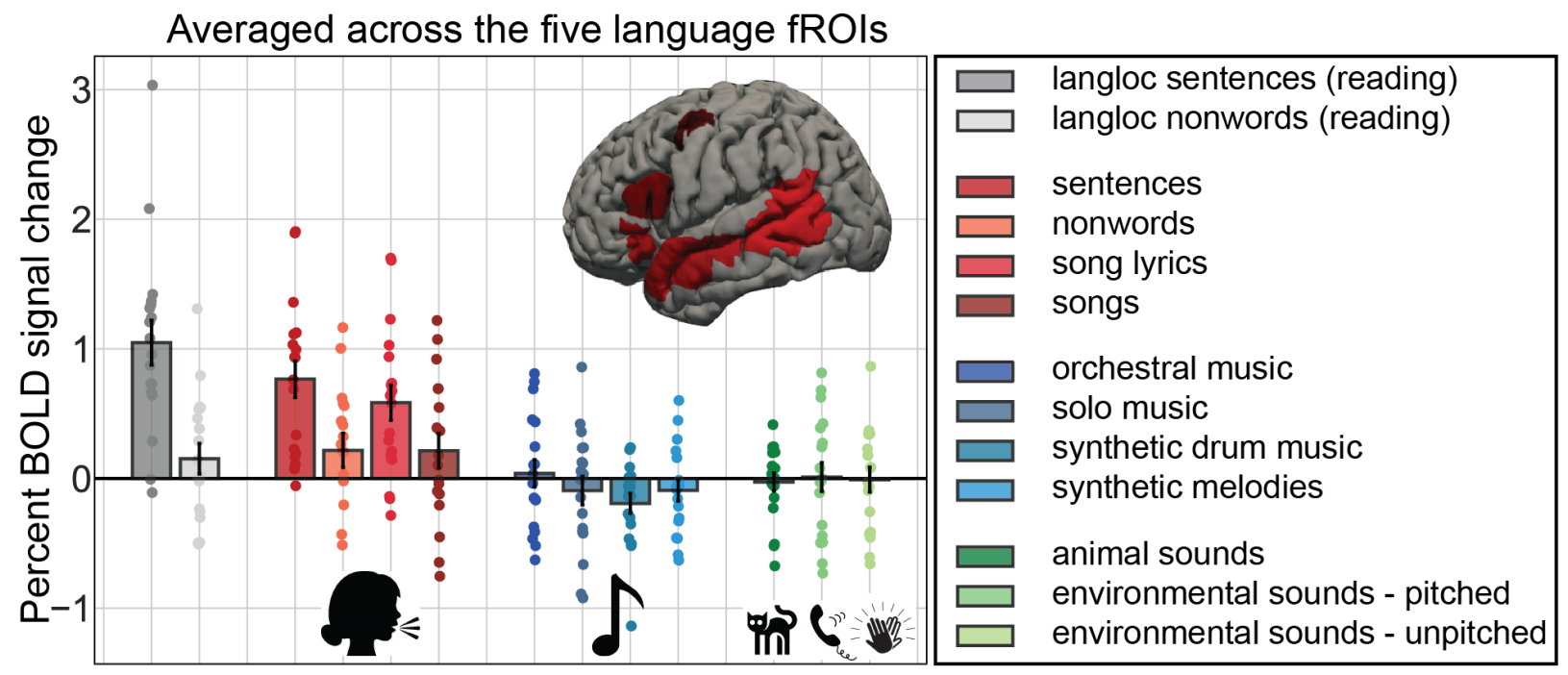

Figure SI-2a. Responses of the language fROIs (defined by auditory sentences $>$ nonwords) to the language localizer conditions (in grey), to the four auditory conditions containing linguistic information in (red shades), to the four music conditions (blue shades), and to the three nonlinguistic/non-music auditory conditions (green shades). For the language localizer results, we include here participants in Experiments 1 and 2. The responses to the music conditions cluster around the fixation baseline, are much lower than the responses to sentences, and not higher than the responses to non-music sounds. 


\begin{tabular}{|c|c|c|c|c|c|c|}
\hline Contrast & \begin{tabular}{|l|} 
Language \\
network
\end{tabular} & LIFGorb & LIFG & LMFG & $\begin{array}{l}\text { LAnt } \\
\text { Temp }\end{array}$ & $\begin{array}{l}\text { LPost } \\
\text { Temp }\end{array}$ \\
\hline \multicolumn{7}{|l|}{ music $>$ fixation } \\
\hline $\begin{array}{l}\text { orchestral music } \\
>\text { fixation }\end{array}$ & $\begin{array}{l}\mathrm{b}=0.040 \\
\mathrm{se}=0.048 \\
\mathrm{t}=0.843 \\
\mathrm{p}=0.400\end{array}$ & $\begin{array}{l}\mathrm{b}=0.125 \\
\mathrm{se}=0.165 \\
\mathrm{t}=0.758 \\
\mathrm{p}=1.000\end{array}$ & $\begin{array}{l}\mathrm{b}=0.090 \\
\mathrm{se}=0.118 \\
\mathrm{t}=0.768 \\
\mathrm{p}=1.000\end{array}$ & $\begin{array}{l}b=-0.018 \\
s e=0.137 \\
t=-0.128 \\
p=1.000\end{array}$ & $\begin{array}{l}\mathrm{b}=-0.001 \\
\mathrm{se}=0.093 \\
\mathrm{t}=-0.008 \\
\mathrm{p}=1.000\end{array}$ & $\begin{array}{l}b=0.004 \\
s e=0.091 \\
t=0.047 \\
p=1.000\end{array}$ \\
\hline $\begin{array}{l}\text { single- } \\
\text { instrument } \\
\text { music } \\
\text { >fixation }\end{array}$ & $\begin{array}{l}\mathrm{b}=-0.092 \\
\mathrm{se}=0.050 \\
\mathrm{t}=-1.834 \\
\mathrm{p}=0.069\end{array}$ & $\begin{array}{l}\mathrm{b}=-0.133 \\
\mathrm{se}=0.146 \\
\mathrm{t}=-0.908 \\
\mathrm{p}=1.000\end{array}$ & $\begin{array}{l}\mathrm{b}=0.033 \\
\mathrm{se}=0.156 \\
\mathrm{t}=0.214 \\
\mathrm{p}=1.000\end{array}$ & $\begin{array}{l}\mathrm{b}=-0.031 \\
\mathrm{se}=0.148 \\
\mathrm{t}=-0.210 \\
\mathrm{p}=1.000\end{array}$ & $\begin{array}{l}\mathrm{b}=-0.219 \\
\mathrm{se}=0.089 \\
\mathrm{t}=-2.459 \\
\mathrm{p}=0.094\end{array}$ & $\begin{array}{l}\mathrm{b}=-0.112 \\
\mathrm{se}=0.089 \\
\mathrm{t}=-1.265 \\
\mathrm{p}=1.000\end{array}$ \\
\hline $\begin{array}{l}\text { drum music } \\
>\text { fixation }\end{array}$ & $\begin{array}{l}\mathrm{b}=-0.192 \\
\mathrm{se}=0.042 \\
\mathrm{t}=-4.577 \\
\mathrm{p}<0.001^{* * *}\end{array}$ & $\begin{array}{l}\mathrm{b}=-0.181 \\
\mathrm{se}=0.131 \\
\mathrm{t}=-1.384 \\
\mathrm{p}=0.874\end{array}$ & $\begin{array}{l}\mathrm{b}=-0.215 \\
\mathrm{se}=0.138 \\
\mathrm{t}=-1.555 \\
\mathrm{p}=0.644\end{array}$ & $\begin{array}{l}\mathrm{b}=-0.209 \\
\mathrm{se}=0.097 \\
\mathrm{t}=-2.164 \\
\mathrm{p}=0.213\end{array}$ & $\begin{array}{l}\mathrm{b}=-0.224 \\
\mathrm{se}=0.073 \\
\mathrm{t}=-3.082 \\
\mathrm{p}=0.027 *\end{array}$ & $\begin{array}{l}\mathrm{b}=-0.132 \\
\mathrm{se}=0.051 \\
\mathrm{t}=-2.584 \\
\mathrm{p}=0.070\end{array}$ \\
\hline $\begin{array}{l}\text { synthetic } \\
\text { melodies } \\
>\text { fixation }\end{array}$ & $\begin{array}{l}\mathrm{b}=-0.092 \\
\mathrm{se}=0.044 \\
\mathrm{t}=-2.086 \\
\mathrm{p}=0.039 *\end{array}$ & $\begin{array}{l}\mathrm{b}=-0.052 \\
\mathrm{se}=0.120 \\
\mathrm{t}=-0.439 \\
\mathrm{p}=1.000\end{array}$ & $\begin{array}{l}\mathrm{b}=-0.056 \\
\mathrm{se}=0.120 \\
\mathrm{t}=-0.466 \\
\mathrm{p}=1.000\end{array}$ & $\begin{array}{l}\mathrm{b}=-0.028 \\
\mathrm{se}=0.139 \\
\mathrm{t}=-0.201 \\
\mathrm{p}=1.000\end{array}$ & $\begin{array}{l}\mathrm{b}=-0.172 \\
\mathrm{se}=0.067 \\
\mathrm{t}=-2.566 \\
\mathrm{p}=0.073\end{array}$ & $\begin{array}{l}\mathrm{b}=-0.151 \\
\mathrm{se}=0.076 \\
\mathrm{t}=-1.989 \\
\mathrm{p}=0.272\end{array}$ \\
\hline \multicolumn{7}{|c|}{ music $>$ nonwords } \\
\hline $\begin{array}{l}\text { orchestral music } \\
>\text { nonwords }\end{array}$ & $\begin{array}{l}\mathrm{b}=-0.176 \\
\mathrm{se}=0.071 \\
\mathrm{t}=-2.499 \\
\mathrm{p}=0.013^{*}\end{array}$ & $\begin{array}{l}\mathrm{b}=-0.224 \\
\mathrm{se}=0.192 \\
\mathrm{t}=-1.165 \\
\mathrm{p}=1.000\end{array}$ & $\begin{array}{l}\mathrm{b}=-0.038 \\
\mathrm{se}=0.169 \\
\mathrm{t}=-0.227 \\
\mathrm{p}=1.000\end{array}$ & $\begin{array}{l}\mathrm{b}=-0.006 \\
\mathrm{se}=0.170 \\
\mathrm{t}=-0.036 \\
\mathrm{p}=1.000\end{array}$ & $\begin{array}{l}\mathrm{b}=-0.436 \\
\mathrm{se}=0.126 \\
\mathrm{t}=-3.452 \\
\mathrm{p}=0.014^{*}\end{array}$ & $\begin{array}{l}\mathrm{b}=-0.177 \\
\mathrm{se}=0.162 \\
\mathrm{t}=-1.092 \\
\mathrm{p}=1.000\end{array}$ \\
\hline $\begin{array}{l}\text { single- } \\
\text { instrument } \\
\text { music } \\
\text { >nonwords }\end{array}$ & $\begin{array}{l}\mathrm{b}=-0.309 \\
\mathrm{se}=0.077 \\
\mathrm{t}=-4.025 \\
\mathrm{p}<0.001^{* * *}\end{array}$ & $\begin{array}{l}\mathrm{b}=-0.482 \\
\mathrm{se}=0.210 \\
\mathrm{t}=-2.289 \\
\mathrm{p}=0.172\end{array}$ & $\begin{array}{l}\mathrm{b}=-0.095 \\
\mathrm{se}=0.209 \\
\mathrm{t}=-0.456 \\
\mathrm{p}=1.000\end{array}$ & $\begin{array}{l}\mathrm{b}=-0.020 \\
\mathrm{se}=0.172 \\
\mathrm{t}=-0.115 \\
\mathrm{p}=1.000\end{array}$ & $\begin{array}{l}\mathrm{b}=-0.654 \\
\mathrm{se}=0.157 \\
\mathrm{t}=-4.165 \\
\mathrm{p}=0.001 * *\end{array}$ & $\begin{array}{l}\mathrm{b}=-0.294 \\
\mathrm{se}=0.161 \\
\mathrm{t}=-1.829 \\
\mathrm{p}=0.420\end{array}$ \\
\hline $\begin{array}{l}\text { synthetic drum } \\
\text { music } \\
\text { >nonwords }\end{array}$ & $\begin{array}{l}\mathrm{b}=-0.409 \\
\mathrm{se}=0.070 \\
\mathrm{t}=-5.877 \\
\mathrm{p}<0.001^{* * *}\end{array}$ & $\begin{array}{l}\mathrm{b}=-0.530 \\
\mathrm{se}=0.167 \\
\mathrm{t}=-3.183 \\
\mathrm{p}=0.026^{*}\end{array}$ & $\begin{array}{l}\mathrm{b}=-0.343 \\
\mathrm{se}=0.202 \\
\mathrm{t}=-1.700 \\
\mathrm{p}=0.532\end{array}$ & $\begin{array}{l}\mathrm{b}=-0.198 \\
\mathrm{se}=0.167 \\
\mathrm{t}=-1.188 \\
\mathrm{p}=1.000\end{array}$ & $\begin{array}{l}\mathrm{b}=-0.659 \\
\mathrm{se}=0.137 \\
\mathrm{t}=-4.828 \\
\mathrm{p}<0.001 * * *\end{array}$ & $\begin{array}{l}\mathrm{b}=-0.313 \\
\mathrm{se}=0.145 \\
\mathrm{t}=-2.165 \\
\mathrm{p}=0.220\end{array}$ \\
\hline $\begin{array}{l}\text { synthetic } \\
\text { melodies } \\
\text { >nonwords }\end{array}$ & $\begin{array}{l}\mathrm{b}=-0.309 \\
\mathrm{se}=0.071 \\
\mathrm{t}=-4.318 \\
\mathrm{p}<0.001^{* * *}\end{array}$ & $\begin{array}{l}\mathrm{b}=-0.402 \\
\mathrm{se}=0.168 \\
\mathrm{t}=-2.387 \\
\mathrm{p}=0.140\end{array}$ & $\begin{array}{l}\mathrm{b}=-0.185 \\
\mathrm{se}=0.180 \\
\mathrm{t}=-1.029 \\
\mathrm{p}=1.000\end{array}$ & $\begin{array}{l}\mathrm{b}=-0.017 \\
\mathrm{se}=0.183 \\
\mathrm{t}=-0.091 \\
\mathrm{p}=1.000\end{array}$ & $\begin{array}{l}\mathrm{b}=-0.608 \\
\mathrm{se}=0.110 \\
\mathrm{t}=-5.520 \\
\mathrm{p}<0.001^{* * *}\end{array}$ & $\begin{array}{l}\mathrm{b}=-0.332 \\
\mathrm{se}=0.156 \\
\mathrm{t}=-2.124 \\
\mathrm{p}=0.239\end{array}$ \\
\hline \multicolumn{7}{|c|}{ music $>$ non-linguistic, non-music condition } \\
\hline $\begin{array}{l}\text { music } \\
\text { (combined) } \\
\text { >animal sounds }\end{array}$ & $\begin{array}{l}\mathrm{b}=-0.057 \\
\mathrm{se}=0.053 \\
\mathrm{t}=-1.085 \\
\mathrm{p}=0.279\end{array}$ & $\begin{array}{l}\mathrm{b}=-0.215 \\
\mathrm{se}=0.152 \\
\mathrm{t}=-1.416 \\
\mathrm{p}=0.806\end{array}$ & $\begin{array}{l}\mathrm{b}=-0.125 \\
\mathrm{se}=0.131 \\
\mathrm{t}=-0.954 \\
\mathrm{p}=1.000\end{array}$ & $\begin{array}{l}\mathrm{b}=-0.022 \\
\mathrm{se}=0.134 \\
\mathrm{t}=-0.161 \\
\mathrm{p}=1.000\end{array}$ & $\begin{array}{l}\mathrm{b}=0.019 \\
\mathrm{se}=0.078 \\
\mathrm{t}=0.237 \\
\mathrm{p}=1.000\end{array}$ & $\begin{array}{l}\mathrm{b}=0.058 \\
\mathrm{se}=0.074 \\
\mathrm{t}=0.779 \\
\mathrm{p}=1.000\end{array}$ \\
\hline $\begin{array}{l}\text { music } \\
\text { (combined) } \\
\text { >environmental } \\
\text { (pitched) }\end{array}$ & $\begin{array}{l}\mathrm{b}=-0.096 \\
\mathrm{se}=0.054 \\
\mathrm{t}=-1.776 \\
\mathrm{p}=0.076\end{array}$ & $\begin{array}{l}\mathrm{b}=-0.111 \\
\mathrm{se}=0.142 \\
\mathrm{t}=-0.780 \\
\mathrm{p}=1.000\end{array}$ & $\begin{array}{l}\mathrm{b}=-0.221 \\
\mathrm{se}=0.135 \\
\mathrm{t}=-1.636 \\
\mathrm{p}=0.532\end{array}$ & $\begin{array}{l}\mathrm{b}=-0.093 \\
\mathrm{se}=0.144 \\
\mathrm{t}=-0.646 \\
\mathrm{p}=1.000\end{array}$ & $\begin{array}{l}\mathrm{b}=0.039 \\
\mathrm{se}=0.079 \\
\mathrm{t}=0.485 \\
\mathrm{p}=1.000\end{array}$ & $\begin{array}{l}\mathrm{b}=-0.091 \\
\mathrm{se}=0.075 \\
\mathrm{t}=-1.210 \\
\mathrm{p}=1.000\end{array}$ \\
\hline $\begin{array}{l}\text { music } \\
\text { (combined) } \\
\text { >environmental } \\
\text { (unpitched) }\end{array}$ & $\begin{array}{l}\mathrm{b}=-0.075 \\
\mathrm{se}=0.056 \\
\mathrm{t}=-1.345 \\
\mathrm{p}=0.179\end{array}$ & $\begin{array}{l}\mathrm{b}=-0.121 \\
\mathrm{se}=0.161 \\
\mathrm{t}=-0.754 \\
\mathrm{p}=1.000\end{array}$ & $\begin{array}{l}\mathrm{b}=-0.067 \\
\mathrm{se}=0.142 \\
\mathrm{t}=-0.474 \\
\mathrm{p}=1.000\end{array}$ & $\begin{array}{l}\mathrm{b}=-0.089 \\
\mathrm{se}=0.143 \\
\mathrm{t}=-0.622 \\
\mathrm{p}=1.000\end{array}$ & $\begin{array}{l}\mathrm{b}=-0.036 \\
\mathrm{se}=0.080 \\
\mathrm{t}=-0.446 \\
\mathrm{p}=1.000\end{array}$ & $\begin{array}{l}\mathrm{b}=-0.065 \\
\mathrm{se}=0.083 \\
\mathrm{t}=-0.774 \\
\mathrm{p}=1.000\end{array}$ \\
\hline
\end{tabular}




\begin{tabular}{|l|l|l|l|l|l|l|}
\hline Songs & $\mathrm{b}=-0.370$ & $\mathrm{~b}=-0.603$ & $\mathrm{~b}=-0.413$ & $\mathrm{~b}=-0.210$ & $\mathrm{~b}=-0.235$ & $\mathrm{~b}=-0.392$ \\
>lyrics & $\mathrm{se}=0.090$ & $\mathrm{se}=0.294$ & $\mathrm{se}=0.220$ & $\mathrm{se}=0.183$ & $\mathrm{se}=0.127$ & $\mathrm{se}=0.153$ \\
& $\mathrm{t}=-4.114$ & $\mathrm{t}=-2.050$ & $\mathrm{t}=-1.876$ & $\mathrm{t}=-1.151$ & $\mathrm{t}=-1.847$ & $\mathrm{t}=-2.563$ \\
& $\mathrm{p}<0.001^{* * *}$ & $\mathrm{p}=0.276$ & $\mathrm{p}=0.385$ & $\mathrm{p}=1.000$ & $\mathrm{p}=0.406$ & $\mathrm{p}=0.098$ \\
\hline
\end{tabular}

Table SI-2a. Statistical results for the contrasts between the music conditions and fixation, nonwords, animal sounds, and environmental sounds, and to the contrast between songs and lyrics in Experiment 1. The significance values for the individual ROIs have been FDR-corrected for the number of fROIs $(n=5)$.

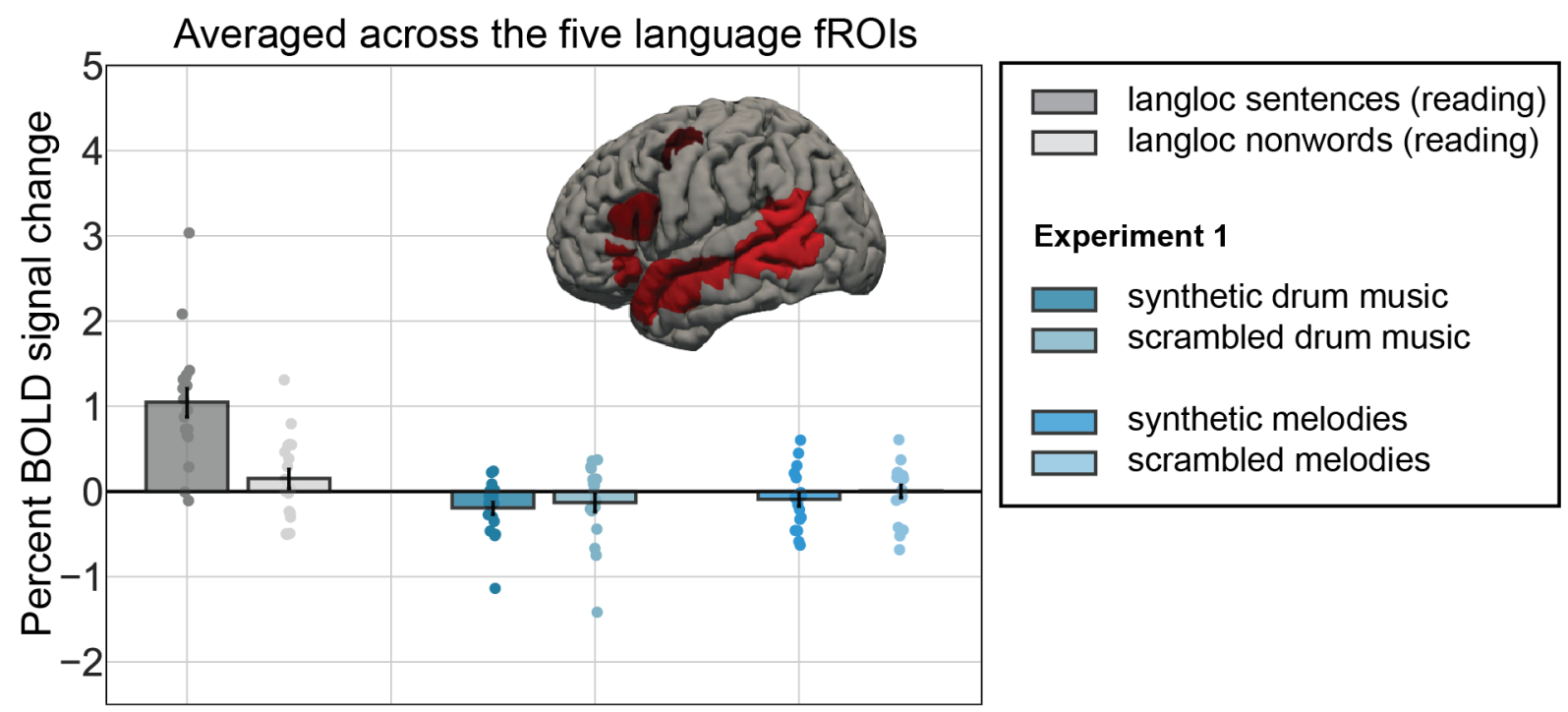

Figure SI-2b. Responses of the language fROIs (defined by auditory sentences $>$ nonwords) to the language localizer conditions (in grey), and to the two sets of conditions targeting structure in music (in blue) from Experiment 1. The responses to the music conditions cluster around the fixation baseline, are much lower than the response to sentences. Neither of the two critical elicits reliable effect.

\begin{tabular}{|l|l|l|l|l|l|l|}
\hline Contrast & $\begin{array}{l}\text { Language } \\
\text { network }\end{array}$ & LIFGorb & LIFG & LMFG & LAntTemp & LPostTemp \\
\hline $\begin{array}{l}\text { synthetic drum } \\
\text { music }\end{array}$ & $\mathrm{b}=-0.061$ & $\mathrm{~b}=0.080$ & $\mathrm{~b}=-0.112$ & $\mathrm{~b}=-0.227$ & $\mathrm{~b}=0.010$ & $\mathrm{~b}=-0.057$ \\
$>$ scrambled drum & $\mathrm{se}=0.061$ & $\mathrm{se}=0.178$ & $\mathrm{se}=0.140$ & $\mathrm{se}=0.123$ & $\mathrm{se}=0.085$ & $\mathrm{se}=0.064$ \\
music & $\mathrm{p}=0.008$ & $\mathrm{t}=0.451$ & $\mathrm{t}=-0.798$ & $\mathrm{t}=-1.851$ & $\mathrm{t}=0.121$ & $\mathrm{t}=-0.892$ \\
$\mathrm{p}=1.00$ & $\mathrm{p}=1.000$ & $\mathrm{p}=1.000$ & $\mathrm{p}=0.403$ & $\mathrm{p}=1.000$ & $\mathrm{p}=1.000$ \\
\hline synthetic & $\mathrm{b}=-0.099$ & $\mathrm{~b}=-0.176$ & $\mathrm{~b}=-0.009$ & $\mathrm{~b}=-0.084$ & $\mathrm{~b}=-0.126$ & $\mathrm{~b}=-0.097$ \\
melodies & $\mathrm{se}=0.058$ & $\mathrm{se}=0.151$ & $\mathrm{se}=0.133$ & $\mathrm{se}=0.172$ & $\mathrm{se}=0.065$ & $\mathrm{se}=0.096$ \\
>scrambled & $\mathrm{t}=-1.698$ & $\mathrm{t}=-1.169$ & $\mathrm{t}=-0.070$ & $\mathrm{t}=-0.491$ & $\mathrm{t}=-1.955$ & $\mathrm{t}=-1.005$ \\
synthetic & $\mathrm{p}=0.091$ & $\mathrm{p}=1.000$ & $\mathrm{p}=1.000$ & $\mathrm{p}=1.000$ & $\mathrm{p}=0.331$ & $\mathrm{p}=1.000$ \\
melodies & & & & & & \\
\hline
\end{tabular}

Table SI-2b. Statistical results for the contrasts between the synthetic drum music and scrambled drum music, and synthetic melodies and scrambled melodies in Experiments 1. The significance values for the individual ROIs have been FDR-corrected for the number of fROIs $(n=5)$. 


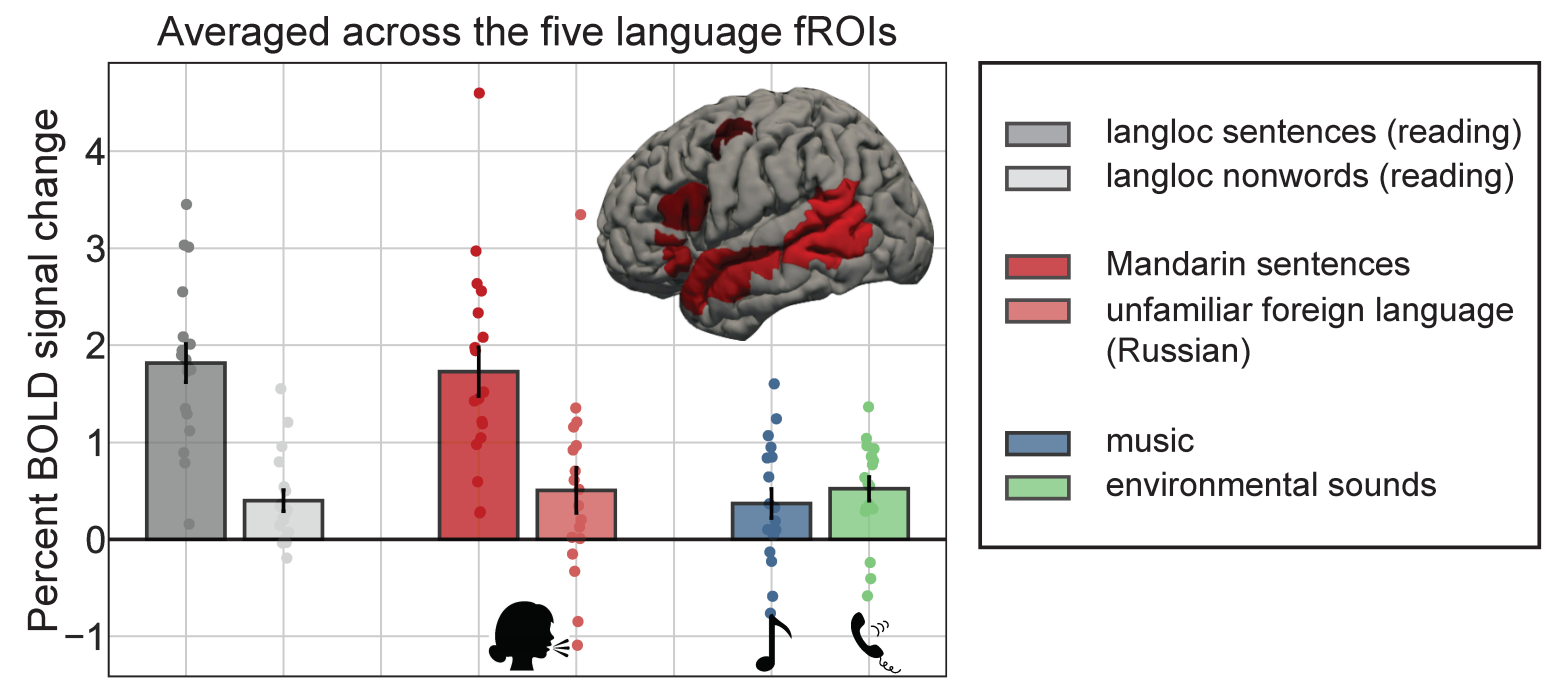

Figure SI-2c. Responses of the language fROIs (defined by Mandarin sentences $>$ foreign) to the language localizer conditions (in grey), to the language localizer conditions (in grey), to the two auditory conditions containing speech (red shades), to the music condition (blue), and to the non-linguistic/non-music auditory condition (green) in Experiment 4. The response to the music condition is much lower than the responses to sentences, and is not higher than the response to foreign language and environmental sounds.

\begin{tabular}{|l|l|l|l|l|l|l|}
\hline Contrast & $\begin{array}{l}\text { Language } \\
\text { network }\end{array}$ & LIFGorb & LIFG & LMFG & LAntTemp & LPostTemp \\
\hline music & $\mathrm{b}=0.370$ & $\mathrm{~b}=0.437$ & $\mathrm{~b}=0.485$ & $\mathrm{~b}=0.353$ & $\mathrm{~b}=0.191$ & $\mathrm{~b}=0.385$ \\
$>$ fixation & $\mathrm{se}=0.072$ & $\mathrm{se}=0.210$ & $\mathrm{se}=0.161$ & $\mathrm{se}=0.223$ & $\mathrm{se}=0.151$ & $\mathrm{se}=0.149$ \\
& $\mathrm{t}=5.178$ & $\mathrm{t}=2.081$ & $\mathrm{t}=3.016$ & $\mathrm{t}=1.579$ & $\mathrm{t}=1.267$ & $\mathrm{t}=2.582$ \\
& $\mathrm{p}<0.001^{* * *}$ & $\mathrm{p}=0.223$ & $\mathrm{p}=0.032^{*}$ & $\mathrm{p}=0.616$ & $\mathrm{p}=1.000$ & $\mathrm{p}=0.070$ \\
\hline music & $\mathrm{b}=-0.134$ & $\mathrm{~b}=-0.127$ & $\mathrm{~b}=-0.097$ & $\mathrm{~b}=0.112$ & $\mathrm{~b}=-0.348$ & $\mathrm{~b}=-0.212$ \\
$>$ foreign & $\mathrm{se}=0.113$ & $\mathrm{se}=0.336$ & $\mathrm{se}=0.294$ & $\mathrm{se}=0.295$ & $\mathrm{se}=0.197$ & $\mathrm{se}=0.178$ \\
& $\mathrm{t}=-1.185$ & $\mathrm{t}=-0.377$ & $\mathrm{t}=-0.331$ & $\mathrm{t}=0.380$ & $\mathrm{t}=-1.763$ & $\mathrm{t}=-1.188$ \\
& $\mathrm{p}=0.238$ & $\mathrm{p}=1.000$ & $\mathrm{p}=1.000$ & $\mathrm{p}=1.000$ & $\mathrm{p}=0.474$ & $\mathrm{p}=1.000$ \\
\hline music & $\mathrm{b}=-0.153$ & $\mathrm{~b}=-0.219$ & $\mathrm{~b}=-0.265$ & $\mathrm{~b}=0.003$ & $\mathrm{~b}=-0.083$ & $\mathrm{~b}=-0.198$ \\
>environmental & $\mathrm{se}=0.092$ & $\mathrm{se}=0.170$ & $\mathrm{se}=0.164$ & $\mathrm{se}=0.181$ & $\mathrm{se}=0.114$ & $\mathrm{se}=0.147$ \\
sounds & $\mathrm{t}=-1.653$ & $\mathrm{t}=-1.286$ & $\mathrm{t}=-1.614$ & $\mathrm{t}=0.017$ & $\mathrm{t}=-0.726$ & $\mathrm{t}=-1.346$ \\
& $\mathrm{p}=0.100$ & $\mathrm{p}=1.000$ & $\mathrm{p}=0.620$ & $\mathrm{p}=1.000$ & $\mathrm{p}=1.000$ & $\mathrm{p}=0.976$ \\
\hline
\end{tabular}

Table SI-2c. Statistical results for the contrasts between the music condition and fixation, foreign language, and environmental sounds in Experiments 4. The significance values for the individual ROIs have been FDR-corrected for the number of fROIs $(n=5)$.

\section{SI-3. Critical analyses with LH fROIs regardless of language network lateralization (Experiment 4)}




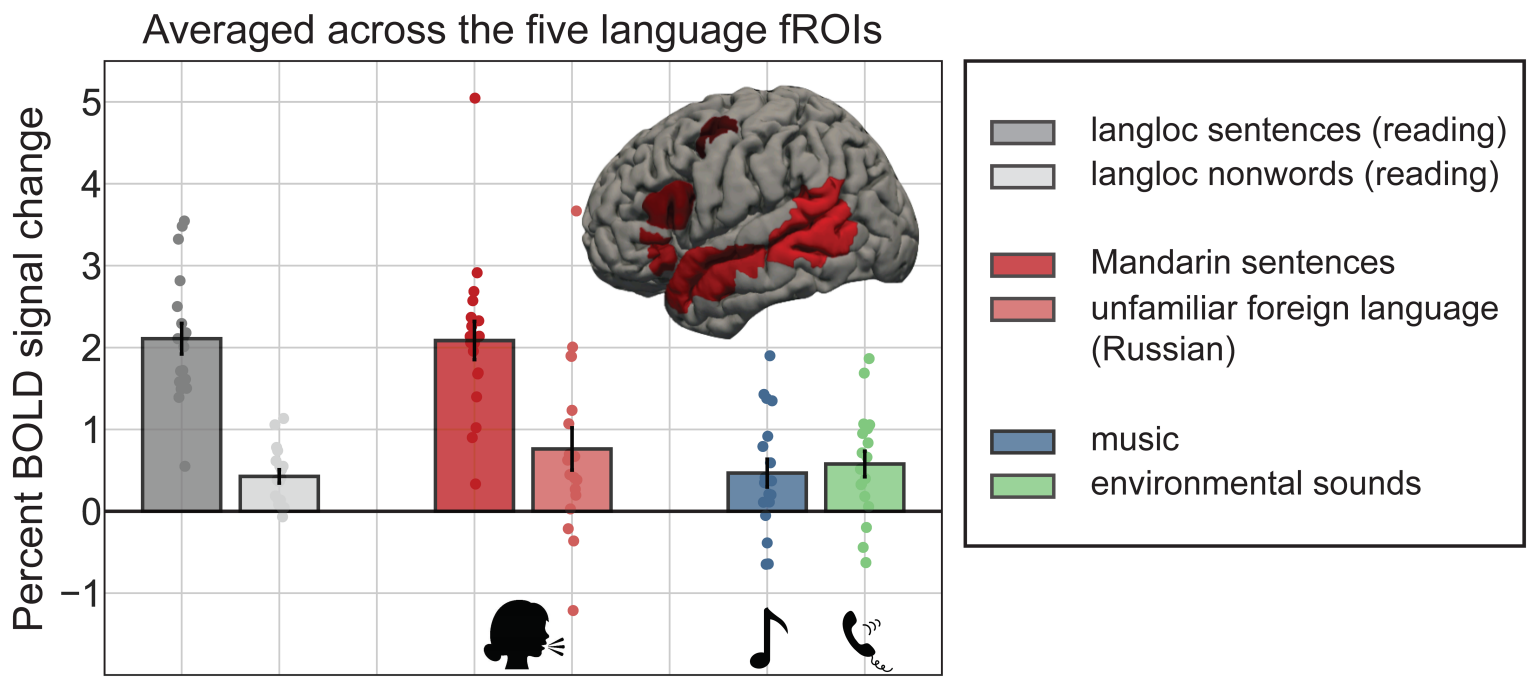

Figure SI-3. Responses of the language fROIs (with all LH fROIs used, including the rightlateralized subject) to the language localizer conditions (in grey), to the two auditory conditions containing speech (red shades), to the music condition (blue), and to the non-linguistic/nonmusic auditory condition (green) in Experiment 4 . The response to the music condition is much lower than the responses to sentences, and is not higher than the response to foreign language and environmental sounds.

\begin{tabular}{|l|l|l|l|l|l|l|}
\hline Contrast & $\begin{array}{l}\text { Language } \\
\text { network }\end{array}$ & LIFGorb & LIFG & LMFG & LAntTemp & LPostTemp \\
\hline music & $\mathrm{b}=0.466$ & $\mathrm{~b}=0.211$ & $\mathrm{~b}=0.787$ & $\mathrm{~b}=0.513$ & $\mathrm{~b}=0.339$ & $\mathrm{~b}=0.481$ \\
$>$ fixation & $\mathrm{se}=0.083$ & $\mathrm{se}=0.247$ & $\mathrm{se}=0.204$ & $\mathrm{se}=0.255$ & $\mathrm{se}=0.148$ & $\mathrm{se}=0.153$ \\
& $\mathrm{t}=5.640$ & $\mathrm{t}=0.855$ & $\mathrm{t}=3.863$ & $\mathrm{t}=2.012$ & $\mathrm{t}=2.295$ & $\mathrm{t}=3.152$ \\
& $\mathrm{p}<0.001^{* * *}$ & $\mathrm{p}=1.000$ & $\mathrm{p}=0.004^{* *}$ & $\mathrm{p}=0.258$ & $\mathrm{p}=0.138$ & $\mathrm{p}=0.024^{*}$ \\
\hline music & $\mathrm{b}=-0.295$ & $\mathrm{~b}=-0.300$ & $\mathrm{~b}=0.161$ & $\mathrm{~b}=-0.075$ & $\mathrm{~b}=-0.676$ & $\mathrm{~b}=-0.585$ \\
$>$ foreign & $\mathrm{se}=0.126$ & $\mathrm{se}=0.367$ & $\mathrm{se}=0.295$ & $\mathrm{se}=0.390$ & $\mathrm{se}=0.222$ & $\mathrm{se}=0.224$ \\
& $\mathrm{t}=-2.341$ & $\mathrm{t}=-0.818$ & $\mathrm{t}=0.546$ & $\mathrm{t}=-0.193$ & $\mathrm{t}=-3.052$ & $\mathrm{t}=-2.616$ \\
& $\mathrm{p}=0.020^{*}$ & $\mathrm{p}=1.000$ & $\mathrm{p}=1.000$ & $\mathrm{p}=1.000$ & $\mathrm{p}=0.034^{*}$ & $\mathrm{p}=0.088$ \\
\hline music & $\mathrm{b}=-0.111$ & $\mathrm{~b}=-0.284$ & $\mathrm{~b}=-0.239$ & $\mathrm{~b}=0.222$ & $\mathrm{~b}=-0.047$ & $\mathrm{~b}=-0.207$ \\
>environmental & $\mathrm{se}=0.102$ & $\mathrm{se}=0.209$ & $\mathrm{se}=0.192$ & $\mathrm{se}=0.207$ & $\mathrm{se}=0.149$ & $\mathrm{se}=0.178$ \\
sounds & $\mathrm{t}=-1.089$ & $\mathrm{t}=-1.359$ & $\mathrm{t}=-1.244$ & $\mathrm{t}=1.076$ & $\mathrm{t}=-0.312$ & $\mathrm{t}=-1.161$ \\
& $\mathrm{p}=0.278$ & $\mathrm{p}=0.955$ & $\mathrm{p}=1.000$ & $\mathrm{p}=1.000$ & $\mathrm{p}=1.000$ & $\mathrm{p}=1.000$ \\
\hline
\end{tabular}

Table SI-3. Statistical results for the contrasts between the music condition and fixation, foreign language, and environmental sounds in Experiments 4. The significance values for the individual ROIs have been FDR-corrected for the number of fROIs $(n=5)$.

\section{SI-4. Information on the music pieces in Experiment 1}

\begin{tabular}{|l|l|}
\hline Original Piece & Composer \\
\hline Anvil Chorus (From 'Il Trovatore') & $\begin{array}{l}\text { Jerry Gray } \\
\text { Originally by Giuseppe Verdi }\end{array}$ \\
\hline
\end{tabular}




\begin{tabular}{|l|l|}
\hline Apple Honey & Woody Herman \\
\hline Central Services/ The Office & Michael Kamen \\
\hline Death of Falstaff & William Walton \\
\hline $\begin{array}{l}\text { Divertimento in D Major, K. 136 "Salzburg } \\
\text { Symphony No. 1": I. Allegro }\end{array}$ & Wolfgang Amadeus Mozart \\
\hline General Lee's Solitude & Randy Edelman \\
\hline I Remember Clifford & Benny Golson \\
\hline Just You \& I & \\
\hline South Rampart Street Parade & Bob Haggart, Ray Bauduc \\
\hline Symphony No. 5 in E-flat major, Op. 82 & Jean Sibelius \\
\hline Symphony No. 7 in D minor, Op. 70, B. 141 & Antonín Dvoŕk \\
\hline
\end{tabular}

Table SI-4a. Original piece and composer of the orchestral music pieces in Experiment 1

\begin{tabular}{|c|c|c|}
\hline Instrument & Original Piece & Composer \\
\hline cello & Suite No. 3 in C major, BWV 1009: VI. Gigue & Johann Sebastian Bach \\
\hline flute & $\begin{array}{l}\text { Partita in A minor for solo flute, BWV 1013: IV. } \\
\text { Bourree Anglaise }\end{array}$ & Johann Sebastian Bach \\
\hline guitar & Blue In Green & Bill Evans, Miles Davis \\
\hline guitar & E Is For Emmett & Richard Hyman \\
\hline guitar & In A Mellow Tone & Duke Ellington \\
\hline guitar & Isn't It A Pity? & $\begin{array}{l}\text { George Gershwin, } \\
\text { Ira Gershwin }\end{array}$ \\
\hline piano & $\begin{array}{l}\text { Piano Sonata No. } 13 \text { in E flat major, Op.27, No.1, } \\
\text { "Quasi una fantasia": III. Adagio con espressione }\end{array}$ & Ludwig van Beethoven \\
\hline piano & Necturne No. 13 In C Minor, Op.48 No.1 & Frédéric Chopin \\
\hline piano & Cubano Chant & Ray Bryant \\
\hline piano & These Foolish Things (Remind Me Of You) & Jack Strachey \\
\hline saxophone & Body and Soul & Johnny Green \\
\hline violin & Partita No. 2 In D Minor, BWV 1004: Giga & Johann Sebastian Bach \\
\hline
\end{tabular}

Table SI-4b. Original piece and composer of the solo music pieces in Experiment 1 